Renata Almeida de Assunção

\title{
Índice de performance miocárdica fetal na doença hemolítica perinatal
}

\author{
Tese apresentada à Faculdade de Medicina da \\ Universidade de São Paulo para obtenção do \\ título de Doutor em Ciências \\ Programa de Obstetrícia e Ginecologia \\ Orientador: Prof. Dr. Adolfo Wenjaw Liao
}

São Paulo 2015 


\section{Dados Internacionais de Catalogação na Publicação (CIP)}

Preparada pela Biblioteca da

Faculdade de Medicina da Universidade de São Paulo

Creprodução autorizada pelo autor

Assunção, Renata Almeida de

Índice de performance miocárdica fetal na doença hemolítica perinatal / Renata Almeida de Assunção. -- São Paulo, 2015.

Tese(doutorado)--Faculdade de Medicina da Universidade de São Paulo.

Programa de Obstetrícia e Ginecologia

Orientador: Adolfo Wenjaw Liao.

Descritores: 1.Isoimunização Rh 2.Anemia hemolítica autoimune 3.Doenças fetais 4.Coração fetal 5.Ultrassonografia Doppler em cores 6.Transfusão de sangue intrauterina 7.Técnicas de imagem cardíaca 8.Função ventricular 9.Eritroblastose fetal

USP/FM/DBD-449/15 


\section{Dedicatória}

Ao meu marido Carlos, pelo amor, apoio e incentivo, que me impulsionam em direção a vencer meus desafios e, principalmente a sempre procurar nova fatia de "QUEIJO".

Ao meu filho Eduardo, razão da minha existência e motivo essencial para eu procurar ser uma pessoa cada vez melhor.

Aos meus pais, João e Railda (in memoriam), que em sua imensa nobreza de espírito, não pouparam esforços para eu pudesse realizar todos os meus sonhos. Meu eterno muito obrigado! 


\section{Agradecimento especial}

Ao meu mestre, Prof. Dr. Adolfo W. Liao, por toda a paciência e perseverança inabalável para que este trabalho pudesse ser realizado. Sua dedicação, paixão e brilhantismo inspiram todos em sua volta, e são exemplos a serem seguidos.

Agradeço por todo o apoio acadêmico e científico que me tornaram a profissional que sou hoje; e pelo apoio emocional nos momentos difíceis. Compartilhar da sua amizade, não tem preço!!!! 


\section{Agradecimentos}

Ao Prof. Dr. Marcelo Zugaib, Professor Titular de Obstetrícia, do Depatamento de Obstetrícia e Ginecologia da Faculdade de Medicina da Universidade de São Paulo, por todas as oportunidades concedidas nesta renomada instituição.

À Profa. Dra. Maria de Lourdes Brizot, por acreditar que eu era capaz de realizar este trabalho e principalmente pela contribuição na obtenção dos dados. Agradeço, de todo coração, pela oportunidade de compartilhar de seus ensinamentos e do seu exemplo de dedicação e paixão à pesquisa e ciência.

À Dra. Lilian M. Lopes, pelas orientações e treinamento que possibilitaram a execução técnica deste trabalho e Prof ${ }^{\text {a. }}$ Dra Luciana Venturini Rossoni, pelas contribuições valiosas sobre a fisiologia cardiovascular.

Ao Prof. Dr. Marco Antonio Borges Lopes e Prof. Dr. Mario Henrique Burlacchini de Carvalho, pela apreciação e contribuições para o aprimoramento deste trabalho na fase de qualificação

À Profa. Dra. Rossana Pulcineli Vieira Francisco, coordenadora da pós graduação do departamento de Obstetrícia, pelo apoio e incentivo à pesquisa.

À Profa. Dra. Roseli Mieko Y Nomura, pela contribuição preciosa à respeito da avalição da função cardíaca fetal. 
A todos os docentes e assistentes da Clínica Obstétrica, por estarem sempre dispostos a dividir seus conhecimentos.

Às amigas do ambulatório Estela Naomi Nishie, Marcela Vieira Xavier, Walkyria Andrade e Karen Nogueira Chinoca, pela amizade, companherismo, incentivo e convivência no ambulatório de medicina fetal, que tornaram esse período muito especial.

À Sandra Frankfurt Centofanti e Isabella Agra pela amizade e por dedicarem o seu tempo em refinar a arte final deste trabalho.

Às amigas eternas Tatiana Bernath Liao, Lília Oliveira Moura Lima, Liane Block Chu, Elaine Crucovik, Raquel Brocanello, Suzana Vilela Praça e minha irmã Selma Ronqui, que sempre tem um "pausa para um cafézinho" com uma palavra de apoio, incentivo e boas risadas. Estes momentos preciosos, nesta vida corrida, nos trazem reequilibrio e nos mostra que a vida é maravilhosa. Obrigada meninas!!!

Aos colegas Lawrence Lin, Mariana Miyadahira, Ellen Beatriz Araujo Freire, Carolina Narciso, pela amizade e convivência, que tornam o ambulatório não apenas o centro de ensino, mas também um prazer nesta jornada.

Aos estagiários da Medicina Fetal e ultrassonografia pela convivencia no ambulatório e momentos de descontração que tornaram este período muito agradável.

A todos os colaboradores e à equipe de enfermagem da Clínica Obstetrica, pela convivência, amizade e disponibilidade em ajudar em todos os momentos.

A todas as gestantes, razão e motivação deste estudo, minha profunda gratidão. 
Esta tese está de acordo com as seguintes normas, em vigor no momento desta publicação:

Referências: adaptado de International Commitee of Medical Journal Editors (Vancouver).

Universidade de São Paulo Faculdade de medicina Divisão de Biblioteca e Documentação. Guia de apresentação de dissertações, teses e monografias. Elaborado por: Anneliese Carneiro da Cunha, Maria Julia de A. L. Freddi, Maria Fazanelli Crestana, Marinalva de Souza Aragão, Suely Campos Cardoso, Valéria Vilhena. $3^{a}$ ed. São Paulo. Divisão de Biblioteca e Documentação, 2011.

Abreiação dos títulos dos períodicos de acordo com o List of Journals Indexed in Index Medicus. 
"Today is a gift"

Alice Morse Earle 


\section{Sumário}

Lista de abreviaturas, siglas e símbolos

Lista de figuras e gráficos

Resumo

Summary

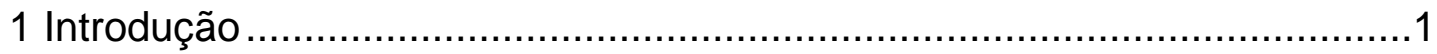

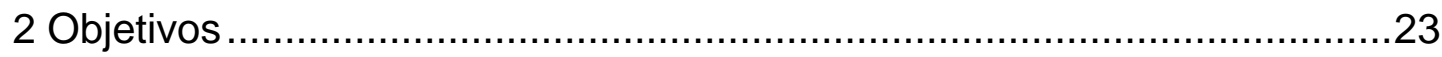

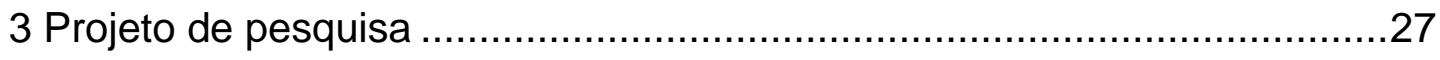

4 Publicações...................................................................... 61

4.1 - Paper 1 - Myocardial performance index in fetal anemia ............63

4.2 - Paper 2 - Changes in fetal myocardial performance index following intravascular transfusion: preliminary report ......................81

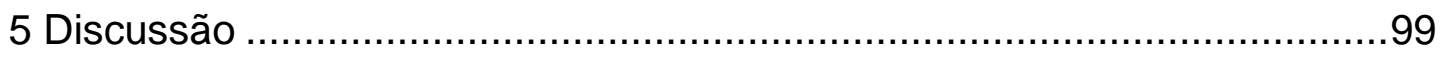

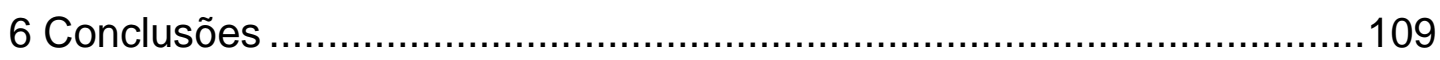

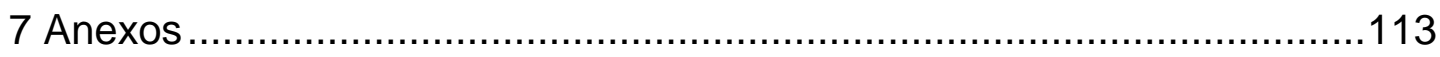

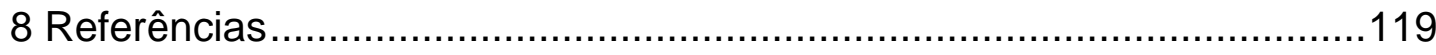




\section{LISTA DE ABREVIATURAS E SIGLAS}

$\begin{array}{ll}\text { ACM } & \text { Artéria cerebral média } \\ \text { BNP } & \text { Peptídeo Natriurético Cerebral (BNP) } \\ \text { cols. } & \text { Colaboradores } \\ \text { cTnT } & \text { Troponina T cardíaca } \\ \text { DHPN } & \text { Doença hemolítica perinatal } \\ \text { DP } & \text { Desvio padrão } \\ \text { DV } & \text { Ducto venoso } \\ \text { FE } & \text { Fração de ejeção } \\ \text { FMUSP } & \text { Faculdade de Medicina da Universidade de São Paulo } \\ \text { Hb } & \text { Hemoglobina } \\ \text { IP } & \text { Índice de pulsatilidade } \\ \text { IPM } & \text { Índice de performance miocárdica } \\ \text { IPM-mod } & \text { Índice de performance miocárdica modificado } \\ \text { MoM } & \text { Múltiplos da mediana } \\ \text { PAI } & \text { Pesquisa de anticorpos irregulares } \\ \text { RCIU } & \text { Restrição de crescimento intrauterino } \\ \text { Rh } & \text { Rhesus } \\ \text { RPMO } & \text { Rotura prematura das membranas ovulares } \\ \text { STFF } & \text { Síndrome da transfusão feto-fetal } \\ \text { TCl } & \text { Tempo contração isovolumétrico } \\ \text { TE } & \text { Tempo de ejeção } \\ \text { TIU } & \text { Transfusão intrauterina } \\ \text { TRI } & \text { Tempo de relaxamento isovolumétrico } \\ \text { VD } & \text { Ventrículo direito } \\ \text { VE } & \text { Ventrículo esquerdo } \\ & \end{array}$




\section{LISTA DE ABREVIATURAS E SIGLAS EM INGLÊS}

$\begin{array}{ll}\text { cTn-T } & \text { cardiac troponin T } \\ \text { et al } & \text { et alii } \\ \text { ET } & \text { ejection time } \\ \text { FPV } & \text { feto-placental volume expansion } \\ \text { ICT } & \text { isovolumetric contraction time } \\ \text { IRT } & \text { isovolumetric relaxation time } \\ \text { IUT } & \text { intruterine transfusion } \\ \text { LV } & \text { left ventricle } \\ \text { MCA } & \text { middle cerebral artery } \\ \text { MoM } & \text { multiple of the median } \\ \text { MPI } & \text { Myocardial performance index } \\ \text { Rh } & \text { Rhesus } \\ \text { RV } & \text { right ventricle } \\ \text { Z-Score } & \text { zeta score }\end{array}$




\section{LISTA DE FIGURAS E GRÁFICOS}

Figura 1 Eventos do ciclo cardíaco no ventrículo esquerdo, demonstrando variações na pressão atrial, ventricular e aortica.

Figura 2A Sonograma da via de entrada do ventrículo direito (valva tricúspide). a: tempo entre fechamento e abertura da valva atrioventricular

Figura 2B Sonograma da via de saída do ventrículo direito (valva pulmonar). PU: valva pulmonar. TE: tempo de ejeção .b: tempo entre abertura e fechamento da valva pulmonar .15

Figura 3 Sonograma do índice de performance miocárdica do ventrículo esquerdo. TCl: tempo de contração isovolumétrico TRI: tempo de relaxamento isovolumétrico; TE: tempo de ejeção.

Figura 4 Ilustração esquemática do cálculo do índice de performance miocárdica. TCl: tempo d contração isovolumétrico; TRI: tempo de contração isovolumétrico; TE: tempo de ejeção; a: somatória dos tempos isovolumétricos (contração e relaxamento) e tempo de ejeção; b: tempo de ejeção 


\section{Resumo}

Assunção RA. Índice de performance miocárdica fetal na doença hemolítica perinatal [Tese]. São Paulo: Faculdade de Medicina, Universidade de São Paulo; 2015.

A hemólise decorrente da doença aloimune desencadeia mecanismos adaptativos hematológicos e hemodinâmicos fetais, com intuito de garantir o suprimento adequado de oxigênio para todos os tecidos e órgãos. $\mathrm{Na}$ anemia grave, a sobrecarga imposta ao coração fetal, devido ao fluxo hiperdinâmico, tem sido considerada responsável pela insuficiencia cardiaca, e posterior desenvolvimento de hidropisia fetal. No entanto, a literatura médica ainda apresenta controvérsias acerca da integridade da função cardiaca nesta doença. $O$ índice de performance miocárdico (IPM) é uma ferramenta propedêutica não invasiva, derivada do Doppler pulsátil, que permite avaliar a função cardíaca global (sistólica e diastólica). Objetivo: Estudar a função cardíaca fetal, na doença aloimune, utilizando o índice de performance miocárdica. Métodos: Foram seguidos, prospectivamente, fetos únicos, de gestantes sensibilizadas pelo antígeno eritrocitário D, sem malformações estruturais, na Clinica Obstétrica, Hospital das Clinicas da Faculdade de Medicina de São Paulo. A cada avaliação ultrassonográfica, o IPM foi investigado por meio de Doppler pulsátil, com janela de $2-4 \mathrm{~mm}$, filtro $>190 \mathrm{~Hz}$ e velocidade de varredura que permitisse observar de 3 a 4 ciclos cardíacos simultâneos no ecrã. O IPM corresponde à soma dos tempos isovolumétricos (contração e relaxamento) dividido pelo tempo de ejeção do ciclo cardíaco. O IPM do ventrículo equerdo (IPM VE) foi realizado em ciclo único, sendo possível obter seus componentes: tempo de contração isovolumétrico (TCl), tempo de relaxamento isovolumétrico (TRI) e tempo de ejeção (TE). O IPM do ventrículo direito (IPM VD) foi obtido em dois tempos. Os valores obtidos de IPM VE, seus componentes foram convertidos em escore zeta para a idade gestacional. Frente à suspeita de anemia fetal, realizou-se cordocentese com determinação dos níveis de hemoglobina fetal antes e após a transfusão intra-uterina. Os respectivos valores foram convertidos em escore-zeta ( $\mathrm{Hb}$ zeta). $\mathrm{Na}$ análise estatística, foram incluidas avaliações do IPM realizadas com menos de 72 horas antes, e até 24 horas após cada transfusão. Para cada transfusão foi calculada a variação no IPM (delta IPM = IPM antes - IPM após). O nível de significância estatísca 
adotado foi de 0,05 . Análises por regressão linear simples e logística foram utilizadas para examinar a associação entre os valores de IPM e delta IPM e as seguintes variáveis: idade gestacional no procedimento, múltiplos da mediana (MoM) da Vmax ACM, Hb zeta pré e após TIU, volume de sangue transfundido e porcentagem da expansão do volume feto-placentário (EVFP). Resultados: Foram incluidas 14 gestações submetidas a 31 procedimentos de cordocentese para transfusão intra-uterina. A idade gestacional média na $1^{\text {a }}$ transfusão foi de $28,2 \pm 4,1$ semanas $\mathrm{Em} 6$ procedimentos, a avaliação do IPM pós transfusional foi incompleta, e esses dados não foram incluídos na análise. Quanto à análise dos dados obtidos nas cordocenteses, observou-se correlação significativa entre os valores de escore zeta de IPM VE $(r=0,59, p<0,001)$, TRI $(r=0,45, p=0,01)$ e o TE ( $r=$ $0,42, p=0,2)$ e o escore zeta da hemoglobina fetal. Não foi observada correlação significativa com o escore zeta do $\mathrm{TCl}(r=0,35, p=0,054)$ e do IPM VD $(r=0,12, p=0,53)$. Quando comparados aos valores observados antes das transfuões intra-uterinas, observou-se aumento significativo do escore zeta de IPM VE após os procedimentos (Delta MPI = 1,10 $\pm 2,47, p=$ $0,036)$. Não foi observada correlação entre os valores de escore zeta de IPM antes e após TIU. Delta MPI do VE se correlacionou inversamente, e de forma significativa, com a idade gestacional no procedimento $(r=0,47$, $p=0,018)$, escore zeta IPM VE pré-TIU $(r=0,50, p=0,012)$ e EVFP $(r=0,41$, $p=0,044)$. Conclusões: $O$ desempenho miocárdico do ventriculo esquerdo fetal permanece preservado frente a anemia, e nos casos de anemia moderada e grave encontra-se ainda mais eficiente. Após a realização da transfusão intrauterina, observou-se aumento significativo do índice de performance miocárdica, e este aumento esteve relacionado com idade gestacional no procedimento, valores de IPM pré-transfusionais e a expansão do volume feto-placentário.

Descritores: Isoimunização Rh; anemia hemolítica autoimune; doenças fetais; coração fetal; ultrassonografia Doppler em cores; transfusão de sangue intrauterina; técnicas de imagem cardíaca; função ventricular; eritroblastose fetal 


\section{Abstract}

Assunção RA. Myocardial performance index in alloimune disease [Thesis]. São Paulo: "Faculdade de Medicina, Universidade de São Paulo"; 2015.

Fetal anemia is associated with several adaptative mechanisms in order to maintain adequate tissue oxygenation. Circulatory changes play a key role in such circumstances. In severe anemia, the overload imposed on the fetal heart, due to the hyperdynamic flow, has been considered to be responsible for cardiac failure and finally hydrops fetalis. However, cardiac failure in this pathology remains controversy. Myocardial performance index (MPI) is a novel technique, Doppler derived and non-invasive that allows assesses global cardiac function (systolic and diatolic). Objective: Evaluate global cardiac function in alloimune disease through myocardial performance index. Methods: This prospective study was carried out at a tertiary referral center for fetal medicine (Clínica Obstetrica do Hospital das Clinicas da Faculdade de Medicina da Universidade de São Paulo). Women with singleton pregnancies and Rh D alloimmune disease were invited to take part in the study and gave informed consent. Fetal examinations did not show structural abnormalities. At every ultrasonography evaluation, MPI was examined with Doppler sample gate set between $2-4 \mathrm{~mm}$, wall motion filter $>190 \mathrm{~Hz}$ and high sweep-speed to allow simultaneous identification of 3-4 cardiac cycles on the screen. MPI is the sum of isovolumetric times (contraction and relaxation) divided by ejection time. Left ventricle MPI (LV MPI) was obtained in a single cycle and the MPI components were obtained: isovolumetric contraction time (ICT), isovolumetric relaxation time (IRT) and ejection time (ET). Right ventricle MPI (RV MPI) was obtained in two cycles. The values obtained for LV MPI and its components were converted in zeta score for gestacional age. Cordocentesis was perfomed if fetal anemia was suspicion and fetal hemoglobin levels were determined: before and after intrauterine transfusion. Hemoglobin values were converted into the zeta score (Hb zeta). Statistical analysis included MPI evaluations performed within less than 72 hours before and until 24 hours after every transfusion. Variation in the MPI was calculated for every transfusion (delta MPI = MPI before - MPI after). Significance level was set at 0,05. Linear and regression analyses were made in order to examine association between MPI values and delta MPI gestational age at procedure, fetal ACM multiples of median (MoM), Hb zeta before and after 
the IUT, volume of blood transfused and percentage of the feto-placental expansion volume (FPEV). Results: 14 pregnancies were included. Overall 31 cordocentesis for intrauterine transfusion were performed at mean gestational age of $28,2 \pm 4,1$ weeks. In 6 procedures, post transfusion MPI evaluation was incomplete and these data were not included in the analysis. Zeta-score values LV MPI $(r=0,59, p<0,001)$, IRT $(r=0,45, p=0,01)$ and ET $(r=0,42, p=0,02)$ correlated significantly with fetal hemoglobin zeta score. Left ventricle ICT zeta-score $(r=0,35, p=0,054)$ and RV MPI $(r=0,12, p=$ 0,53 ). did not show significant correlation. After intrauterine transfusion, LV MPI z-score ]increases and it was statistical significant (Delta MPI $=1,10 \pm$ $2,47, p=0,036$ ). No correlation was observed between MPI zeta score values before and after the IUT. Delta LV MPI had inverse and significant correlation with pregnancy age in the proceedings $(r=0,47, p=0,018), \mathrm{LV} \mathrm{MPI}$ zeta score before IUT $(r=0,50, p=0,012)$ and FPEV $(r=0,41, p=0,044)$. Conclusions: Left ventricle myocardial performance not only remains preserved but is actually enhanced in cases of moderate/severe fetal anemia. After intrauterine transfusion procedure, left ventricle myocardial performance index increases significantly and greater changes are associated with procedures at earlier gestational age, lower pre transfusion MPI z-scores and smaller feto-placental volume expansion.

Descriptors: Rh Isoimmunization; anemia, hemolytic, autoimmune; fetal diseases; fetal heart; ultrassonography, Doppler, color; blood transfusion, intrauterine; cardiac imaging techniques; ventricular function; erythroblastosis, fetal 
1 Introdução 

Aloimunização é definida como resposta imune do organismo contra antígenos presentes em membros da mesma espécie. A formação de anticorpos pode ocorrer frente a tecidos transplantados, transfusões sanguíneas incompatíveis e nas hemorragias feto-maternas ${ }^{(1)}$. Os antígenos eritrocitários são substâncias presentes nas membranas dos glóbulos vermelhos, herdados geneticamente e bioquimicamente e podem ser proteicos ou carboidratos (ligados a lipídios ou proteínas) ${ }^{(2)}$.

No período gestacional, a aloimunização é a principal causa de anemia fetal, levando à doença hemolítica perinatal (DHPN) ${ }^{(3)}$. Esta doença se caracteriza pela destruição das hemácias fetais por anticorpos eritrocitários da classe $\operatorname{lgG}$ que atravessam a barreira placentária, levando a altas taxas de morbi-mortalidade perinatal ${ }^{(3-5)}$. Os principais antígenos do sistema Rh são: D, c, C, e, e E. O antígeno D é o que possui maior potencial de desencadear o mecanismo de antigenicidade e, quando classificamos um paciente em Rh positivo ou negativo, estamos nos referindo apenas à presença ou ausência desta proteína na superfície eritrocitária ${ }^{(6-8)}$.

Até a década de 60 , aproximadamente $10 \%$ dos todos os recémnascidos eram acometidos pela DHPN ${ }^{(4,9)}$. A partir da introdução da profilaxia da imunoglobulina anti-D na prática clínica (no pós parto imediato, nos sangramentos na gestação, abortos e após procedimentos invasivos) houve queda vertiginosa nesta incidência ${ }^{(10-14)}$. Martin e colaboradores (cols.) em 2002 descrevem que a incidência de anemia na população de recém-nascidos dos Estados Unidos é de 1\%, referindo ainda que esta incidência representa redução de $50 \%$ em relação ao ano de $1989{ }^{(15)}$.

Nos países em desenvolvimento, incluindo o Brasil, a incidência de anemia em recém-nascidos filhos de mães susceptíveis é de 2 a 8,2\% ${ }^{(16,17)}$. Acredita-se que esta alta incidência é decorrente da deficiência na assistência pré-natal, falhas nos protocolos de profilaxia, omissão das políticas governamentais, custo da medicação, além da falta de 
conscientização das pacientes Rh negativas em relação aos fatores de risco durante a gestação, como sangramentos e procedimentos invasivos, cumulativamente contribuindo para alta incidência de mulheres sensibilizadas no nosso país ${ }^{(18,19)}$.

Na Clínica Obstétrica do Hospital das Clínicas da Faculdade de Medicina da Universidade de São Paulo, no período de 2009 a 2013 foi observado que $21,1 \%$ das gestantes apresentavam algum tipo de aloanticorpo. Destas, a frequência de anticorpos irregulares anti-D isolado foi de $42,1 \%$ e associada com outros anticorpos foi de $60,4 \%{ }^{(20)}$.

\section{Fisiopatologia}

A interação entre anticorpos maternos e os antígenos eritrocitários presentes na superfície da hemácia fetal leva à hemólise. A redução na quantidade de hemoglobina $(\mathrm{Hb})$ circulante, por sua vez, leva à diminuição na capacidade de transporte de oxigênio aos tecidos, causando hipóxia ${ }^{(4,6)}$. Paul Bert, em $1878^{(21)}$, descreve em seu estudo que, quando o transporte de oxigênio diminui, a eritropoiese é ativada, com consequente aumento das células jovens na circulação. Este fenômeno também foi observado por outros autores ${ }^{(22-24)}$

De forma semelhante, Nicolaides e cols. (1989) observam aumento dos reticulócitos na circulação fetal em casos de anemia moderada (déficit de hemoglobina entre 2 a $7 \mathrm{~g} / \mathrm{dl}$ ) ${ }^{(25)}$. Com o agravamento da doença, foi observado recrutamento da eritropoiese em sítios extramedulares, principalmente fígado e baço, ocorrendo então a liberação de eritoblastos na circulação fetal. Relatam que a presença de eritroblastos costuma ocorrer quando o déficit de hemoglobina encontra-se acima de $7 \mathrm{~g} / \mathrm{dl}$ (anemia grave) (25).

A presença de eritroblastos na circulação fetal pode ser responsável pela congestão hepática e esplênica, secundária à obstrução do sistema porta, com consequente hepatoesplenomegalia. A hidropisia fetal, na 
anemia, está associada ao esgotamento dos mecanismos adaptativos, sugerindo insuficiência cardíaca congestiva associada a esta patologia $(25,26)$.

Concomitante às alterações hematológicas, ocorrem alterações hemodinâmicas no fluxo sanguíneo. Estudos em animais submetidos à anemia demonstraram significante aumento do débito cardíaco, que foi proporcional à diminuição do hematócrito fetal. As principais causas consideradas foram a diminuição da viscosidade sanguínea e a vasodilatação periférica $^{(27)}$.

Em 1984, Fumia e cols. ${ }^{(28)}$ sugerem que, na anemia fetal, de acordo com estudos em animais e extrapolando modelo matemático para humanos, o débito cardíaco está aumentado para suprir a necessidade de oxigênio tecidual, e que os mecanismos associados seriam: diminuição da viscosidade sanguínea, levando ao aumento do retorno venoso e aumento da pré-carga; e vasodilatação periférica decorrente da diminuição da tensão de oxigênio, com consequente diminuição da pós-carga ${ }^{(28)}$. Nicolaides e cols. (1988) sugerem haver um terceiro mecanismo, no qual a estimulação hipóxica aos quimiorreceptores conduziria ao aumento da contratilidade miocárdica e aumento do débito cardíaco ${ }^{(29)}$.

A partir da década de 80, com o surgimento dos primeiros estudos utilizando técnica do Doppler, foi possível avaliar diretamente a hemodinâmica dos fetos humanos frente a diversas patologias, e dentre elas a DHPN ${ }^{(30)}$. Diferentes grupos passaram a avaliar o debito cardíaco, a velocidade dos fluxos arteriais e venosos e índice de pulsatilidade (IP) em diferentes territórios vasculares, antes e após o tratamento de correção da anemia com a transfusão intrauterina ${ }^{(31-36)}$. A partir do conhecimento proporcionado por estes estudos, foi observado que, com a diminuição dos valores do hematócrito fetal, ocorria aumento do débito cardíaco, com consequente aumento na velocidade do fluxo em vários segmentos arteriais fetais, possibilitando utilizar a técnica do Doppler como uma ferramenta não invasiva no diagnóstico de fetos anêmicos ${ }^{(35,36)}$. 
Em 1995, Mari e cols. ${ }^{(37)}$ estudam a velocidade máxima na artéria cerebral média pela técnica do Doppler pulsátil, nos fetos em risco de anemia. Observam haver correlação inversa entre queda da hemoglobina fetal e a velocidade máxima na artéria cerebral média e desta forma concluem que a avaliação da velocidade máxima da ACM pode ser útil como diagnóstico não invasivo de anemia fetal nas pacientes aloimunizadas. No ano de 2000, Mari e cols. ${ }^{(38)}$, em estudo multicêntrico, descrevem que a velocidade máxima da $\mathrm{ACM}$, acima de 1,5 múltiplos da mediana (MoM) para a idade gestacional, apresenta sensibilidade de $100 \%$ e especificidade de $88 \%$ em predizer anemia fetal de intensidade moderada a grave ${ }^{(38)}$.

A utilização da velocidade máxima na $\mathrm{ACM}$ se tornou o método de escolha na avaliação de risco para a anemia fetal, por se tratar de uma técnica não invasiva, utilizando uma artéria de fácil insonação e reprodutibilidade ${ }^{(39-41)}$.

\section{Diagnóstico e Tratamento}

Toda gestante, no início do pré-natal, deve realizar exame para identificação da tipagem sanguínea $A B O R h$ e pesquisa de anticorpos irregulares (PAl), uma vez que há possibilidade de aloimunização por anticorpos de classes não $D$ é de 5 a $10 \%{ }^{(42-47)}$.

Nos casos de gestante Rh negativa, cujo parceiro é Rh positivo ou de tipagem ignorada, é possível realizar a genotipagem do $\mathrm{Rh}$ fetal em sangue materno pela técnica de reação em cadeia de polimerase ${ }^{(48)}$.

Gestantes com resultado de genotipagem fetal Rh positivo e/ou coombs indireto com titulação em técnica de diluição em tubo maior que 16, devem ser acompanhadas em pré-natal especializado, com avaliação ultrassonográfica (derrames cavitários e alteração da vitalidade fetal), dopplervelocimétrica (avaliação da velocidade máxima da ACM) e cardiotocografia, segundo protocolos assistenciais preestabelecidos. 
Nos casos suspeitos de anemia fetal, a cordocentese diagnóstica é indicada, com bolsa de sangue preparada para realizar a transfusão intrauterina (TIU). Atualmente utiliza-se a técnica intravascular direta, guiada pela ultrassonografia, pois permite maior infusão de volume de sangue, menor tempo de procedimento e melhor resultado perinatal nos fetos hidrópicos ${ }^{(16)}$.

Nos estudos realizados por Linderburg e cols. ${ }^{(49)}$ e Garabedian e cols. ${ }^{(50)}$, a transfusão intrauterina tem sido considerada técnica segura, com sobrevida global superior a $80 \%$ e taxa de insucesso de $3,5 \%$. As principais complicações agudas observadas foram: sofrimento fetal (por lesão do cordão e/ou sangramento excessivo), sobrecarga volêmica, rotura prematura das membranas (RPMO) e trabalho de parto prematuro. A taxa de perda fetal neste estudo foi de 0,9 a 4,9\% e esteve relacionada com a hidropisia fetal, idade gestacional precoce, experiência do operador, punção em alça livre do cordão umbilical e a gravidade da anemia.

Devido à taxa de perdas fetais ocorridas ao longo dos anos, foi observado que, nos casos de fetos extremamente comprometidos, preferese a realização de transfusões intrauterina seriadas, em curto intervalo de tempo, para que haja melhor desempenho cardíaco e melhor sobrevida ${ }^{(16)}$. Ademais, observam-se piores resultados perinatais nos pré-termos extremos, principalmente abaixo de 22 semanas. Este fato parece estar associado à dificuldade destes fetos em tolerar as alterações hemodinâmicas após a transfusão intrauterina ${ }^{(51,52)}$.

Nota-se, portanto, que a integridade da função cardíaca parece ser fundamental na manutenção das adaptações fisiológicas, desde os estágios iniciais dos mecanismos compensatórios frente à anemia, até as modificações após a TIU. 


\section{Avaliação da função cardíaca fetal}

Nos últimos 30 anos, a cardiologia fetal evoluiu, tanto no diagnóstico quanto no tratamento das cardiopatias. Inicialmente, somente era possível avaliar a morfologia cardíaca, detectando alterações estruturais congênitas e esta detecção ocorria em fases avançadas da gestação. A evolução dos equipamentos de ultrassonografia possibilitou a realização do diagnóstico das cardiopatias congênitas em estágios mais precoces da gestação, a compreensão da hemodinâmica fetal e atualmente a avaliação da função cardíaca $^{(53)}$.

A possibilidade de avaliar a função cardíaca é reconhecida como marcador significativo de gravidade e prognóstico da gestação, tanto nas doenças de origem cardíacas, quanto nas patologias maternas que possam apresentar repercussão cardíaca fetal ${ }^{(54,55)}$. Destacam-se a restrição do crescimento intrauterino $(56,57)$, síndrome da transfusão feto-fetal $(58,59)$, hérnia diafragmática ${ }^{(57)}$, tumores intratorácicos ${ }^{(60)}$, entre outras.

A função primária do coração consiste em transmitir energia cinética para o sangue, de modo a gerar e manter uma pressão sanguínea arterial necessária para perfusão adequada dos órgãos e tecidos ${ }^{(61)}$. O coração realiza esta função contraindo suas paredes musculares em torno de uma câmara fechada, gerando pressão suficiente para empurrar o sangue a partir da câmara ventricular cardíaca (esquerda/direita), através das valvas semilunares (aórtica/pulmonar) para a aorta/tronco pulmonar. Para manter a função cardíaca normal, as fases da sístole e diástole têm que estar preservadas e sincronizadas. A descrição do ciclo cardíaco e suas fases é fundamental para o entendimento da avaliação da função cardíaca ${ }^{(61)}$.

\section{Ciclo cardíaco}

A diástole se inicia com a queda na pressão intraventricular, que permite o fechamento das valvas semilunares (aórtica e pulmonar). O intervalo de tempo entre o fechamento das valvas semilunares e a abertura 
das valvas atrioventriculares (mitral e tricúspide) é chamado de tempo de relaxamento isovolumétrico (TRI). Este período é responsável pela complacência ventricular, na qual o relaxamento das câmaras ventriculares é responsável pela acomodação do sangue que irá compor volume de ejeção (volume sistólico) da próxima sístole. Quando a pressão intraventricular fica abaixo da pressão intra-atrial, as valvas atrioventriculares se abrem e permitem o enchimento ventricular passivo (diástole precoce). O final da diástole corresponde ao período de enchimento ventricular ativo, quando ocorre a contração atrial ${ }^{(61)}$.

A sístole se inicia com a contração dos cardiomiócitos que elevam a pressão intraventricular. Este aumento da pressão leva ao fechamento das valvas atrioventriculares, elevando a força da contração das miofibrilas, até que ocorra a abertura das valvas semilunares. Este período é conhecido por tempo de contração isovolumétrica $(\mathrm{TCl})$. Quando a pressão ventricular suplanta a pressão sistêmica, as valvas semilunares se abrem e o sangue é ejetado. Este é conhecido como tempo de ejeção (TE) ${ }^{(61)}$. Assim, nota-se que a alteração em algum destes componentes pode ocasionar insuficiência cardíaca sistólica, diastólica ou combinada.

A figura 1 demonstra os eventos do ciclo cardíaco.

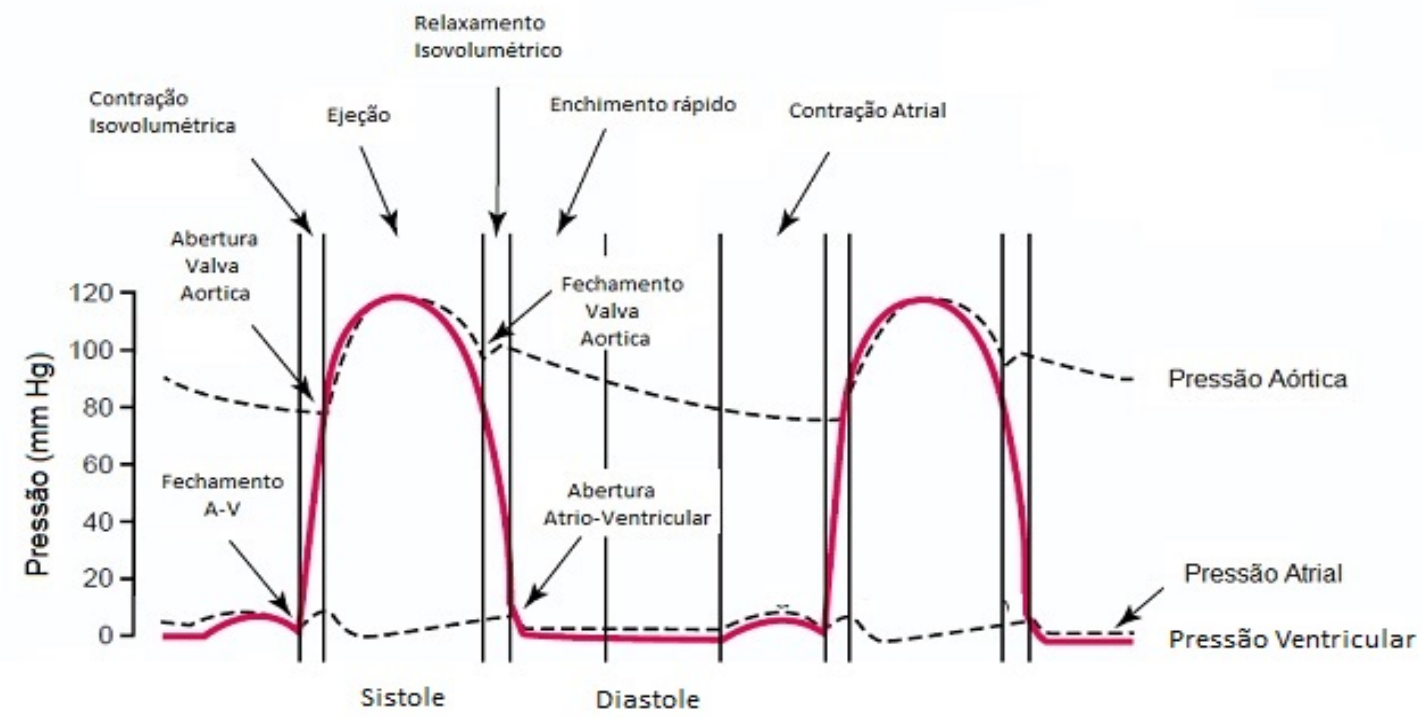

Figura 1 - Eventos do ciclo cardíaco no ventrículo esquerdo, demonstrando variações na pressão atrial, ventricular e aórtica 
A avaliação da função cardíaca fetal permite a detecção precoce das alterações miocárdicas e pode guiar o manejo nestas gestações, melhorando o prognóstico neonatal. No entanto, pelo fato do feto se encontrar no interior do corpo materno, algumas ferramentas propedêuticas não encontraram seu espaço na aplicação clínica: algumas por apresentarem custo-benefício alto; outras, pela dificuldade de aplicabilidade da técnica ou por avaliar a função sistólica ou diastólica isoladamente ${ }^{(54)}$.

Em 1995, Chuwa Tei ${ }^{\left({ }^{62}\right)}$ descreve técnica propedêutica derivada do Doppler pulsátil, não invasiva, na qual foi possível avaliar quantitativamente a função cardíaca global (função sistólica e diastólica). O índice é obtido pela soma dos tempos isovolumétricos (contração e relaxamento) do ciclo cardíaco, divido pelo tempo de ejeção ${ }^{(62,63)}$. Neste mesmo ano, publica estudo com demais colaboradores que avaliou 53 pacientes adultos com miocardiopatia dilatada idiopática estadio II NYHA e 47 com miocardiopatia dilatada estadio III-IV NYHA aguardando transplante. O grupo controle foi composto de 70 pacientes sem patologias. Os valores obtidos do novo índice proposto foram respectivamente: $0,59 \pm 0,10 ; 1,06 \pm 0,24$ e 0,39 \pm 0,$05 ; p<0,001$ em todas as comparações. Concluem que este índice é simples e reprodutível na avaliação da performance miocárdica global e aparentemente independente da frequência cardíaca. Neste momento, os autores descrevem o cálculo apenas como índice, por se tratar de um valor absoluto, obtido por uma razão matemática.

A partir deste trabalho pioneiro, o índice de Tei foi utilizado para acompanhar pacientes adultos com patologias diversas. Foi observado correlação significativa entre os valores obtidos pelo novo índice com medidas invasivas e não invasivas para detecção da insuficiência cardíaca (64-66). Foi avaliado em diferentes situações clínicas, tais como infarto agudo do miocárdio, miocardiopatia dilatada e amiloidose ${ }^{(63,64,67)}$.

Esta técnica foi paulatinamente incorporada na população pediátrica e neonatal ${ }^{(68-71)}$. Objetivando evitar-se o uso de pseudônimos, atualmente o índice de Tei é conhecido por Índice Performance Miocárdica (IPM). 
Desde então, utiliza-se o IPM para detectar o grau de disfunção miocárdica no seguimento de pacientes e/ou risco de reinternação e no prognóstico de doenças cardíacas. Diversos estudos observaram correlação significativa do IPM com parâmetros hemodinâmicos e como preditor de efeitos adversos $(65,67,70,72)$. Além disso, foi demonstrado que o IPM apresenta correlação significativa com medidas invasivas de função ventricular e com fração de ejeção, ambas consideradas padrão ouro na avaliação da função cardíaca ${ }^{(67,73)}$. Pelo fato de avaliar os tempos do ciclo cardíaco, a avaliação do IPM independe da geometria ventricular e da frequência cardíaca, sua utilização se aplica, inclusive nas malformações congênitas e nas remodelações cardíacas frente à hiperplasia miocárdica ${ }^{\text {(74- }}$ 79).

Em 1998, Eidem e cols. ${ }^{(69)}$ avaliam o IPM em 152 crianças saudáveis, com idade entre 3 e 18 anos, com o intuito de determinar a curva de normalidade do IPM na população pediátrica. Observam que o IPM VD foi de $0,32 \pm 0,03$ e VE foi 0,35 $\pm 0,03$. Neste estudo também foram obtidos IPM em 45 crianças que seriam submetidas a cirurgia para correção de cardiopatia - anomalia de Ebstein. Constatam que o IPM no grupo com cardiopatia, em ambos os ventrículos, encontra-se significativamente elevado. Os valores de IPM VD foi de 0,49 $\pm 0,12$ e VE 0,42 $\pm 0,09$. Concluem que 0 índice de performance miocárdica reflete, quantitativamente, a performance ventricular em pacientes com geometria ventricular complexa.

O IPM tem contribuído para avaliação funcional ventricular no seguimento de crianças em uso de quimioterápico e transplante cardíaco e em outras patologias, tais como Tetralogia de Fallot, cardiopatias congênitas de ventrículo único, anomalia de Ebstein ${ }^{(68-70,75,78,80)}$.

Por se tratar de um método não invasivo, independente da geometria e da frequência cardíaca, o IPM se apresenta como uma ferramenta atraente na avaliação da função cardíaca fetal na prática clínica. 
O primeiro estudo utilizando IPM na população fetal foi conduzido por Tsutsumi e cols. ${ }^{(81)}$ em 1999. Foram incluídos 50 fetos normais, 35 fetos com restrição do crescimento intrauterino (RCIU) e 30 fetos de mães com diabetes gestacional. $\mathrm{O}$ objetivo era determinar se era factível a realização do IPM na população fetal e quais seus valores na vida intrauterina. Foi observada correlação inversa entre índice de Tei e o avançar da idade gestacional. Os valores do índice de Tei para o ventrículo esquerdo (VE) entre 18-26 semanas, 27-33 semanas e 34-40 semanas foram respectivamente de: $0,62 \pm 0,07 ; 0,51 \pm 0,04$ e $0,43 \pm 0,03$ e para o ventrículo direito $(V D)$ respectivamente de: $0,62 \pm 0,06 ; 0,53 \pm 0,04$ e 0,49 \pm 0,03 . Este trabalho foi o primeiro a relatar que havia alteração do índice de Tei nos fetos com RCIU e em fetos de mães diabéticas no final da gestação (81)

Eidem e cols. ${ }^{(77)}$ em 2001 avaliam IPM para ambos os ventrículos, em 125 fetos normais de diferentes idades gestacionais. Os autores descrevem valor de normalidade para o VE de $0,36 \pm 0,06$ e para o VD 0,35 $\pm 0,05$ e não encontram diferença significativa ao longo da gestação. Também relatam que o índice de Tei é de fácil obtenção e reprodutibilidade e que pode ser incorporado aos exames de ecocardiografia fetal ${ }^{(77)}$. Valores próximos a estes foram observados por Mori e cols., com média de índice de Tei dos ventrículos esquerdo e direito, respectivamente de $0,34 \pm 0,07$ e $0,35 \pm 0,07^{(82)}$.

Após esta fase inicial, na qual foi observada a viabilidade da realização do exame na população fetal, muitos estudos propuseram métodos para a padronização e reprodutibilidade da técnica, desenvolvendo curvas de normalidade.

Em 2003, Friedman e cols. ${ }^{(83)}$ descrevem técnica para avaliar o IPM em ciclo único para o ventrículo esquerdo. Os autores observam que, devido à conformação espacial do VE fetal à ultrassonografia, era possível obter simultaneamente a via de entrada e a de saída em um único sonograma. Ainda, com esta técnica também era possível calcular os tempos dos 
componentes do IPM, isto é tempo de contração isovolumétrico (TCl), tempo de relaxamento isovolumétrico (TRI) e o tempo de ejeção (TE). Estes autores encontraram os seguintes valores de normalidade para o segundo e terceiro trimestre: $\mathrm{TCl}=43 \pm 14 \mathrm{~ms}$; $\mathrm{TRI}=48 \pm 13 \mathrm{~ms} ; \mathrm{TE}=173 \pm 16 \mathrm{~ms}$ e IPM $=0,53 \pm 0,13$, valor similar ao descrito por Tsutsumi et al. ${ }^{(83)}$.

Hernandez-Andrade e cols. ${ }^{(84)}$ (2005) observam que a técnica de obtenção em tempo único seria menos predisposta a variabilidade da frequência cardíaca e da movimentação fetal. Os autores propõem novo posicionamento do caliper, que deveria se situar abaixo da valva mitral e o eixo de insonação margear a parede da aorta, permitindo assim avaliar os "clicks" de abertura e fechamento das valvas. Desta forma, observam melhora na reprodutibilidade da técnica, que passou de 0,62 (em relação à tecnica de descrita por Friedman e cols.) para 0,80. Nomeam este novo método de obtenção do sonograma de IPM-modificada (IPM mod). No entanto, os valores do IPM-mod encontrados foram significativamente inferiores aos valores obtidos em outros estudos, além de observarem haver variação em relação à idade gestacional. $O$ valor encontrado para $19^{\mathrm{a}}$ semana de gestação foi $0,35 \pm 0,027$ e $39^{\text {a }}$ semana foi $0,37 \pm 0,029$. Relatam também que o $\mathrm{TCl}$ se manteve constante ao longo da idade gestacional. O TRI apresentou aumento enquanto o TE apresentou discreta redução. $O$ tempo médio de realização do exame foi de 3 min (entre 1 a 10 minutos).

Em 2012, este mesmo grupo publica nova curva de referência para gestações entre 11 a 41 semanas. Neste estudo foram avaliados 730 fetos, e obteve-se variação do IPM em relação à idade gestacional. Os valores obtidos entre 11 e 41 semanas de gestação variavam de 0,39 a 0,55, com percentil 95 correspondente 0,51 a 0,78. Observam que os valores do $\mathrm{TCl}$ e TRI aumentaram com a idade gestacional de 25 a $32 \mathrm{~ms}$ e de 39 a $51 \mathrm{~ms}$, respectivamente ${ }^{(85)}$.

Em 2009, Van Mieghem e cols. ${ }^{(86)}$ realizam estudo com 117 fetos comparando o IPM-mod e a fração de ejeção. A fração de ejeção é 
considerada padrão-ouro na detecção da insuficiência cardíaca, apesar de avaliar somente a função sistólica. Observam haver correlação significativa inversa entre a FE e o IPM $(p<0,001)$. Observam ainda que o IPM apresenta melhor correlação inter e intraobservador do que a FE (respectivamente: correlação intraclasse interobservador e intraobservador- IPM: 0,98 (IC95\%: 0,85 - 0,99) e 0,82 (IC95\%: 0,14 - 0,95) e FE: 0,58 (IC95\%: 0,16 - 0,85) e 0,51 (IC95\%: 0,46 - 0,83), validando, assim a utilização do IPM na clínica prática.

\section{Técnica de realização do IPM em fetos}

No estudo original realizado por Chuwa Tei e cols. ${ }^{(62,63)}$, a obtenção do sonograma ocorre em dois tempos, isto é, com a avaliação das vias de entrada e de saída dos ventrículos, em dois sonogramas distintos.

No entanto, Friedman e cols. ${ }^{(83)}$ em 2003, corroborado por Hernandez-Andrade e cols. ${ }^{(84)}$ em 2005, observam que, devido à conformação espacial do coração fetal, era possível avaliar as vias de entrada e de saída do ventrículo esquerdo, em um sonograma único. Segundo os autores, esta técnica permite diminuir o viés de avaliação em dois tempos, minimizando a interferência da frequência cardíaca e da movimentação fetal. Adicionalmente possibilita avaliar os componentes do IPM ${ }^{(83)}$. Porém, esta mesma técnica não pode ser aplicada para o ventrículo direito.

\section{Ventrículo direito}

Com o coração no corte apical de 4 câmaras, posiciona-se o caliper abaixo dos folhetos da valva tricúspide. Calcula-se o tempo entre o fechamento da valva tricúspide (final da onda A) até a abertura da mesma no ciclo seguinte (início da onda E). Este período corresponde somatória do $\mathrm{TCl}, \mathrm{TRI}$ e do TE (Figura 2A). Em segundo tempo, obtém-se o corte paraesternal do eixo curto do VD e posiciona-se o caliper imediatamente 
abaixo da valva pulmonar, e obtém-se o sonograma do TE (Figuras 2B). O cálculo do IPM do VD é: (a-b)/b (Figura 4).

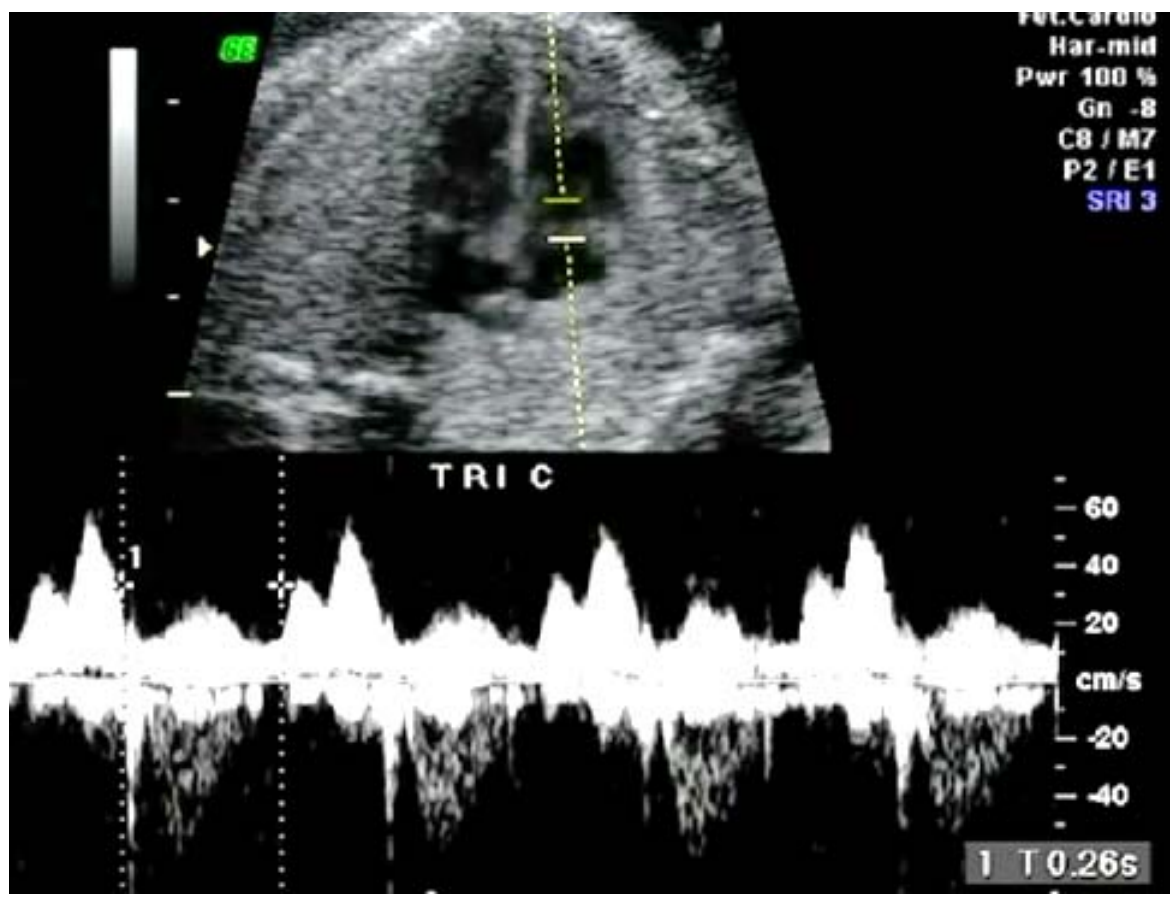

Figura 2A Sonograma da via de entrada do ventrículo direito (valva tricúspide). tempo entre fechamento e abertura da valva atrioventricular

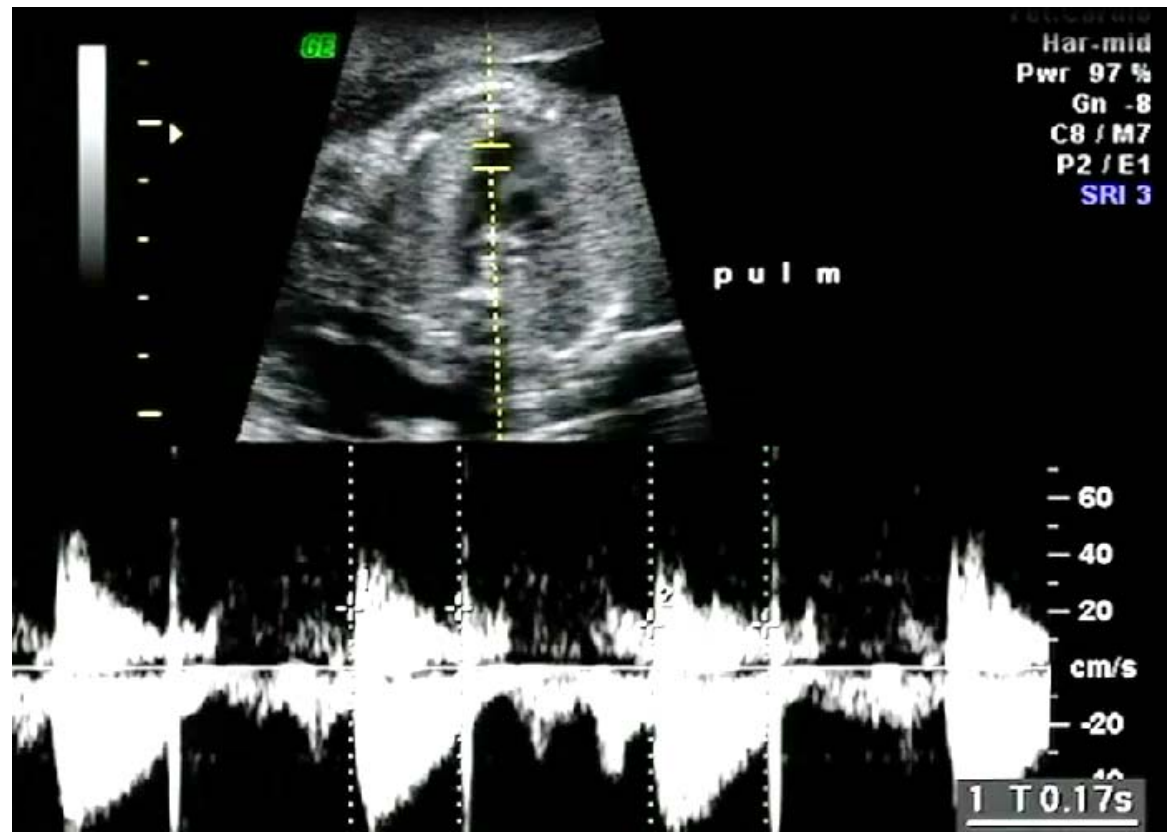

Figura 2B Sonograma da via de saída do ventrículo direito (valva pulmonar). PU: valva pulmonar. TE: tempo de ejeção (b) 


\section{Ventrículo esquerdo}

Com o coração em corte apical de 5 câmaras, posiciona-se o caliper abaixo da valva mitral e o seu trajeto margeando a parede da aorta. Desta forma, obtém-se simultaneamente o traçado da via de entrada e de saída do VE. TCl é o período entre o fechamento da valva mitral (final da onda A) e a abertura da valva aórtica. TE é o período entre abertura e o fechamento da valva aórtica. TRI é o período entre o fechamento da valva aórtica e a abertura da valva mitral (Figura 3).

O cálculo do IPM do VE é: (TCI + TRI)/TE (Figura 4).

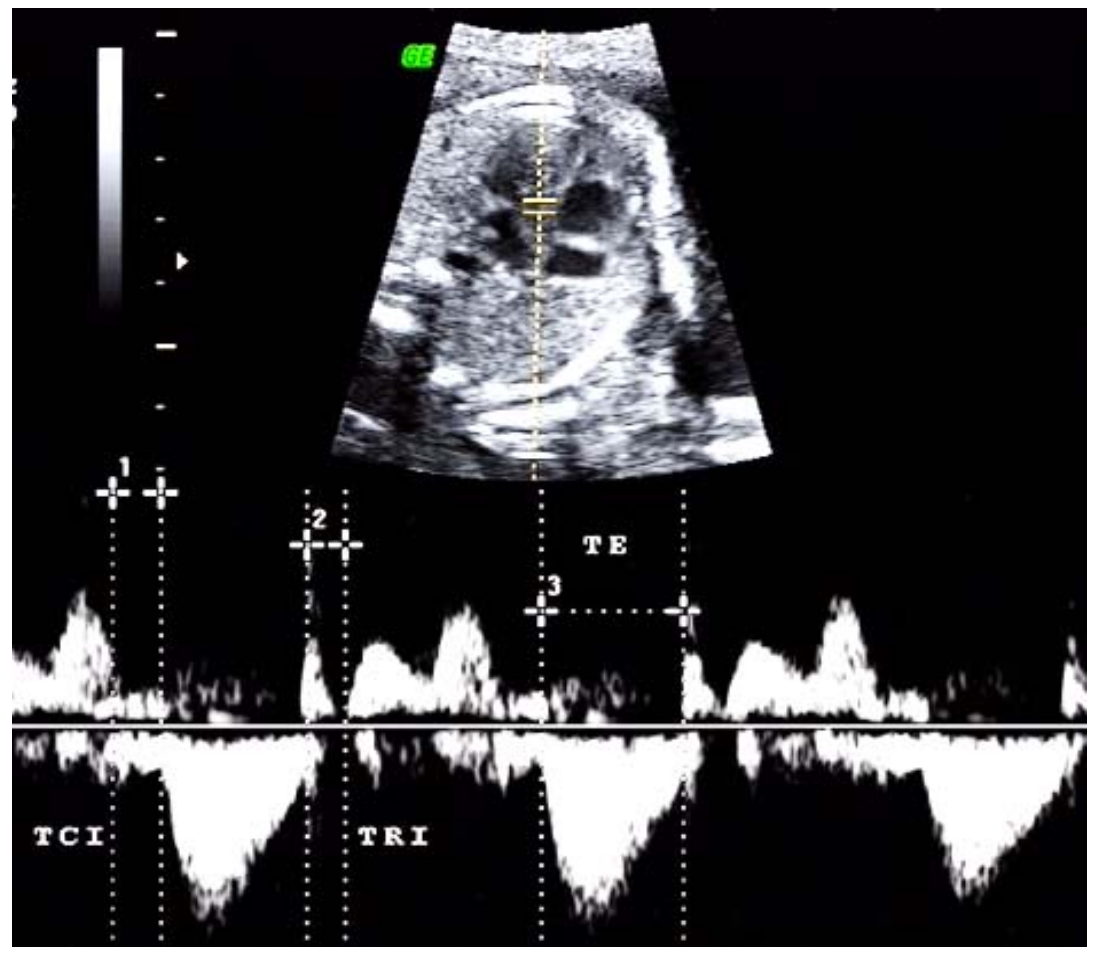

Figura 3 - Sonograma do índice de performance miocárdica do ventrículo esquerdo. TCl: tempo de contração isovolumétrico TRI: tempo de relaxamento isovolumétrico; TE: tempo de ejeção 


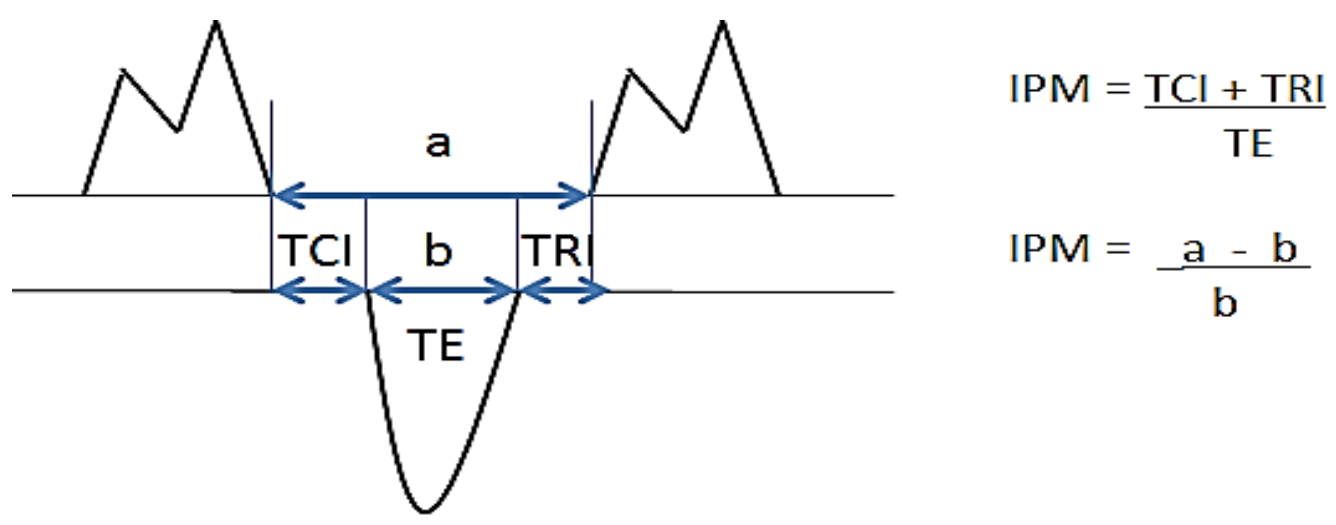

Figura 4 - Ilustração esquemática do cálculo do índice de performance miocárdica. IPM: Índice de performance miocárdica; TCI: tempo de contração isovolumétrico; TRI: tempo de relaxamento isovolumétrico; TE: tempo de ejeção; a: tempo entre fechamento e abertura da valva átrio-ventricular; b: tempo de ejeção

A partir da constatação da viabilidade da utilização do IPM na avaliação da função cardíaca na população fetal, diversos centros de estudos passaram a aplicá-lo na prática clínica.

Ichizuka e cols. ${ }^{(57)}$, em 2005 avaliam o IPM fetal frente à doenças fetais e maternas. O grupo de estudo foi constituido de: 10 pares de gestações gemelares monocoriônicas/diamnióticas sem alterações patológicas; 4 pares de gestações monocoriônicas que apresentavam síndrome da transfusão feto-fetal (STFF); 12 fetos com restrição de crescimento intrauterino; 14 fetos grandes para idade gestacional (gestantes diabéticas), 3 fetos hidrópicos e 8 fetos de mães submetidas a tocólise (inibição medicamentosa do trabalho de parto). O grupo controle consistiu de 40 fetos sem patologias (IPM VE: 0,29 (0,10 - 0,56); VD: 0,31 $(0,15$ - 0,48)). Como resultado, descrevem que o IPM encontrou-se estatisticamente elevado nos fetos receptores da STFF (IPM VE: 0,685 (0,56 - 0,79) e VD: $0,780(0,61-0,85) ; p<0,001)$, nos fetos grandes para idade gestacional das mães diabéticas (IPM VE: 0,490 (0,47 - 0,52) e VD: 0,530 (0,5 - 0,57); $p<$ 0,001) e nos fetos hidrópicos (IPM VE: 0,610 (0,56 - 0,66) e VD: 0,590 (0,57 - 0,67); $p<0,001)$. Concluem que o IPM pode ser uma ferramenta útil na avaliação da função cardíaca fetal em determinadas patologias. Desde 
então, o IPM tem sido estudado em diferentes patologias maternas e fetais (57)

Em 2008, Crispi e cols. ${ }^{(87)}$, avaliam a função cardíaca nos fetos com restrição de crescimento intrauterino em diferentes estágios da doença, segundo os valores do índice de pulsatilidade da artéria umbilical. Para este estudo, foram realizados avaliação do IPM-mod, índice E/A, débito cardíaco, dosagem do peptídeo natriurético cerebral (BNP), Troponina I e PCR. Foram incluídos 120 fetos com desenvolvimento normal para idade gestacional como controle e 81 fetos com RCIU. Os fetos com RCIU foram classificados em 3 estágios em relação ao IP da artéria umbilical (estágio 1: diástole presente; estágio 2: diástole zero e estágio 3: diástole reversa). Como resultado, observam que tanto o IPM-mod, o BNP e o índice E/A encontravam-se aumentados. Este aumento estava correlacionado com a piora nos estágios da RCIU. Concluem que fetos com RCIU apresentam sinais de disfunção cardíaca desde estágios precoces e que ocorre piora da disfunção cardíaca com a progressão do comprometimento fetal. Concomitantemente, ocorre o aparecimento de biomarcadores de lesão miocárdica (BNP).

Em 2011, Cruz-Martinez e cols. ${ }^{(88)}$, avaliam a sequência de alterações do IPM-mod, o fluxo do istmo aórtico e o fluxo do ducto venoso (DV) nos fetos em estágios iniciais de RCIU e Doppler da artéria umbilical acima do percentil 95. O intervalo de avaliação foi de 1 a 7 dias. Foram avaliados 115 fetos e realizados 430 exames. Foi observado que o percentil 95 do IPM-mod, PI Istmo Aórtico e PI do ducto venoso foi atingido, respectivamente, em 26, 12 e 5 dias antes do parto. A proporção de fetos com aumento do IPM-mod na avaliação antes do parto foi de $70,4 \%$, enquanto pra o PI istmo aórtico foi de $55,7 \%$ e do PI DV foi de $47,8 \%$. Todos os valores obtidos foram estatisticamente significativos.

No mesmo ano, Cruz-Martinez e cols. ${ }^{(89)}$ publicam artigo avaliando os mesmos parâmetros descritos no estudo anterior, porém em 178 fetos pequenos para idade gestacional e doppler de artéria umbilical dentro da normalidade e comparando-os com 178 controles. Foi observado que dentre 
os fetos pequenos para a IG, $28,1 \%$ apresentavam valores aumentados do IPM e 14,6\% apresentavam aumento do IP istmo aórtico, demonstrando que estes fetos poderiam apresentar alteração cardiovascular. Este achado sugere que, para casos de fetos pequenos para IG de início tardio, se intensifique a frequência de avaliação.

Nas gestações gemelares, Raboisson e cols. ${ }^{(59)}$ realizam estudo comparando a função miocárdica entre os fetos doadores e receptores na STFF nas gestações monocoriônicas. Os valores do IPM neste grupo foram comparados com grupo de fetos com RCIU. Observam que o IPM estava aumentado nos fetos receptores e que este aumento foi causado pelo prolongamento dos períodos isovolumétricos, comparado com o doador. Ichizuka e cols. ${ }^{(57)}$ também descrevem aumento do IPM nos fetos receptores das gestações monocoriônicas com STFF.

Em 2009, Van Mieguem e cols. ${ }^{(86)}$ realizam a avaliação da função cardíaca dos fetos doadores e receptores, antes e após a fotocoagulação à laser das anastomoses vasculares. Foram avaliados 39 pares de gêmeos com STFF e 23 pares de gêmeos monocoriônicos sem complicações. Observa-se que o IPM tanto do VE quanto do VD estava significativamente aumentado nos fetos receptores em relação ao grupo controle, entretanto houve normalização de todos os índices 4 semanas após a cirurgia.

Papanna e cols. ${ }^{(58)}$ em 2011, avaliam a alteração no IPM durante o procedimento de fotocoagulação à laser nos fetos receptores STFF. A avaliação ocorreu em 4 momentos diferentes: 1 - Uma hora antes da cirurgia; 2- Durante a amniodrenagem após a fotocoagulação dos vasos; 3 12 horas após o procedimento cirúrgico e 4 - 24 horas após o procedimento cirúrgico. Foram avaliados tanto $\mathrm{V} V \mathrm{~V}$ quanto $\mathrm{O} V \mathrm{~V}$. Os resultados mostraram aumento significativo do IPM, tanto para o ventrículo esquerdo quanto para o direito, durante o intra-operatório. Houve regressão do valor IPM para os níveis pré-operatórios após 24 horas do procedimento. Não houve correlação entre o IPM e o número de vasos coagulados. Descrevem que ocorre aumento passageiro no IPM nos fetos receptores durante 0 
procedimento de fotocoagulação à laser, porém este aumento retorna aos níveis pré-operatório após $24 \mathrm{~h}$. No entanto, refletem sobre o fato de que, a despeito de realizar cirurgia conforme a prática habitual, 5 a 10\% dos fetos receptores evoluem para óbito, e que estes óbitos podem estar associados à piora da função cardíaca durante o procedimento.

Em nosso meio, Letti Muller e cols. ${ }^{(90)}$ em 2010 avaliam o IPM do VE nos fetos de mães com rotura prematura das membranas ovulares. Foram incluídas 15 pacientes com idade gestacional entre 24 e 33 semanas e 15 controles pareados para idade gestacional. A avaliação da função cardíaca foi avaliada na admissão e depois a cada 7-10 dias. O IPM foi calculado para o VE em tempo único. Foi observado aumento significativo no IPM dos fetos com RPMO versus o controle $(0,63 \pm 0,13$ vs. $0,51 \pm 0,96 ; p=0,007)$, e que este aumento do IPM esteve relacionado com o encurtamento do tempo de ejeção. Relatam também que no grupo com RPMO, 73,3\% tiveram diagnóstico de sepse neonatal e 53,3\% tiveram diagnóstico de síndrome da resposta inflamatória (demonstrado pela presença de sinais inflamatórios no cordão umbilical e vasculite placentária). Discorrem também que, o aumento no IPM às custas do encurtamento no tempo de ejeção, pode ser uma tentativa do organismo de proteger o sistema nervoso central contra as endotoxinas da resposta inflamatória, e salientam que o IPM pode ser uma ferramenta útil na avaliação dos fetos de pacientes com RPMO.

\section{Índice de Performance Miocárdica e Doença Hemolítica Perinatal}

O índice de performance miocardica é uma técnica derivada do Doppler pulsátil, não invasiva que permite avaliar a função cardíaca global (sistólica e diastólica) e já foi validada para utilização na população fetal. Contudo, não há estudos na literatura que avaliaram a função cardiaca fetal através do IPM na doença hemolitica perinatal.

Em 2012, Nomura e cols. ${ }^{(91)}$ observam haver relação inversamente proporcional entre os niveis de hemoglobina fetal e os valores obtidos de troponina T colhida imediatamente antes da TIU. Este achado sugere que 
fetos com anemia decorrente da aloimunização RhD apresentam lesão miocárdica. No entanto, a obtenção da amostra de troponina fetal é através da cordocentese, procedimento este considerado invasivo.

Os fetos em risco de anemia ficam submetidos a uma circulação hiperdinâmica para tentar manter a perfusão adequada de oxigênio para os tecidos. O coração parece ser órgão alvo na manutenção deste mecanismo, porém o desempenho miocárdico nesta circunstância (patologia) ainda não foi descrito na literatura.

Em razão da incidência elevada da doença hemolítica perinatal na nossa população e da lacuna na literatura sobre a função cardíaca neste grupo de fetos, nos propusemos a investigar a relação entre a função cardíaca e os níveis de hemoglobina, bem como a repercussão da transfusão sanguínea intrauterina sobre a função cardíaca fetal. 

2 Objetivos 

Estudar a função cardíaca fetal na doença aloimune, utilizando o índice de performance miocárdica. 

3 Projeto de Pesquisa 



\section{PROJETO DE PESQUISA}

Clínica Obstétrica do Hospital das Clínicas da Faculdade de Medicina da Universidade de São Paulo - São Paulo - 2011

\section{AVALIAÇÃO DAS ALTERAÇÕES CARDIOVASCULARES EM FETOS COM ANEMIA}

Pesquisador responsável:

Prof. Dr. Adolfo W Liao

Pesquisadores executantes:

Dra. Renata A. de Assunção

Profa. Dra. Maria de Lourdes Brizot

Outros pesquisadores:

Profa. Dra. Rossana Pulcineli Vieira Francisco

Profa. Vera Lúcia Jornada Krebs

Prof. Dr. Marcelo Zugaib 


\section{INTRODUÇÃO}

A anemia fetal é condição que ocorre em fetos de gestantes complicadas pela aloimunização ${ }^{(1,2)}$, em casos de infecções fetais ${ }^{(3,4)}$ ou na hemorragia feto materna ${ }^{(5,6)}$.

Na suspeita de anemia fetal o acompanhamento fetal é realizado pela ultrassonografia com Doppler para a detecção de anemia moderada ou grave, com base no aumento de velocidade de pico sistólica na artéria cerebral média $(\mathrm{ACM})^{(7-10)}$. Na suspeita de anemia uma abordagem invasiva é necessária para a correção da mesma, por meio da transfusão de sangue intra-útero ${ }^{(11,12)}$.

A queda da hemoglobina traz prejuízos ao organismo fetal, promovendo estado de circulação hiperdinâmica ${ }^{(13,14)}$. Em graus extremos, ocorre aumento do débito cardíaco e insuficiência cardíaca congestiva, e o quadro de maior gravidade caracteriza-se pelo desenvolvimento da hidropisia fetal ${ }^{(15,16)}$. Além disso, a anemia fetal secundária à aloimunização está associada à redução da massa ventricular esquerda e na área atrial esquerda na infância, e o mecanismo relacionado pode estar ligado aos eventos na vida intrauterina ${ }^{(17)}$. Uma das hipótese seria que a anemia na fase intrauterina causa uma aumento da massa cardíaca fetal relacionada à aceleração da proliferação e diferenciação dos miócitos. O processo de maturação e diferenciação final dos miócitos, em um período precoce da gestação levaria a uma redução no número final dos miócitos, resultando em redução do volume final da massa miocárdica na infância e na vida adulta (18)

A aloimunização pelo fator Rh (antígeno D) representa potencial complicação obstétrica com conseqüente comprometimento fetal e neonatal. Nestes casos, a gestante previamente aloimunizada possui anticorpos circulantes anti-D, da classe IgG, capazes de atravessar a barreira placentária e se aderir às hemácias fetais, destruindo-as e provocando anemia fetal. A gravidade da doença é determinada pela quantidade de 
anticorpos maternos que atravessam a placenta, bem como pela afinidade destes anticorpos aos antígenos presentes nas hemácias fetais ${ }^{(19)}$.

Algumas infecções virais (citomegalovírus, parvovírus, sífilis, etc), quando acometem o organismo fetal, também podem determinar anemia por lesões de células hematopoiéticas e distúrbios de oxigenação no produto conceptual. O comprometimento de órgãos como o fígado pode contribuir também para anemia e hipoproteinemia ${ }^{(20-22)}$.

Quando a anemia fetal moderada ou grave é diagnosticada, a transfusão intrauterina é o tratamento de escolha, com o objetivo de reduzir a mortalidade fetal e perinatal. Entretanto, nos casos graves a eficiência da terapia intrauterina e a sobrevida fetal dependem não apenas da etiologia da hidropisia, mas também do grau de comprometimento cardíaco fetal ${ }^{(23)}$.

A anemia fetal reduz a capacidade de transporte de oxigênio aos tecidos, gerando hipóxia e desencadeando respostas hemodinâmicas e metabólicas que privilegiam o fluxo sangüíneo para tecidos e órgãos nobres do feto (cérebro, coração, glândulas supra-renais) em detrimento de outros órgãos como os rins, pulmões e pele. Este processo, conhecido como centralização da circulação fetal, procura preservar a oxigenação desses tecidos. Entretanto, a hipoxia progressiva pode levar a comprometimento cardíaco e dano miocárdico fetal, que pode ou não se refletir nos parâmetros dopplervelocimétricos da circulação arterial e venosa fetal ${ }^{(24)}$.

Diante de um quadro de anemia, o feto apresenta resposta hemodinâmica à diminuição da tensão de oxigênio, que se manifesta por alterações no fluxo sangüíneo do compartimento arterial. A queda da viscosidade sangüínea e o aumento do débito cardíaco, decorrentes da anemia, determinam elevação da velocidade de fluxo nas artérias fetais, objetivando manter aporte adequado de oxigênio para os tecidos, que pode ser demonstrado pelo exame de dopplervelocimetria da artéria cerebral média ${ }^{(25)}$.

A ACM tem sido o vaso mais estudado para a predição da anemia fetal, não apenas por ser de fácil insonação, mas também por apresentar 
boa correlação com os níveis de hemoglobina fetal ${ }^{(26)}$. MARI et al. ${ }^{(9)}$ descrevem sensibilidade de $100 \%$ e especificidade de $88 \%$ para o pico da velocidade sistólica da ACM (PVS-ACM) em predizer anemia fetal de intensidade moderada a grave, usando o corte de 1,5 múltiplos da mediana. Os estudos de Bahado-Singh et al. ${ }^{(27)}$, Stefos et al. ${ }^{(28)}$ e Nishie et al. ${ }^{(29)}$ corroboram esses achados.

Posteriormente às alterações adaptativas refletidas no Doppler arterial, surgem alterações nos segmentos venosos da circulação, representando o início da deterioração da função cardíaca fetal ${ }^{(30)}$. Kirkinen e Jouppila em 1983, iniciaram os estudos hemodinâmicos na veia umbilical e observam correlação inversa entre a velocidade de fluxo sangüíneo na veia umbilical e a hemoglobina fetal ao nascimento ${ }^{(31)}$. A hemodinâmica do ducto venoso também é comprometida pela anemia fetal. Opeke et al. em 1993 demonstram que fetos anêmicos apresentam aumento nos picos de velocidade de fluxo, levando a acréscimo no fluxo diastólico final na fase de contração atrial no Doppler do ducto venoso, sugerindo mecanismo de manutenção do suprimento de oxigênio aos órgãos nobres do feto, especialmente ao cérebro. Contudo, em estágios mais avançados, o feto pode desenvolver insuficiência cardíaca congestiva ${ }^{(32)}$.

Em situações de hipoxia, outros vasos da circulação venosa fetal, tais como o sistema portal (veia porta esquerda) podem apresentar alteração em seus fluxos. Porém os poucos estudos na literatura demonstram as suas alterações relacionados com a hipoxemia decorrente da insuficiência placentária, não havendo estudos em relação à hemodinâmica do sistema portal frente à anemia fetal.

Os avanços tecnológicos tem possibilitado a avaliação detalhada da função cardíaca por meio da ultrassonografia com dopplervelocimetria. Tei et al. (1995) descrevem uma técnica derivada do Doppler, para avaliar a função miocárdica global, isto é, avaliar tanto a função sistólica quanto a diastólica e encontram boa correlação com outras medidas invasivas e não invasivas em adultos ${ }^{(33-38)}$. O índice de TEI ou índice de performance miocárdica é 
definido como a soma do tempo de contração isovolumétrica (TCI) e o tempo de relaxamento isovolumétrico (TRI) dividido pelo tempo de ejeção (TE).

O índice de TEI encontra-se elevado tanto na disfunção sistólica, pois resulta em prolongamento do tempo de contração isovolumétrico e encurtamento do tempo de ejeção, quanto na disfunção diastólica pelo prolongamento do tempo de relaxamento isovolumétrico ${ }^{(39,40)}$.

Inicialmente a técnica foi elaborada para pacientes adultos que apresentavam infarto, miocardiopatia dilatada e amiloidose, tanto para detectar o grau de disfunção miocárdica quanto para realizar o seguimento $(34,35,37,38,41)$. Posteriormente, o índice de TEI também foi utilizado para avaliar a função miocárdica de crianças em uso de terapia com antracíclicos, anomalia de Ebstein, cardiopatias congênitas com fisiologia de ventrículo único e seguimento de transplante cardíaco ${ }^{(42-45)}$.

Nos fetos, o índice de TEI foi inicialmente utilizado por Tsutsumi et al. para descrever seu padrão ao longo da gestação tanto em fetos normais quanto em fetos com restrição de crescimento e fetos de mães diabéticas. Estes autores observam correlação inversa entre índice de TEl e o avançar da idade gestacional. Os valores do índice de TEI para o ventrículo esquerdo entre 18 e 26 semanas, 27 e 33 semanas e, 34 e 40 semanas foram respectivamente de: $0,62 \pm 0,07 ; 0,51 \pm 0,04$ e 0,43 $\pm 0,03$ e para o ventrículo direito respectivamente de: 0,62 $\pm 0,06 ; 0,53 \pm 0,04$ e 0,49 0,03. Os autores relatam que pode haver alteração do índice de TEl nos fetos com restrição do crescimento e em fetos de mães diabéticos no final da gestação ${ }^{(46)}$.

Eidem et al. em 2001 avaliam índice de TEl tanto para o ventrículo esquerdo quanto para o direito, em 125 fetos normais e em diferentes idades gestacionais. Os autores descrevem valor de normalidade para o ventrículo esquerdo de 0,36 $\pm 0,06$ e para o ventrículo direito 0,35 \pm 0,05 e não encontram diferença significativa ao longo da gestação. Também relatam que o índice de TEl é de fácil obtenção e reprodutibilidade e que pode ser incorporado aos exames de ecocardiografia ${ }^{(47)}$. Valores próximos a estes 
foram observados por Mori et al., com média de índice de TEl dos ventrículos esquerdo e direito respectivamente de 0,34 $\pm 0,07$ e 0,35 \pm 0,07 (48).

No entanto, Friedman et al. (2003) descrevem valores de normalidade apenas para o ventrículo esquerdo, utilizando técnica modificada do índice de TEI, com avaliação em ciclo único (inflow/outflow) para o segundo e terceiro trimestre, e encontram os seguintes valores de normalidade: $\mathrm{TCl}=$ $43 \pm 14 \mathrm{~ms} ; \mathrm{TRI}=48 \pm 13 \mathrm{~ms} ; \mathrm{TE}=173 \pm 16 \mathrm{~ms}$ e índice de TEI $=0,53 \pm 0,13$, valor similar ao descrito por Tsutsumi et al. ${ }^{(49)}$.

O fato do índice de TEI ser um método não invasivo, independente da geometria cardíaca e da frequência cardíaca, o torna uma possibilidade atraente para a avaliação da função cardíaca global fetal em exames ultrassonográficos.

Mais recentemente, estudos avaliando alterações hemodinâmicas que poderiam alterar a pré e pós carga cardíaca demonstraram elevação do índice de TEI nos fetos hidrópicos (de causa não imune), nos fetos com tumores intratorácicos, nos fetos receptores na síndrome da transfusão fetofetal, nos fetos grandes para idade gestacional de mães diabéticas e nos fetos com síndrome da resposta inflamatória nos casos de rotura prematura das membranas ovulares $(50,51)$. No entanto, até a presente data, não se encontra na literatura avaliação da função global miocárdica nos fetos com anemia. Somente o estudo de Ichizuka et al descreve alterações da função miocárdica relacionada com fetos hidrópicos, porém de causa não imune, demonstrando que ocorre um aumento do índice de TEi nestes casos ${ }^{(50)}$.

A resposta hiperdinâmica compensatória, como descrita anteriormente pode em estágios mais avançados, evoluir para insuficiência cardíaca congestiva, secundária ao déficit de transporte de oxigênio aos tecidos. Makikallio et al. (2002), verificam que a concentração da troponina T cardíaca (cTnT) encontra-se aumentada em neonatos que apresentavam pulsações da veia umbilical intra-abdominal, avaliada à Dopplervelocimetria realizada antes do nascimento, indicando aumento da pressão venosa 
sistêmica fetal (52). Chaiworapongsa et al. (2002), demonstram que um subgrupo de fetos pequeno para a idade gestacional apresenta aumento da Troponina I no nascimento, o que pode significar lesão miocárdica subclínica nesses recém-nascidos, e estar relacionado à predisposição desses fetos desenvolverem doenças cardiovasculares prematuramente na vida adulta (53). Nomura et al. avaliando fetos com anemia de causa não imune, demonstram haver pior prognóstico nos casos em que, a Troponina $T$ avaliada no momento da transfusão intra-uterina encontrava-se elevada, sugerindo que o dano do miocárdio fetal interfere no prognóstico desses fetos ${ }^{(54)}$.

Outro hormônio produzido pelo miocárdio e que possivelmente se encontra aumentado quando ocorre aumento da sobrecarga cardíaca é o peptídeo natriurético cerebral (em inglês Brain Natriuretic Peptide - BNP). Este hormônio é sintetizado e liberado pelo miocárdio ventrícular e, sua concentração plasmática está aumentada nos casos de cardiopatia congestiva e hipertensão arterial ${ }^{(55,56)}$. Diversos estudos na literatura sugerem que a análise do BNP seja uma ferramenta importante para o rastreamento, classificação e seguimento de pacientes com insuficiência cardíaca nos adultos. Dao et al. sugerem inclusive a necessidade da avaliação do BNP nas salas de emergência nos casos suspeitos de insuficiência cardíaca ${ }^{(57)}$.

Walther et al. (2001) demonstram que a concentração de BNP na circulação fetal é significativamente maior do que na circulação materna. Eles demonstram que o sistema peptídeo natriurético fetal responde a estímulo de sobrecarga de modo semelhante aos adultos ${ }^{(58)}$.

Recentemente, Ferreira et al. avaliam o BNP em fetos aloimunizados submetidos à transfusão intra-uterina e correlacionaram com o Índice Cardiofemural. O índice Cardiofemural é um marcador para dilatação cardíaca e encontraram uma correlação positiva entre este marcador e o BNP sugerindo que o BNP seja um marcador para dilatação cardíaca consequente à anemia fetal ${ }^{(59)}$. 
Apesar da disponibilidade de sangue fetal por meio de procedimentos invasivos, em casos de anemia fetal, pouco foi investigado a respeito dos marcadores de disfunção cardíaca nesses fetos. Nossa principal hipótese é que a quantificação da cTnT e do BNP em sangue de cordão umbilical, previamente à TIU possa ser utilizada como marcador de prognóstico nos casos de anemia fetal, relacionando-se com o valor da hemoglobina fetal, os parâmetros de avaliação da circulação fetal e os resultados perinatais.

\section{JUSTIFICATIVA DO ESTUDO}

Apesar do diagnóstico e manejo das anemias fetais estarem bem consolidados na literatura, pouco foi investigado sobre as alterações na circulação venosa fetal e os danos ao miocárdico fetal. Portanto diante dessa lacuna, o presente estudo justifica-se pela necessidade de melhor entendimento sobre: a disfunção cardíaca, a circulação venosa e a análise dos marcadores de lesão e função miocárdica nos fetos anêmicos. 


\section{OBJETIVO}

Avaliar nos fetos com anemia ou risco de anemia fetal:

1. a função miocárdica global utilizando o índice de TEI

2. a circulação venosa por meio do estudo do fluxo sanguíneo no ducto venoso, veia porta esquerda e veia umbilical

3. os marcadores bioquímicos de função (BNP) e lesão miocárdica (cTnT) nos casos submetidos à transfusão intra-uterina ou no sangue do cordão ao nascimento. 


\section{MATERIAL E MÉTODOS}

Serão analisadas prospectivamente as gestações encaminhadas para o Setor de Medicina Fetal da Clínica Obstétrica do Hospital das Clínicas da Faculdade de Medicina da Universidade de São Paulo (HCFMUSP), com suspeita de anemia fetal, independente da etiologia.

\subsection{TIPO DE ESTUDO}

Estudo prospectivo e descritivo.

\subsection{CRITÉRIOS DE INCLUSÃO}

Serão incluídas gestantes que preencham os seguintes critérios:

- Gestação única;

- Idade gestacional maior ou igual a 18 semanas;

- Fetos em risco de anemia;

- Fetos sem anomalia estrutural ou cromossômica;

- Ritmo cardíaco sinusal.

\subsection{CRITÉRIOS DE EXCLUSÃO}

Serão excluídos os casos em que ocorrer:

- Última avaliação com intervalo maior do que 7 dias do desfecho da gestação

- Perda de seguimento pós-natal;

- Diagnóstico pós-natal de anomalias estruturais ou cromossômicas. 


\subsection{DESENHO DO ESTUDO}

As gestantes encaminhadas para o Setor de Medicina Fetal da Clínica Obstétrica que preencherem os critérios de inclusão serão convidadas a participar do estudo. Após esclarecimento dos objetivos da pesquisa e dos exames a que serão submetidas, será solicitado o consentimento da paciente (ANEXO I).

A avaliação do índice de TEI e do fluxo sanguíneo venoso fetal será realizada na ocasião em que a paciente for submetida à avaliação fetal e o seguimento destes casos seguirá o protocolo para as pacientes com suspeita de anemia fetal. A avaliação destes parâmetros não será utilizada para orientação da conduta assistencial dos casos analisados, tendo apenas caráter investigativo, devendo acrescentar, ao período de realização do exame cerca de 20 minutos.

No caso da necessidade de correção da anemia fetal pela transfusão intra-uterina, previamente à infusão de sangue, habitualmente é coletado $1 \mathrm{~mL}$ de sangue fetal para análise do hemograma completo, $1 \mathrm{~mL}$ para cariótipo fetal. No presente estudo será coletado adicionalmente $2 \mathrm{~mL}$ para dosagem da c e do BNP.

\subsubsection{TAMANHO DA AMOSTRA}

Para o cálculo do tamanho da amostra foi considerado que o valor médio do índice de TEI na população de fetos normais é de $0,53 \pm 0,10$, valor descrito em estudos da literatura.

A literatura sugere que o valor do índice de TEi se eleva em cerca de $20 \%$ frente a algumas patologias fetais nas quais ocorra sobrecarga cardíaca, tais como, fetos receptores das gestações gemelares monocoriônicas, nos fetos grandes para idade gestacional das pacientes com diabetes gestacional e nos fetos após ruptura das membranas ovulares. 
Desta forma, a tabela a seguir lista o tamanho amostral necessário (segundo diferentes valores de erro alfa e beta) para demonstrar diferença de $20 \%$ nos valores de TEl observados no grupo de estudo, assumindo os valores de normalidade para TEI descritos na literatura:

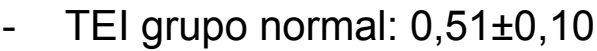

- TEl grupo estudo: $0,40 \pm 0,15$ ou $0,60 \pm 0,15$ (assume diferença de $20 \%$ no valor médio e desvio padrão mais amplo de 0,15$)$.

Tabela: Tamanho amostral necessário para demonstrar diferença de $20 \%$ no valor de TEl em fetos com anemia segundo diferentes valores de erro alfa e beta

\begin{tabular}{|c|c|c|c|c|c|}
\hline \multicolumn{2}{|c|}{} & \multicolumn{5}{c|}{ Erro alfa } \\
\cline { 2 - 6 } \multicolumn{2}{|c|}{} & 0,20 & 0,10 & 0,05 & 0,01 \\
\hline \multirow{2}{*}{ Erro beta } & 0,20 & 15 & 21 & 26 & 38 \\
\cline { 2 - 6 } & 0,10 & 22 & 28 & 35 & 49 \\
\cline { 2 - 6 } & 0,05 & 28 & 36 & 43 & 58 \\
\cline { 2 - 6 } & 0,01 & 43 & 52 & 60 & 79 \\
\hline
\end{tabular}

Considerando uma perda de seguimento de $10 \%$, recrutaremos 30 pacientes cujos fetos apresentem risco de anemia fetal, para a avaliação do índice de TEI.

\subsection{AVALIAÇÃO DOPPLERVELOCIMÉTRICA}

\subsubsection{AVALIAÇÃO DO ÍNDÍCE DE TEI}

O estudo será realizado em equipamento de ultrassonografia modelo Voluson 730 Expert (General Electric, Austria) e será realizada a avalição pelos dois pesquisadores executantes, usando transdutor convexo de 3,5 a 5,5 Mhz. Inicialmente será avaliada a anatomia cardíaca fetal. Todas as 
imagens serão armazenadas no hard drive do equipamento e também impressas em filme de papel especifico para ultrassonografia. As medidas serão obtidas utilizando o software do próprio equipamento.

O índice de TEl será calculado pela média de três intervalos consecutivos do ciclo cardíaco, com o feto em repouso e na ausência de movimentos respiratórios. O ângulo de correção máximo adotado será de $30^{\circ}$ e a abertura da janela do Doppler pulsátil será entre 2 a $4 \mathrm{~mm}$. Será realizada a avaliação tanto para a função do ventrículo esquerdo quanto para o ventrículo direito.

O índice de TEl corresponde à soma do tempo de contração isovolumétrico (TCl) e do tempo de relaxamento isovolumétrico (TRI) dividido pelo tempo de ejeção (TE). O mesmo resultado pode ser obtido pela subtração do tempo de ejeção do intervalo entre o fechamento e a abertura da valva atrioventricular, e este resultado dividido pelo tempo de ejeção (vide figura 1).

Como padronização da análise do sonograma, as valvas átrioventriculares serão analisadas sempre acima da linha de base e as valvas semilunares em posição inferior à linha de base.

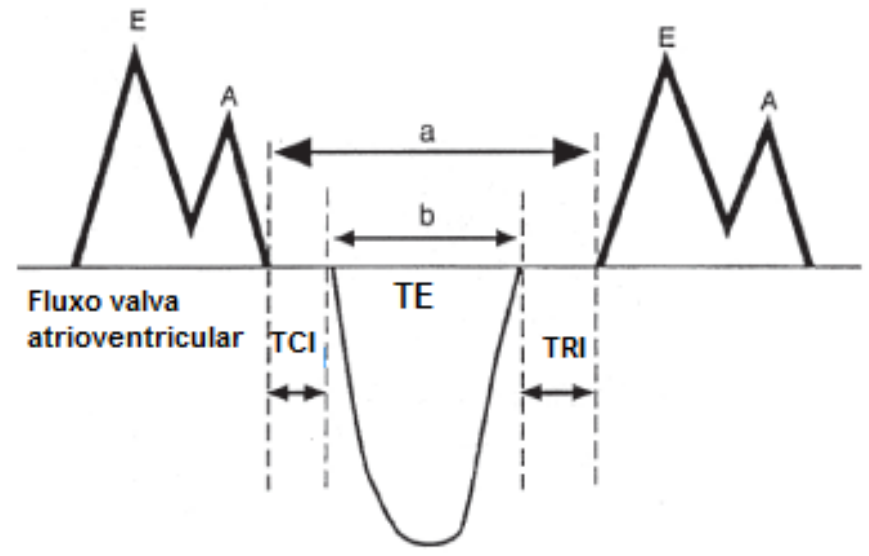

Fluxo valva semilunar

$T E I=\frac{(T C 1+T R I)}{T E}=\frac{a-b}{b}$

Figura 1 - Ilustração esquemática do cálculo do índice de TEI 
O cálculo do índice de TEI para o ventrículo direito será realizado em dois tempos. O primeiro ciclo contempla a análise da valva tricúspide e no segundo ciclo será avaliado a valva pulmonar. Com o coração em corte apical, na posição das quatro câmaras, a janela do Doppler é posicionada na abertura da valva tricuspide e obtido o tempo entre o seu fechamento e a sua abertura subsequente, o que representa esquematicamente na análise do Doppler ao intervalo entre o final da onda $A$ e início da próxima onda $E$. A análise da valva pulmonar será realizada com a janela do Doppler posicionada logo abaixo da sua inserção, no ventrículo direito, e o tempo de ejeção será calculado entre o tempo de abertura e fechamento da respectiva valva.

Para o cálculo do índice de TEI do ventrículo esquerdo será utilizada a técnica de medida da sístole e da diástole em ciclo único. Com o coração na posição apical de cinco câmaras, a janela do Doppler é posicionada no ventrículo esquerdo na junção da valva mitral e a valva aórtica (imediatamente abaixo da sua inserção) (vide figura 2). O TCl corresponde ao tempo de fechamento da valva mitral (Mi) e a abertura da valva aórtica (Ao). O TRI corresponde ao intervalo entre o fechamento da valva aórtica e a abertura da valva mitral. O tempo de ejeção corresponde ao intervalo entre a abertura e o fechamento da valva aórtica. Serão realizados para o calculo de TEl as duas formulas descritas acima. 


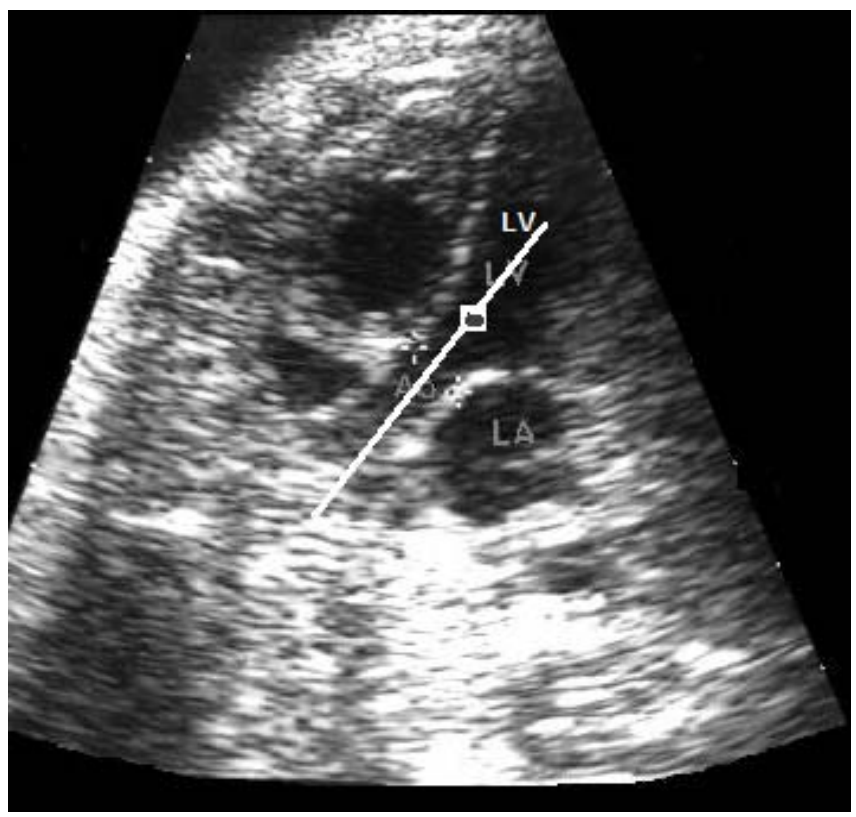

Figura 2 - Visão corte apical cinco câmaras cardíacas

\subsubsection{AVALIAÇÃO FLUXO VENOSO FETAL}

Serão avaliadas a dopplervelocimetria do ducto venoso (índice de pulsatilidade), da veia porta esquerda (TAVmáx e espessura da veia porta esquerda) e veia umbilical (TAVmáx).

\subsubsection{AVALIAÇÃO DA TROPONINA T E BNP}

Nas pacientes que realizarem transfusão intra-uterina serão colhidos sangue de cordão umbilical para realizar dosagem de Troponina $\mathrm{T}$ (1 $\mathrm{ml} \mathrm{em}$ tubo seco) e da BNP (1 $\mathrm{ml}$ em tubo com EDTA). 


\section{VARIÁVEIS A SEREM ANALISADAS}

\section{Maternas}

- Idade (anos);

- Cor (branca/ Não Branca);

- $\quad$ Número de Gestações;

- Paridade $\left(\mathrm{n}^{\circ}\right)$;

- Numero de Abortos;

- Número de cesáreas;

- Número de filhos vivos;

- Gravidade da doença hemolítica prévia (leve: RN com necessidade de fototerapia; moderada: $\mathrm{RN}$ de termo com necessidade de exsanguineo transfusão; grave: RN prematuro com necessidade de exsanguineo transfusão ou transfusão intraútero, ou óbito intra-útero tendo como causa aloimunização)

\section{Fetal em cada exame}

- Idade gestacional;

- Dopplervelocimetria de artéria cerebral média (PS-VMax);

- Dopplervelocimetria da artéria umbilical (relação A/B e índice de pulsatilidade);

- índice de TEI para ventrículo direito e esquerdo;

- Dopplervelocimetria do sistema venoso fetal (veia umbilical, veia portal esquerda, ducto venoso);

- Medida do diâmetro da veia porta esquerda; 


\section{Fetal na transfusão sanguinea}

- troponina T pré-TIU;

- $\quad$ BNP pré TIU;

- Hb pré-e pós TIU;

- Volume de sangue transfundido;

- Porcentagem de expansão de volume na TIU;

- Complicações na TIU;

\section{Vitalidade fetal pós TIU}

- Cardiotocografia (normal, suspeita, alterada);

- Perfil Biofísico (0 a 10);

- I Índice de líquido amniótico (cm);

- Dopplervelocimetria da artéria cerebral média (PS-VMax);

- Dopplervelocimetria da artéria umbilical (relação A/B e índice de pulsatilidade);

- $\quad$ índice de TEI para ventrículo direito e esquerdo;

- Dopplervelocimetria do ducto venoso (índice de pulsatilidade para veias);

- Dopplervelocimetria do sistema venoso fetal (velocidade máxima da veia umbilical e da veia portal esquerda);

\section{Parto}

- Idade gestacional no nascimento (semanas);

- Tipo de parto;

- Peso do Recém-Nascido (gramas);

- Índices de Apgar de $1^{\circ}, 5^{\circ}$ e $10^{\circ}$ minutos (0 a 10);

- Sofrimento fetal (sim; não); 


\section{Perinatais}

- Peso da placenta (gramas);

- Hemoglobina ao nascimento;

- Dosagem Troponina T e BNP do cordão umbilical

- $\quad \mathrm{pH}$ de artéria umbilical no nascimento;

- Reanimação neonatal;

- Necessidade de intubação orotraqueal do RN (sim ou não);

- Infecção fetal congênita;

- Necessidade de exsanguineotransfusão pós-natal (sim, número; não);

- Morbidade neonatal precoce (não ou sim, se sim, qual);

- Tempo de internação;

- Mortalidade perinatal (sim ou não);

- Sobrevida pós-natal (sim ou não); 


\section{RISCOS E BENEFÍCIOS PARA OS SUJEITOS DA PESQUISA}

O presente estudo prospectivo tem como base a investigação das alterações cardíacas nos fetos com suspeita e/ou diagnostico de anemia fetal. Os exames dopplervelocimétricos realizados durante o pré-natal e a dosagem da Troponina e do BNP nos procedimentos de TIU, serviram para verificar a associação entre a anemia fetal e as possíveis alterações cardíacas, comparando os exames de avaliação fetal e os resultados perinatais. Consiste em análise de fatores que podem associar-se a pior prognóstico fetal, porém não acarretam risco aos pacientes, pois a investigação não alterará o protocolo já consolidado e adotado pela Clínica Obstétrica do HCFMUSP.

A análise dos dados obtidos na avaliação do índice de TEI, na dopplervelocimetria do sistema venoso e nos procedimentos de TIU oferecerá dados concretos que permitirão, no futuro, melhor planejamento na assistência ao procedimento em gestações que cursam com anemia fetal.

Todas as informações obtidas com a presente investigação serão mantidas em sigilo, garantindo-se assim a privacidade e confidencialidade dos dados das pacientes.

\section{RECURSOS HUMANOS E INFRA-ESTRUTURA PARA REALIZAÇÃO DA PESQUISA}

O presente estudo será realizado na Clínica Obstétrica do HCFMUSP e não necessita de orçamento específico. Será utilizado aparelho de ultrassonografia já disponível na Clínica Obstétrica e a coleta de dados será realizada durante os exames agendados rotineiramente para o seguimento dessas gestações. As dosagens de troponina T e do BNP serão realizados pelo laboratório de apoio da clínica Obstetrica do Instituto Central do HCFMUSP. Os pesquisadores constituem os recursos humanos necessário para efetivação da pesquisa. 


\section{TERMO DE CONSENTIMENTO LIVRE E ESCLARECIDO}

O termo de consentimento livre e esclarecido será aplicado, pois se trata de pesquisa prospectiva, e encontra-se em anexo. Serão respeitadas a privacidade e a confidencialidade dos dados obtidos e nenhuma identificação das pacientes dos casos será divulgada.

\section{CRONOGRAMA DE REALIZAÇÃO}

A pesquisa está planejada para ser finalizada no prazo de dois anos, desde o início da revisão de literatura e o encaminhamento do manuscrito para publicação. O cronograma de realização deverá obedecer ao seguinte esquema, após aprovação do presente projeto:

- Revisão bibliográfica: dois meses

- Coleta das informações: um ano e quatro meses;

- Análise estatística e elaboração do texto: seis meses

\section{JUSTIFICATIVA DOS AUTORES}

- Seguimento das gestantes com fetos de risco para anemia fetal: Dra Renata A de Assunção, Prof Adolfo Liao, Profa Maria Brizot

- Auxílio e consultoria para avaliação ecocardiográfica e do índice de performance miocárdica: Dra Lilian Maria Lopes

- Dosagens bioquímicas dos marcadores Troponina T e peptídeo natriurético cerebral (BNP): Profa Roseli Nomura

- Assistência neonatal: Profa Vera Krebs 


\section{PUBLICAÇÕES PROPOSTAS}

1. Descrição dos valores de índice de performance miocárdica em fetos com anemia

2. Correlação entre índice de performance miocárdica e marcadores bioquímicos de lesão miocárdica fetal e desfecho perinatal na doença aloimune. 


\section{INSTRUMENTO DE COLETA DE DADOS:}

$\mathrm{N}^{\circ}$.

NOME:

RGHC:

ID:..... DUM:............... DEP $\ldots . . . . / \ldots \ldots / \ldots \ldots$

$1^{\circ}$ USG: realizado dia:................ IG no $1^{\circ}$ USG:........sem Comp: ( )S ( )N

AO:.....................A Partos VAG........ CES....... Filhos vivos:

PATOLOGIAS.

MEDICAÇÕES

Avaliação do índice de TEl e do sistema venoso

\begin{tabular}{|l|c|c|c|c|c|c|c|c|c|c|c|c|}
\hline \multirow{2}{*}{ Data } & \multirow{2}{*}{ IG } & \multicolumn{2}{|c|}{$\begin{array}{c}\text { TEI VD } \\
\text { Média 3 ciclos }\end{array}$} & \multicolumn{5}{c|}{$\begin{array}{c}\text { TEI VE } \\
\text { Média 3 ciclos }\end{array}$} & \multicolumn{2}{|c|}{ DV } & \multicolumn{3}{|c|}{ Doppler Venoso } & \multicolumn{2}{c|}{$\begin{array}{c}\text { Peso } \\
\text { fetal }\end{array}$} \\
\hline & & a & b & a & b & TCI & TRI & PIV & VU & VPE & P & \\
\hline & & & & & & & & & & & & \\
\hline & & & & & & & & & & & & \\
\hline & & & & & & & & & & & \\
\hline & & & & & & & & & & & & \\
\hline & & & & & & & & & & & & \\
\hline & & & & & & & & & & & & \\
\hline
\end{tabular}

TIU: $\quad n^{\circ}$

DATA:

INDICAÇÃO PARA TIU:

HIDROPSIA FETAL: ( ) SIM ( ) NÃO

Hb pré-TIU:

Troponina T:

BNP:.

Volume infundido:

\% de expansão:

Hb p'pos-TIU: 
Avaliação fetal pós TIU:

\begin{tabular}{|l|l|l|l|l|l|l|l|l|l|l|l|l|l|l|l|}
\hline \multirow{2}{*}{ Data } & \multirow{2}{*}{ IG } & \multirow{2}{*}{ CTR } & PBF & LA & \multicolumn{2}{|c|}{ Umb } & \multicolumn{2}{|c|}{ ACM } & \multicolumn{2}{|c|}{ DV } & \multicolumn{3}{|c|}{ D Venoso } & \multirow{2}{*}{ Peso } \\
\cline { 5 - 12 } & & & & & A/B & PI & PI & Vs & PIV & VU & VPE & p & \\
\hline & & & & & & & & & & & & & \\
\hline & & & & & & & & & & & & & \\
\hline & & & & & & & & & & & & & \\
\hline & & & & & & & & & & & & & \\
\hline & & & & & & & & & & & & & \\
\hline & & & & & & & & & & & & & \\
\hline
\end{tabular}

PARTO:

Tipo de Parto:................ IG:................ Data:............... Hora:.

$\mathrm{pH}:$.

Sofrimento fetal intraparto: (....) sim (....) não Indicação:.

Placenta: Peso..................... Aspecto:

RESULTADOS PERINATAIS:

Peso do RN:

( ) Masc ( ) Fem Índice de Apgar:...................

Intubação do RN:

( ) AIG ( )PIG ( ) GIG

UTI neonatal: ..dias

Tempo total de intern. no berçário:. .dias

Transfusão:

Infecção congênita:.

Complicações: 


\section{REFERÊNCIAS}

1. Schumacher B, Moise KJ Jr. Fetal transfusion for red blood cell alloimmunization in pregnancy. Obstet Gynecol. 1996 jul;88(1):137-50.

2. Moise $\mathrm{KJ}$ Jr. Management of rhesus alloimmunization in pregnancy. Obstet Gynecol. 2008 jul;112(1):164-76.

3. De Haan TR, Beersma MF, Oepkes D, De Jong EP, Kroes AC, Walther FJ Parvovirus B19 infection in pregnancy: maternal and fetal viral load measurements related to clinical parameters. Prenat Diagn. 2007 jan;27(1):46-50.

4. Dembinski J, Haverkamp F, Maara H, Hansmann M, Eis-Hubinger AM, Bartmann P. Neurodevelopmental outcome after intrauterine red cell transfusion for parvovirus b19-induced fetal hydrops. Bjog. 2002 nov;109(11):1232-4.

5. Sifakis S, Koukoura O, Konstantinidou AE, Kikidi K, Prezerakou M, Kaminopetros $P$. Sonographic findings in severe fetomaternal transfusion. Arch Gynecol Obstet. 2010 feb;281(2):241-5.

6. Votino C, Mirlesse V, Gourand I, Parnet-Mathieu F, Bessieres B, Daffos F. Successful treatment of a severe second trimester fetomaternal hemorrhage by repeated fetal intravascular transfusions. Fetal Diagn Ther. 2008;24(4):503-5.

7. Hernandez-Andrade E, Scheier M, Dezerega V, Carmo A, Nicolaides $\mathrm{KH}$. Fetal middle cerebral artery peak systolic velocity in the investigation of non-immune hydrops. Ultrasound Obstet Gynecol. 2004 may;23(5):442-5. 
8. Mari G. Middle cerebral artery peak systolic velocity: is it the standard of care for the diagnosis of fetal anemia? J Ultrasound Med. 2005 may;24(5):697-702.

9. Mari G, Deter RL, Carpenter RL, Rahman F, Zimmerman R, Moise KJ, Jr., et al. Noninvasive diagnosis by doppler ultrasonography of fetal anemia due to maternal red-cell alloimmunization. Collaborative group for doppler assessment of the blood velocity in anemic fetuses. N Engl J Med. 2000 jan $6 ; 342(1): 9-14$.

10. Mari G, Zimmermann R, Moise KJ Jr., Deter RL. Correlation between middle cerebral artery peak systolic velocity and fetal hemoglobin after 2 previous intrauterine transfusions. Am J Obstet Gynecol. 2005 sep;193(3 pt 2):1117-20.

11. Lobato G, Soncini CS. Fetal hydrops and other variables associated with the fetal hematocrit decrease after the first intrauterine transfusion for red cell alloimmunization. Fetal Diagn Ther. 2008;24(4):349-52.

12. Yinon Y, Visser J, Kelly EN, Windrim R, Amsalem H, Seaward PG, et al. Early intrauterine transfusion in severe red blood cell alloimmunization. Ultrasound Obstet Gynecol. 2010 nov;36(5):601-6.

13. Illanes $S$, Soothill P. Noninvasive approach for the management of hemolytic disease of the fetus. Expert Rev Hematol. 2009 oct;2(5):577-82.

14. Sikkel E, klumper FJ, Oepkes D, Teunissen AK, Meerman RH, Le Cessie $S$, et al. Fetal cardiac contractility before and after intrauterine transfusion. Ultrasound Obstet Gynecol. 2005 nov;26(6):611-7.

15. Craparo FJ, Bonati F, Gementi P, Nicolini U. The effects of serial intravascular transfusions in ascitic/hydropic rhd-alloimmunized fetuses. Ultrasound Obstet Gynecol. 2005 feb;25(2):144-8. 
16. Mesogitis S, Daskalakis G, Pilalis A, Papantoniou N, Antsaklis A. Fetal intravascular transfusion for hydropic disease due to rhesus isoimmunization. Fetal Diagn Ther. 2005 sep-oct;20(5):431-6.

17. Dickinson JE, Sharpe J, Warner TM, Nathan EA, D'orsogna I. Childhood cardiac function after severe maternal red cell isoimmunization. Obstet Gynecol. 2010 oct;116(4):851-7.

18. Jonker SS, Giraud MK, Giraud GD, Chattergoon NN, Louey S, Davis LE, et al. Cardiomyocyte enlargement, proliferation and maturation during chronic fetal anaemia in sheep. Exp Physiol. 2009 jan;95(1):131-9.

19. Lobato g, Soncini CS. Relationship between obstetric history and $\mathrm{rh}(\mathrm{d})$ alloimmunization severity. Arch Gynecol Obstet. 2008 mar;277(3):245-8.

20. Chen I, Chandra S, Singh A, Kumar M, Jain V, Turnell R. Successful outcome with intrauterine transfusion in non-immune hydrops fetalis secondary to congenital syphilis. J Obstet Gynaecol Can. 2010 sep;32(9):861-5

21. Lamont RF, Sobel JD, Vaisbuch E, Kusanovic JP, Mazaki-tovi S, Kim SK, et al. Parvovirus b19 infection in human pregnancy. Bjog. 2011 jan;118(2):175-86.

22. Rodriguez MM, Chaves F, Romaguera RL, Ferrer PL, De la Guardia C, Bruce $\mathrm{JH}$. Value of autopsy in nonimmune hydrops fetalis: series of 51 stillborn fetuses. Pediatr Dev Pathol. 2002 jul-aug;5(4):365-74.

23. Abrams ME, Meredith KS, Kinnard P, Clark RH. Hydrops fetalis: a retrospective review of cases reported to a large national database and identification of risk factors associated with death. Pediatrics. 2007 jul;120(1):84-9. 
24. Nicolini U, Talbert DG, Fisk NM, Rodeck CH. Pathophysiology of pressure changes during intrauterine transfusion. Am J Obstet Gynecol. 1989 may;160(5 pt 1):1139-45.

25. Nicolaides $\mathrm{KH}$, Soothill $\mathrm{PW}$, Clewell WH, Rodeck $\mathrm{CH}$, Mibashan RS, Campbell S. Fetal haemoglobin measurement in the assessment of red cell isoimmunisation. Lancet. 1988 may 14;1(8594):1073-5.

26. Whitecar PW, Moise KJ Jr. Sonographic methods to detect fetal anemia in red blood cell alloimmunization. Obstet Gynecol Surv. 2000 apr;55(4):240-50.

27. Bahado-singh RO, Oz AU, Hsu C, Kovanci E, Deren O, Onderoglu L, et al. Middle cerebral artery doppler velocimetric deceleration angle as a predictor of fetal anemia in rh-alloimmunized fetuses without hydrops. Am J Obstet Gynecol. 2000 sep;183(3):746-51.

28. Stefos T, Cosmi E, Detti I, Mari G. Correction of fetal anemia on the middle cerebral artery peak systolic velocity. Obstet Gynecol. 2002 feb;99(2):211-5.

29. Nishie EN, Brizot ML, Liao AW, Carvalho MHB, Toma O, Zugaib M. A comparison between middle cerebral artery peak systolic velocity and amniotic fluid optical density at $450 \mathrm{~nm}$ in the prediction of fetal anemia. Am J Obstet Gynecol. 2003 jan;188(1):214-9.

30. Harrington K, Cooper D, Lees C, Hecher K, Campbell S. Doppler ultrasound of the uterine arteries: the importance of bilateral notching in the prediction of pre-eclampsia, placental abruption or delivery of a small-forgestational-age baby. Ultrasound Obstet Gynecol. 1996 mar;7(3):182-8.

31. Kirkinen P, Jouppila P, Eik-nes $S$. Umbilical vein blood flow in rhesusisoimmunization. Br J Obstet Gynaecol. 1983 jul;90(7):640-3. 
32. Oepkes D, Vandenbussche FP, Van bel F, Kanhai HH. Fetal ductus venosus blood flow velocities before and after transfusion in red-cell alloimmunized pregnancies. Obstet Gynecol. 1993 aug;82(2):237-41.

33. Tei C, Nishimura RA, Seward JB, Tajik AJ. Noninvasive dopplerderived myocardial performance index: correlation with simultaneous measurements of cardiac catheterization measurements. $J$ Am Soc Echocardiogr. 1997 mar;10(2): 169-78.

34. Tei C, Ling LH, Hodge DO, Bailey KR, Oh JK, Rodeheffer RJ, et al. New index of combined systolic and diastolic myocardial performance: a simple and reproducible measure of cardiac function--a study in normals and dilated cardiomyopathy. J Cardiol. 1995 dec;26(6):357-66.

35. Tei C, Dujardin KS, Hodge DO, Kyle RA, Tajik AJ, Seward JB. Doppler index combining systolic and diastolic myocardial performance: clinical value in cardiac amyloidosis. J Am Coll Cardiol. 1996 sep;28(3):658-64.

36. Tei C. New non-invasive index for combined systolic and diastolic ventricular function. J Cardiol. 1995 aug;26(2):135-6.

37. Poulsen SH, Jensen SE, Tei C, Seward JB, Egstrup K. Value of the doppler index of myocardial performance in the early phase of acute myocardial infarction. J Am Soc Echocardiogr. 2000 aug;13(8):723-30.

38. Dujardin KS, Tei C, Yeo TC, Hodge DO, Rossi A, Seward JB. Prognostic value of a doppler index combining systolic and diastolic performance in idiopathic-dilated cardiomyopathy. Am J Cardiol. 1998 nov 1;82(9):1071-6.

39. Nishimura RA, Housmans PR, Hatle LK, Tajik AJ. Assessment of diastolic function of the heart: background and current applications of doppler 
echocardiography. Part i. Physiologic and pathophysiologic features. Mayo Clin Proc. 1989 jan;64(1):71-81.

40. Lax JA, Bermann AM, Cianciulli TF, Morita LA, Masoli O, Prezioso HA. Estimation of the ejection fraction in patients with myocardial infarction obtained from the combined index of systolic and diastolic left ventricular function: a new method. J Am Soc Echocardiogr. 2000 feb;13(2):116-23.

41. Eto G, Ishii M, Tei C, Tsutsumi T, Akagi T, Kato H. Assessment of global left ventricular function in normal children and in children with dilated cardiomyopathy. J Am Soc Echocardiogr. 1999 dec;12(12):1058-64.

42. Williams RV, Ritter S, Tani LY, Pagoto LT, Minich LL. Quantitative assessment of ventricular function in children with single ventricles using the doppler myocardial performance index. Am J Cardiol. 2000 nov 15;86(10):1106-10.

43. Mooradian SJ, Goldberg CS, Crowley DC, Ludomirsky A. Evaluation of a noninvasive index of global ventricular function to predict rejection after pediatric cardiac transplantation. Am J Cardiol. 2000 aug 1;86(3):358-60.

44. Ishii M, Tsutsumi T, Himeno W, Eto G, Furui J, Hashino K, et al. Sequential evaluation of left ventricular myocardial performance in children after anthracycline therapy. Am J Cardiol. 2000 dec 1;86(11):1279-81, a9.

45. Eidem BW, Tei C, O'leary PW, Cetta F, Seward JB. Nongeometric quantitative assessment of right and left ventricular function: myocardial performance index in normal children and patients with ebstein anomaly. $J$ Am Soc Echocardiogr. 1998 sep;11(9):849-56.

46. Tsutsumi T, Ishii M, Eto $G$, Hota M, Kato $H$. Serial evaluation for myocardial performance in fetuses and neonates using a new doppler index. Pediatr Int. 1999 dec;41(6):722-7. 
47. Eidem BW, Edwards JM, Cetta F. Quantitative assessment of fetal ventricular function: establishing normal values of the myocardial performance index in the fetus. Echocardiography. 2001 jan;18(1):9-13.

48. Mori Y, Rice MJ, Mcdonald RW, Reller MD, Wanitkun S, Harada K, et al. Evaluation of systolic and diastolic ventricular performance of the right ventricle in fetuses with ductal constriction using the doppler tei index. Am J Cardiol. 2001 nov 15;88(10):1173-8.

49. Friedman D, Buyon J, Kim M, Glickstein JS. Fetal cardiac function assessed by doppler myocardial performance index (tei index). Ultrasound Obstet Gynecol. 2003 jan;21(1):33-6.

50. Ichizuka K, Matsuoka R, Hasegawa J, Shirato N, Jimbo M, Otsuki K, et al. The tei index for evaluation of fetal myocardial performance in sick fetuses. Early Hum Dev. 2005 mar;81(3):273-9.

51. Letti Muller al, Barrios PDE M, Kliemann LM, Valerio EG, Gasnier R, Magalhaes JA. Tei index to assess fetal cardiac performance in fetuses at risk for fetal inflammatory response syndrome. Ultrasound Obstet Gynecol. Jul;36(1):26-31.

52. Makikallio K, Vuolteenaho O, Jouppila P, Rasanen J. Ultrasonographic and biochemical markers of human fetal cardiac dysfunction in placental insufficiency. Circulation. 2002 apr 30;105(17):2058-63.

53. Chaiworapongsa T, Espinoza J, Yoshimatsu J, Kalache K, Edwin S, Blackwell S, et al. Subclinical myocardial injury in small-for-gestational-age neonates. J Matern Fetal Neonatal Med. 2002 jun;11(6):385-90.

54. Nomura RM, Brizot ML, Liao AW, Andrade JQ, Zugaib M. Fetal cardiac troponin $\mathrm{t}$ as a marker of poor prognosis in nonimmune hydrops fetalis. Fetal Diagn Ther. 2009;26(1):57-60. 
55. Vitlianova KD, Donova TI, Apostolova MD. Predictive factors for high brain (b-type) natriuretic peptide at discharge in properly treated heart failure patients. Folia Med (plovdiv). Jan-mar;53(1):19-27.

56. Lobos Bejarano JM, Horrillo Garcia C, Gonzalez-Gonzalez AI, Castellanos Rodriguez A, Diaz Sanchez S, Castellanos Maroto J, et al. [validity and usefulness of b-type natriuretic peptide (bnp) for early detection of left ventricular dysfunction in high-risk patients in primary care.]. Aten primaria. May 31.

57. Dao Q, Krishnaswamy $P$, Kazanegra R, Harrison A, Amirnovin R, Lenert L, et al. Utility of b-type natriuretic peptide in the diagnosis of congestive heart failure in an urgent-care setting. J Am Coll Cardiol. 2001 feb;37(2):379-85.

58. Walther T, Stepan H, Faber R. Dual natriuretic peptide response to volume load in the fetal circulation. Cardiovasc Res. 2001 mar;49(4):817-9.

59. Ferreira AL, Reis ZS, Braga J, Leite HV, Cabral AC. Relationship between cardiofemoral index and the plasma concentration of brain natriuretic peptide in anemic fetuses associated with rh alloimmunization. Arch Gynecol Obstet. 2009 mar;279(3):335-9. 

4 Publicações 



\section{PRENATAL DIAGNOSIS}

Original Article

\section{Myocardial performance index in fetal anemia}

Renata Almeida de Assunção, Adolfo Wenjaw Liao*, Maria de Lourdes Brizot, Rossana Pulcineli Vieira Francisco and Marcelo Zugaib

Article first published online: 15 DEC 2014 DOI: $10.1002 / p d .4526$

(C) 2014 John Wiley \& Sons, Ltd
Issue

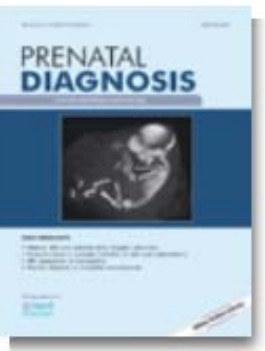

Prenatal Diagnosis

Volume 35 , Issue 2 , pages 192-196, February 2015 



\section{PAPER 1: MYOCARDIAL PERFORMANCE INDEX IN FETAL ANEMIA.}

de Assunção RA, Liao AW, de Lourdes Brizot M, Francisco RP, Zugaib M.

Prenatal Diagnosis. 2015 Feb; 35 (2) :192-6

DOI: 10.1002/pd.4526. Epub 2014 Dec 15

PMID: 25377887

\section{ABSTRACT}

Objective: To examine the correlation between fetal myocardial performance index (MPI) and hemoglobin levels.

Methods: Prospective study involving singleton pregnancies at risk of fetal anemia due to maternal anti-D alloimmune disease. Right and left ventricle MPI were evaluated by ultrasound up to 72 hours before cordocentesis. Zetascore values for fetal MPI and hemoglobin levels $(\mathrm{Hb})$ were calculated and correlation was examined with linear regression analysis. Significance level was set as 0.05 .

Results: Fourteen singleton pregnancies underwent 31 cordocentesis procedures at a mean gestation of $28.2 \pm 4.1$ weeks. Zeta-score values for left ventricle (LV) MPI, isovolumetric relaxation (IRT) and ejection (ET) times correlated significantly with fetal hemoglobin zeta score (LV MPI zeta $=3.816$ +0.336 * Hb zeta, $r=0.59, p<0.001$; LV IRT zeta $=2.643+0.218$ * Hb zeta, $r=0.45, p=0.01$; LV ET zeta $=-2.474-0.271{ }^{*} \mathrm{Hb}$ zeta, $r=-0.42, p=0.02$ ). Left ventricle isovolumetric contraction time (ICT) zeta-score and right ventricle (RV) MPI did not show significant correlation (LV ICT zeta: $r=0.35$, $p=0.054 ;$ RV MPI: $r=0.12, p=0.53$.

Conclusion: Left ventricle myocardial performance not only remains preserved but is actually enhanced in cases of moderate/severe fetal anemia.

Keywords: cardiac function, alloimmunization, fetal anemia and myocardial performance index. 
GRANTS: none to be declared

DISCLOSURES: none to be declared

\section{What's already Known about this topic?}

Myocardial performance index (MPI) is a non invasive technique that evaluates global cardiac function. Changes have been demonstrated in early stages of fetal growth restriction when end diastolic flow is still present. Likewise $40 \%$ of recipient fetuses in Quintero stage I twin-twin transfusion syndrome show increased MPI.

\section{What does this study add?}

Our results show that left ventricle myocardial performance not only remains preserved but is actually enhanced in cases of moderate/severe fetal anemia.

\section{INTRODUCTION}

Fetal anemia is associated with several adaptative mechanisms in order to maintain an adequate tissue oxygenation. Circulatory changes play a key role in such circumstances. Fetal hyperdinamic circulation and increased cardiac output are attributed to reduced blood viscosity, increased cardiac contractility and peripheral vasodilatation due to hypoxia ${ }^{1-3}$. As a matter of fact, screening for fetal anemia in current practice is essentially based on Doppler evaluation of middle cerebral artery peak systolic velocity ${ }^{4}$.

Severe fetal anemia may be associated with progressive loss of adaptative mechanisms due to inadequate tissue oxygenation. Ultimately metabolic changes result in fetal acidosis and increased perinatal morbidity and mortality ${ }^{2,5}$. Although cardiac decompensation does not seem to be the principal mechanism involved in the development of overt fetal hydrops ${ }^{6}$, severe anemia may lead to cardiac ischemia, reduced contractility and dysfunction. 
Myocardial performance index (MPI) is a noninvasive technique that evaluates systolic and diastolic cardiac function by pulsed Doppler ${ }^{7}$. Fetal MPI evaluation was originally described by Tsutsumi et al $(1999)^{8}$ and several studies have subsequently shown that it is a simple and reproducible technique ${ }^{9,10}$. Significant changes in fetal MPI have been demonstrated in twin-twin transfusion syndrome recipient fetuses, intra uterine growth restriction, diabetes and fetal inflammatory response syndrome ${ }^{8,11-15}$.

Likewise, changes in cardiac contractility due to fetal anemia may play a role in the evaluation of disease severity and prognosis. To the best of our knowledge, the effects of anemia on fetal MPI have not been previously reported.

\section{METHODS}

This prospective study was carried out at a tertiary referral center for fetal medicine (Hospital das Clínicas, São Paulo University Medical School, Brazil). Women with singleton pregnancies and alloimmune disease were invited to take part in the study. Institutional ethics committee approved the study (CAPPesq 80460) and all women who participated gave informed consent.

Fetal anomaly and echocardiographic examinations did not show structural abnormalities at the first evaluation. Gestational age was based on the first date of the last menstrual period (LMP) whenever it was confirmed by ultrasound scan findings. When there was discrepancy between LMP and ultrasound dates, or LMP was uncertain or unknown, dating was based on the earliest ultrasound scan information.

At each visit, fetal middle cerebral artery (MCA) and myocardial performance index (MPI) were evaluated in the absence of fetal corporal and respiratory movements. All examinations were carried out abdominally with a curved 3.5-5.0MHz probe and Voluson 730 Expert / E8 equipment (General Eletric Medical Systems, Austria). Data was prospectively entered into an 
electronic spreadsheet (Excel, Microsoft Corporation, USA). MCA was examined according to previously described technique ${ }^{16}$. Peak systolic velocity measurements were recorded and multiples of the median (MoM) values were calculated according to gestational age ${ }^{4}$.

MPI evaluation was performed with Doppler sample gate set between $2-4 \mathrm{~mm}, 190 \mathrm{~Hz}$ wall motion filter and high sweep-speed to allow simultaneous identification of 3-4 cardiac cycles on the screen. Doppler beam was manually adjusted to keep angle of insonation below $20^{\circ}$. No angle corrections were performed.

\section{Left ventricle $\mathrm{MPI}$ assessment}

In an apical five-chamber view of the heart, Doppler sample volume was placed on the lateral wall of the ascending aorta, below the aortic valve and just above the mitral valve. Pulsed Doppler trace included both the E/A and the aortic blood flow waveforms and care was also taken to clearly identify valve click echoes. Isovolumetric contraction time (ICT) was estimated from the closure of the mitral valve, to the opening of the aortic valve. Ejection time (ET) was determined from the opening to the closure of the aortic valve. Isovolumetric relaxation time (IRT) was defined from the closure of the aortic valve to the opening of the mitral valve. Time calipers were placed just before the echo of the each valve click ${ }^{17}$. Left ventricle (LV) MPI was calculated as (ICT + IRT)/ET (figure 1). Zeta-score values for LV $\mathrm{MPI}$ and its components were calculated according to reference values published by Cruz-Martínez et al by the following formula: (observed value expected mean value for gestation)/ standard deviation ${ }^{18}$. 
Right ventricle MPI assessment

In an apical four-chamber view of the heart, Doppler sample volume was positioned at the tip of the tricuspid leaflets during diastole. Right ventricle inflow time interval (a) was obtained from the cessation (end of ' $A$ ' wave) to the onset of inflow (beginning of ' $E$ ' wave) through the valve. This measurement corresponds to the sum of isovolumetric contraction time, ejection time and isovolumetric relaxation time. In a parasternal short-axis view of the right ventricle outflow tract, Doppler sample volume was positioned just below the pulmonary valve and ejection time interval (b) was obtained as the duration of outflow. Right ventricle MPI was calculated as (ab)/b (figure 1) ${ }^{7}$.

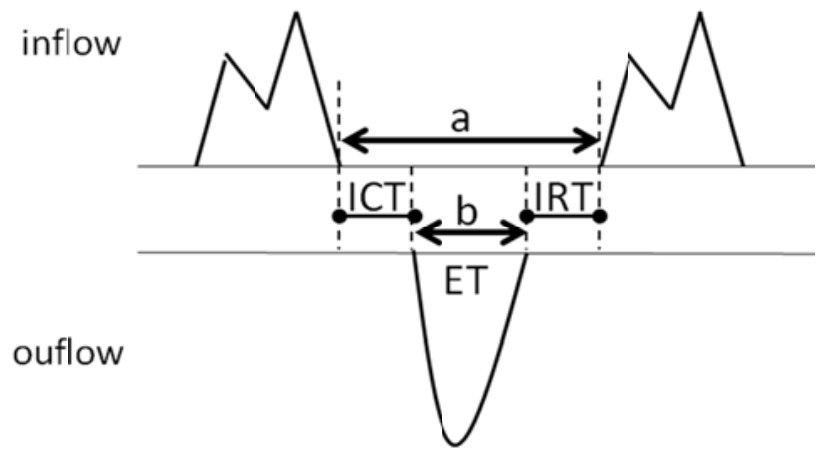

Figure 1 - Scheme depicting Doppler trace with isovolumetric contraction time (ICT), ejection time (ET) and isovolumetric relaxation time (IRT). Left ventricle myocardial performance index $(\mathrm{MPI})=(\mathrm{ICT}+$ IRT) / ET. Right ventricle MPI = (a - b) / b

Pregnancies with increased fetal MCA peak velocity or hydrops underwent cordocentesis. At each procedure, fetal hemoglobin levels were measured in blood samples collected prior to transfusion. Hemoglobin zetascore ( $\mathrm{Hb}$ zeta) values were calculated as: measured hemoglobin - mean hemoglobin for gestation / standard deviation 19. All transfusions were performed with fresh type $\mathrm{O}$ Rh negative adult packed red blood cells, previously irradiated with 25 Gy of gamma radiation, washed, and filtered. After the first transfusion, follow-up appointments and ultrasound 
examinations were performed every 7 to 14 days. The decision to perform a subsequent transfusion was based on MCA PSV values or an expected decline rate in fetal hemoglobin levels of $0.3 \mathrm{~g} / \mathrm{dl}$ per day.

The correlation between zeta-score values of fetal MPI and its components and hemoglobin was examined with linear regression analysis. Data was also analyzed according to the first and subsequent procedures. Significance level was set as 0.05. All Doppler evaluations were performed up to 72 hours before cordocentesis.

\section{RESULTS}

Fourteen singleton pregnancies underwent cordocentesis due to maternal anti-D alloimmune disease and suspected fetal anemia. Maternal characteristics and perinatal outcome are summarized in table 1 . Three $(21.4 \%)$ fetuses were hydropic at the first procedure. 
Table 1 - Maternal characteristics and perinatal outcome in 14 singleton pregnancies with maternal anti-D alloimmune disease

\begin{tabular}{|c|c|}
\hline & mean \pm standard deviation I n (\%) \\
\hline maternal age, years & $33.6 \pm 4.5$ \\
\hline \multicolumn{2}{|l|}{ past history of alloimmune disease } \\
\hline none & $3(21.4)$ \\
\hline phototherapy & $2(14.3)$ \\
\hline intrauterine/exchange transfusion & $2(14.3)$ \\
\hline stillbirth / neonatal death & $7(50.0)$ \\
\hline gestational age at delivery, weeks & $34.1 \pm 2.5$ \\
\hline still birth & $1(7.1)$ \\
\hline live birth & $13(92.9)$ \\
\hline birthweight, grams & $2322 \pm 626$ \\
\hline$<1500 \mathrm{~g}$ & $1(7.1)$ \\
\hline$<2500 \mathrm{~g}$ & $7(50.0)$ \\
\hline exchange transfusion & $1.5 \pm 0.9$ \\
\hline \multicolumn{2}{|l|}{ postnatal complications } \\
\hline cholestasis & $1(7.1)$ \\
\hline kernicterus & $1(7.1)$ \\
\hline pulmonary hypertension & $1(7.1)$ \\
\hline respiratory distress syndrome & $1(7.1)$ \\
\hline pulmonary broncho dysplasia & $2(14.3)$ \\
\hline sepsis & $3(21.4)$ \\
\hline hospital stay, days & $27.2 \pm 24.4$ \\
\hline
\end{tabular}

Overall 31 cordocentesis were performed at a mean gestational age of $28.2 \pm 4.1$ weeks. Table 2 summarizes ultrasound and fetal hemoglobin levels at the time of these procedures. 
Table 2 - Ultrasound findings and fetal hemoglobin levels in 14 singleton pregnancies that underwent cordocentesis and intrauterine transfusions for fetal anemia. MPI: myocardial performance index

\begin{tabular}{lccc}
\hline & $\begin{array}{c}\text { all } \\
\text { procedures }\end{array}$ & $\begin{array}{c}\text { first } \\
\text { cordocentesis }\end{array}$ & $\begin{array}{c}\text { subsequent } \\
\text { procedures }\end{array}$ \\
\hline $\mathrm{N}$ & 31 & 14 & 17 \\
gestational age at procedure, weeks \pm & $28.2 \pm 4.1$ & $28.3 \pm 4.7$ & $28.1 \pm 3.7$ \\
SD & & & \\
middle cerebral artery peak velocity & $65.6 \pm 14.6$ & $66.2 \pm 17.8$ & $65.2 \pm 11.8$ \\
cm/s \pm SD & $1.75 \pm 0.25$ & $1.74 \pm 0.29$ & $1.75 \pm 0.22$ \\
MoM \pm SD & $0.51 \pm 0.19$ & $0.50 \pm 0.22$ & $0.52 \pm 0.16$ \\
right ventricle MPI, mean \pm SD & $0.54 \pm 0.13$ & $0.55 \pm 0.15$ & $0.54 \pm 0.10$ \\
Left ventricle MPI, mean \pm SD & $1.80 \pm 1.43$ & $1.70 \pm 1.73$ & $1.88 \pm 1.19$ \\
zeta score \pm SD & $6.9 \pm 2.6$ & $6.1 \pm 3.0$ & $7.5 \pm 2.1$ \\
fetal hemoglobin, g/dl \pm SD & $-6.0 \pm 2.5$ & $-6.8 \pm 3.0$ & $-5.3 \pm 2.0$ \\
zeta score \pm SD & $18(58)$ & $7(50)$ & $11(65)$ \\
-2 to $-6, \mathrm{n}(\%)$ & $12(39)$ & $7(50)$ & $5(29)$ \\
\hline$\leq-6, \mathrm{n}(\%)$ & & &
\end{tabular}

Zeta-score values for left ventricle myocardial performance index, isovolumetric relaxation and ejection times correlated significantly with fetal hemoglobin zeta score (LV MPI zeta $=3.816+0.336$ * Hb zeta, $r=0.59$, $p<0.001 ;$ LV IRT zeta $=2.643+0.218 * \mathrm{Hb}$ zeta, $r=0.45, p=0.01 ;$ LV ET zeta $=-2.474-0.271{ }^{*} \mathrm{Hb}$ zeta, $\left.r=-0.42, p=0.02\right)$. Left ventricle isovolumetric contraction time zeta-score and right ventricle MPI did not show significant correlation (LV ICT zeta: $r=0.35, p=0.054$; RV MPI: $r=0.12, p=0.53$; figures 2 and 3).

Considering data from the first procedure of each patient $(n=14)$, zeta values of left ventricle myocardial performance index and both isovolumetric relaxation and contraction times were significantly correlated with the degree of fetal anemia (LV MPI zeta $=4.952+0.476 *$ Hb zeta, $r=0.81, p<0.001 ;$ LV ICT zeta $=3.688+0.357^{*} \mathrm{Hb}$ zeta, $r=0.66, p=0.01 ;$ LV IRT zeta $=4.163+$ $0.391{ }^{*} \mathrm{Hb}$ zeta, $\left.r=0.81, p<0.001\right)$. Left ventricle ejection time zeta-score and right ventricle MPI did not correlate significantly with fetal hemoglobin zeta score (LV ET zeta: $r=-0.46, p=0.11$; RV MPI: $r=0.14, p=0.63$ ). 
Seven (50\%) women underwent 2 transfusions, 5 (35.7\%) had three transfusions, $4(28.6 \%)$ had four, and one $(7.1 \%)$ underwent five transfusions. For subsequent transfusions $(n=17)$, right ventricle MPI and left ventricle MPI zeta-score did not correlate significantly with the degree of fetal anemia (LV MPI zeta: $r=0.24, p=0.35$; RV MPI: $r=0.04, p=0.86$ ).
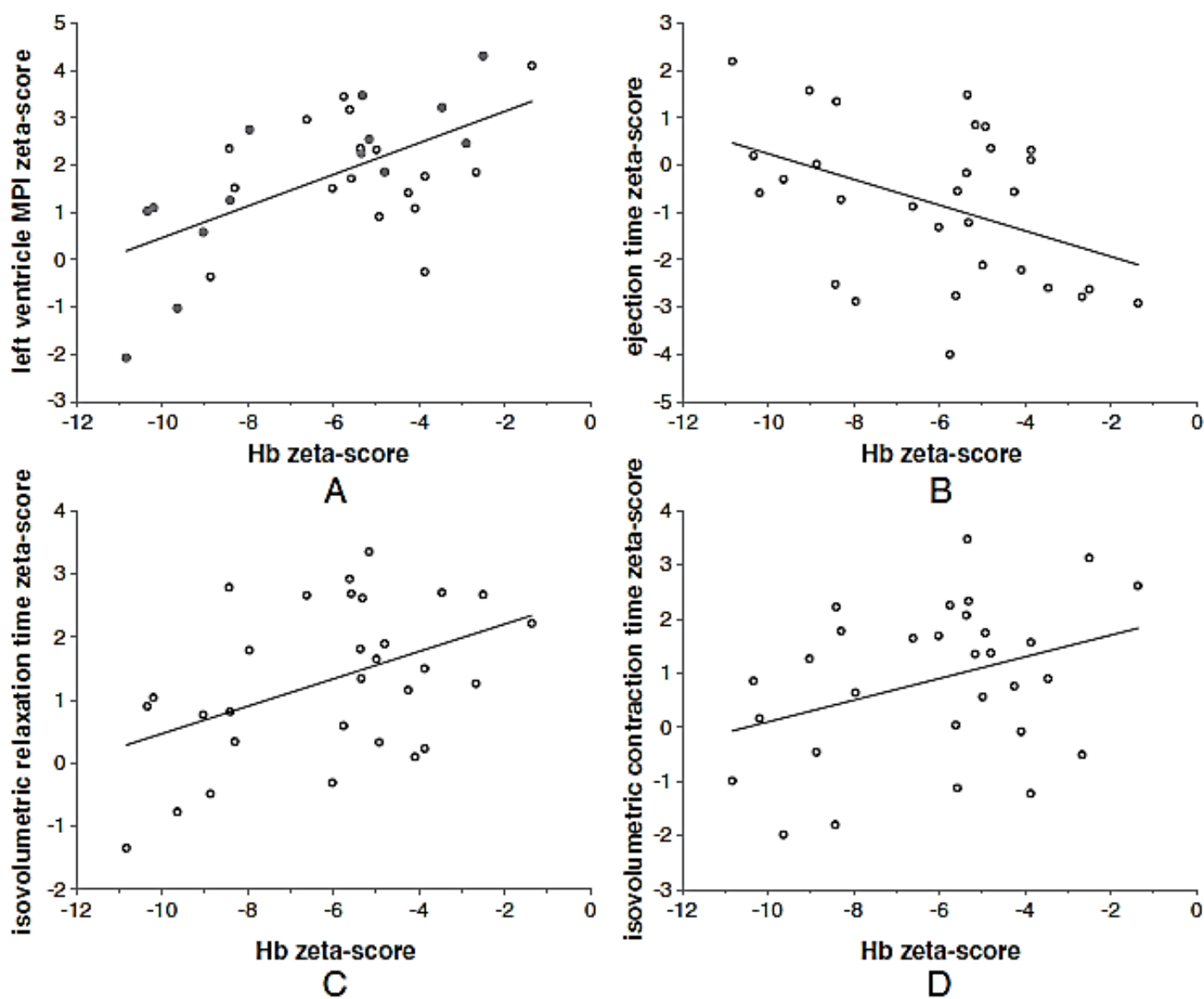

Figure 2 - Correlation between left ventricle myocardial performance index and time component zeta-score values and fetal hemoglobin zeta score observed in 31 cordocentesis procedures performed in 14 singleton pregnancies with maternal anti-D alloimmune disease. $\mathrm{Hb}$, fetal hemoglobin; MPI, myocardial performance index. (A) Left ventricle myocardial performance index zeta-score $=3.816+$ $0.336 \times \mathrm{Hb}$ zeta, $r=0.59, p<0.001$. Filled circles, first cordocentesis $(n=14)$; open circles, subsequent procedures $(n=$ 17). (B) Ejection time zeta score $=2.474 \_0.271 \times \mathrm{Hb}$ zeta, $r$ $=0.42, p=0.02$. (C) Isovolumetric relaxation time zeta-score $=$ $2 . \overline{6} 43+0.218 \times \mathrm{Hb}$ zeta, $r=0.45, p=0.01$. (D) Isovolumetric contraction time zeta-score $(r=0.35, p=0.054)$ 


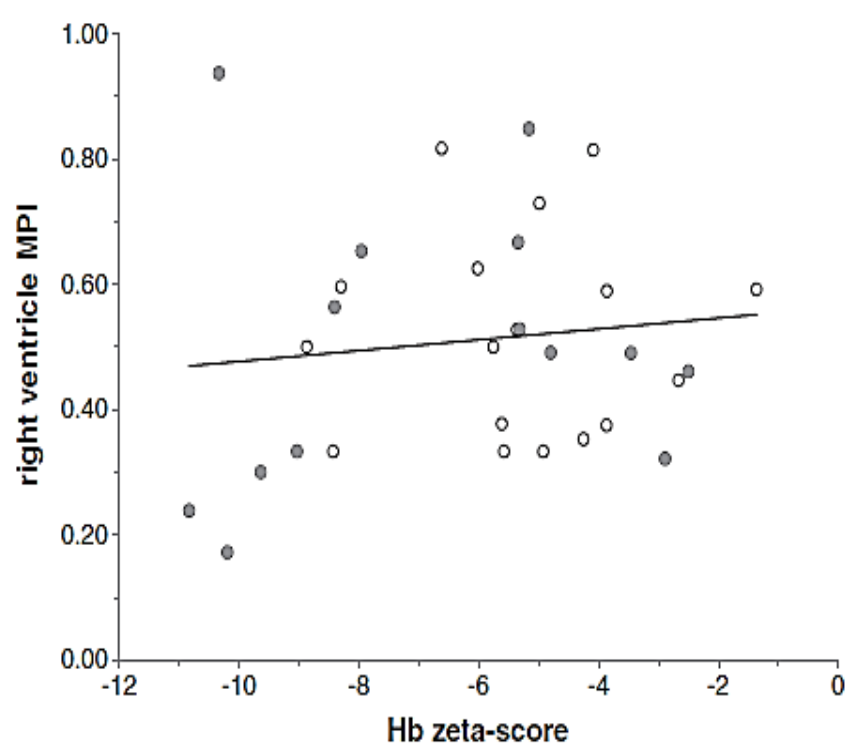

Figure 3 - Correlation between right ventricle myocardial performance index and fetal hemoglobin zeta score $(r=0.12, p=0.53)$. Hb: fetal hemoglobin, MPI: myocardial performance index. Filled circles: first cordocentesis $(n=14)$; open circles: subsequent procedures $(n=17)$

\section{DISCUSSION}

The present study shows that left ventricle myocardial performance index reduces as fetal anemia worsens whereas no significant changes are observed in the right ventricle. These findings indicate that fetal cardiac performance not only remains preserved but is actually enhanced in cases of moderate/severe fetal anemia. Sikkel et al. also examined myocardial contractility in alloimune disease and showed a slight increase in shortening fraction compared to controls, though non significant ${ }^{20}$. To the best of our knowledge this is the first study that examines changes in fetal MPI during anemia.

Due to the close proximity between the aortic and mitral valves, and peculiar left ventricle spatial anatomy, inflow and outflow across these valves can be simultaneously registered in a single Doppler waveform. Thus, each component of left ventricle MPI (ejection, isovolumetric contraction and 
relaxation times) was individually determined by the technique employed in the present study.

Analysis of these components showed that reduction in left ventricle MPI with progressive fetal anemia is a consequence of both increase in the ejection time and simultaneous reduction in the isovolumetric relaxation component. These changes likely reflect adaptative mechanisms observed in fetal anemia.

Animal studies have shown that vasodilatation and reduction of mean arterial blood pressure occur during anemia ${ }^{21}$. Therefore, prolongation of ejection time is possibly related to earlier opening of the aortic valve due to reduced fetal peripheral vascular resistance and lower pressure gradient.

On the other hand, increased pressure in the left atria due to the hyperdinamic circulation and increased venous return may cause earlier opening of the mitral valve during diastole and reduction in isovolumetric relaxation time ${ }^{1,2}$. Hecher et al demonstrated that E/A ratio values in the atrio ventricular valves were normal suggesting normal ventricular filling despite severe fetal anemia ${ }^{3}$.

Interestingly, the correlation between LV MPI and fetal hemoglobin deficit was not significant in the subgroup of fetuses that had undergone a previous transfusion. Possibly this could be related to changes in fetal hemodynamic and blood viscosity due to the presence of adult transfused erythrocytes in the fetal circulation.

Despite right ventricle predominance during fetal life, no significant changes were observed in right ventricle MPI according to fetal anemia. Although MPI assessment is independent of fetal heart rate ${ }^{7,15}$, right ventricle MPI evaluation was based on the measurement of 2 time periods, in different locations, and at different moments. Therefore small differences in the heart rate could have introduced a bias on the final result and partially explain a wider deviation in right ventricle MPI values. In order to clarify if lack of a significant association between right ventricle MPI and the degree of fetal anemia is due to greater measurement variability or reflects a true 
absence of association, additional studies investigating simple and reproducible methods such as STIC TAPSE (tricuspid annular plane systolic excursion) are necessary ${ }^{22}$.

MPI is considered a reliable marker of cardiac dysfunction and changes have been demonstrated in early stages of fetal growth restriction when end diastolic flow is still present ${ }^{23}$. Likewise, $40 \%$ of recipient fetuses in Quintero stage I twin-twin transfusion syndrome show increased MPI values ${ }^{24}$. Moreover, a previous animal study showed increased MPI in acute fetal hypoxia induced by intermittent cord occlusion; changes were more pronounced in the left ventricle compared to the right one ${ }^{25}$.

Although cardiac function changes including increased output and a hyperdinamic circulation play a key role in fetal adaptation to anemia, Tongsong et al. showed that cardiac decompensation is not the underlying mechanism in Bart's disease fetal hydrops ${ }^{6}$. Further evidence is provided by a long term follow up study that enrolled children that had undergone intrauterine transfusions due to red cell isoimmunization. Childhood echocardiographic evaluation did not show differences in resting ventricular function compared to controls ${ }^{26}$. As a matter of fact, if severe anemia was associated with myocardial decompensation, one would expect that correlation between MPI and Hb zeta-score values to be a "U"-shaped curve.

Besides myocardial performance index, additional techniques such as ejection fraction, tissue Doppler and 2D speckle tracking can be used to assess myocardial contractility by ultrasound ${ }^{27}$. However, our results show that fetal myocardial performance remains normal despite severe anemia and this parameter is unlikely to be useful in the management of such pregnancy complication. 


\section{ACKNOWLEDGMENTS:}

The authors thank Dr Lilian Maria Lopes, fetal cardiology specialist, for the technical advices. And Dr Luciana Venturini Rossoni for the valuable input with cardiovascular physiology knowledge.

\section{REFERENCES}

1. Bilardo $\mathrm{CM}$, Nicolaides $\mathrm{KH}$, Campbell S. Doppler studies in red cell isoimmunization. Clin Obstet Gynecol 1989;32:719-27.

2. Nicolaides $\mathrm{KH}$. Studies on fetal physiology and pathophysiology in rhesus disease. Semin Perinatol 1989;13:328-37.

3. Hecher K, Snijders R, Campbell S, Nicolaides K. Fetal venous, arterial, and intracardiac blood flows in red blood cell isoimmunization. Obstet Gynecol 1995;85:122-8.

4. Mari G, Deter RL, Carpenter RL, et al. Noninvasive diagnosis by Doppler ultrasonography of fetal anemia due to maternal red-cell alloimmunization. Collaborative Group for Doppler Assessment of the Blood Velocity in Anemic Fetuses. N Engl J Med 2000;342:9-14.

5. Moise KJ, Mari G, Fisher DJ, Huhta JC, Cano LE, Carpenter RJ. Acute fetal hemodynamic alterations after intrauterine transfusion for treatment of severe red blood cell alloimmunization. Am J Obstet Gynecol 1990;163:77684.

6. Tongsong T, Tongprasert F, Srisupundit K, Luewan S. Venous Doppler studies in low-output and high-output hydrops fetalis. Am J Obstet Gynecol 2010;203:488.e1-6. 
7. Tei C, Ling LH, Hodge DO, et al. New index of combined systolic and diastolic myocardial performance: a simple and reproducible measure of cardiac function--a study in normals and dilated cardiomyopathy. J Cardiol 1995;26:357-66.

8. Tsutsumi T, Ishii M, Eto G, Hota M, Kato H. Serial evaluation for myocardial performance in fetuses and neonates using a new Doppler index. Pediatr Int 1999;41:722-7.

9. Eidem BW, Edwards JM, Cetta F. Quantitative assessment of fetal ventricular function: establishing normal values of the myocardial performance index in the fetus. Echocardiography 2001;18:9-13.

10. Friedman D, Buyon J, Kim M, Glickstein JS. Fetal cardiac function assessed by Doppler myocardial performance index (Tei Index). Ultrasound Obstet Gynecol 2003;21:33-6.

11. Ichizuka K, Matsuoka R, Hasegawa J, et al. The Tei index for evaluation of fetal myocardial performance in sick fetuses. Early Hum Dev 2005;81:273-9.

12. Szwast A, Tian Z, McCann M, et al. Impact of altered loading conditions on ventricular performance in fetuses with congenital cystic adenomatoid malformation and twin-twin transfusion syndrome. Ultrasound Obstet Gynecol 2007;30:40-6.

13. Crispi F, Hernandez-Andrade E, Pelsers MM, et al. Cardiac dysfunction and cell damage across clinical stages of severity in growthrestricted fetuses. Am J Obstet Gynecol 2008;199:254.e1-8.

14. Letti Müller AL, Barrios PEM, Kliemann LM, Valério EG, Gasnier R, Magalhães JA. Tei index to assess fetal cardiac performance in fetuses at 
risk for fetal inflammatory response syndrome. Ultrasound Obstet Gynecol 2010;36:26-31.

15. Van Mieghem $T$, Gucciardo L, Lewi $P$, et al. Validation of the fetal myocardial performance index in the second and third trimesters of gestation. Ultrasound Obstet Gynecol 2009;33:58-63.

16. Nishie EN, Brizot ML, Liao AW, Carvalho MH, Toma O, Zugaib M. A comparison between middle cerebral artery peak systolic velocity and amniotic fluid optical density at $450 \mathrm{~nm}$ in the prediction of fetal anemia. Am J Obstet Gynecol 2003;188:214-9.

17. Hernandez-Andrade E, López-Tenorio J, Figueroa-Diesel H, et al. A modified myocardial performance (Tei) index based on the use of valve clicks improves reproducibility of fetal left cardiac function assessment. Ultrasound Obstet Gynecol 2005;26:227-32.

18. Cruz-Martínez R, Figueras F, Bennasar M, et al. Normal reference ranges from 11 to 41 weeks' gestation of fetal left modified myocardial performance index by conventional Doppler with the use of stringent criteria for delimitation of the time periods. Fetal Diagn Ther 2012;32:79-86.

19. Nicolaides $\mathrm{KH}$, Soothill PW, Clewell WH, Rodeck CH, Mibashan RS, Campbell S. Fetal haemoglobin measurement in the assessment of red cell isoimmunisation. Lancet 1988;1:1073-5.

20. Sikkel E, Klumper FJ, Oepkes D, et al. Fetal cardiac contractility before and after intrauterine transfusion. Ultrasound Obstet Gynecol 2005;26:611-7.

21. Jonker SS, Giraud MK, Giraud GD, et al. Cardiomyocyte enlargement, proliferation and maturation during chronic fetal anaemia in sheep. Exp Physiol 2010;95:131-9. 
22. Messing B, Gilboa Y, Lipschuetz M, Valsky DV, Cohen SM, Yagel S. Fetal tricuspid annular plane systolic excursion (f-TAPSE): evaluation of fetal right heart systolic function with conventional M-mode ultrasound and spatiotemporal image correlation (STIC) M-mode. Ultrasound Obstet Gynecol 2013;42:182-8.

23. Cruz-Martinez R, Figueras F, Benavides-Serralde A, Crispi F, Hernandez-Andrade E, Gratacos E. Sequence of changes in myocardial performance index in relation to aortic isthmus and ductus venosus Doppler in fetuses with early-onset intrauterine growth restriction. Ultrasound Obstet Gynecol 2011;38:179-84.

24. Stirnemann JJ, Mougeot M, Proulx F, et al. Profiling fetal cardiac function in twin-twin transfusion syndrome. Ultrasound Obstet Gynecol 2010;35:19-27.

25. Guorong L, Shaozheng $\mathrm{H}$, Zhenghua W, et al. Tei index for prenatal diagnosis of acute fetal hypoxia due to intermittent umbilical cord occlusion in an animal model. Prenat Diagn 2007;27:817-23.

26. Dickinson JE, Sharpe J, Warner TM, Nathan EA, D'Orsogna L. Childhood cardiac function after severe maternal red cell isoimmunization. Obstet Gynecol 2010;116:851-7.

27. Crispi F, Gratacós E. Fetal cardiac function: technical considerations and potential research and clinical applications. Fetal Diagn Ther 2012;32:47-64. 
Taylor \& Francis Taylor \& Francis Group

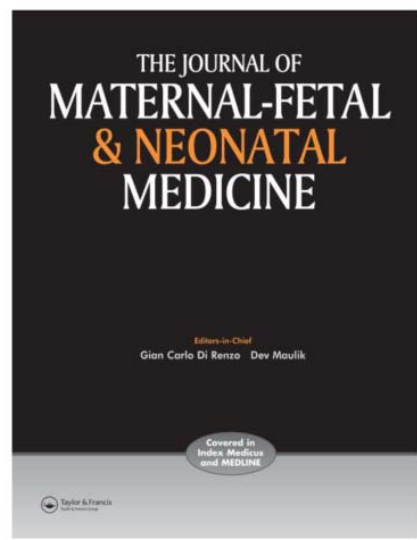

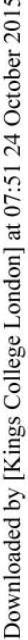
placental volume percentage expansion. Adjustments were made for repeat measurements within the same fetus, and across different time points. Significance level was set as 0.05 .

Results: MPI z-score values increased significantly following transfusion (delta MPI $=1.10 \pm 2.47, p=0.036$ ). Delta MPI showed a significant correlation with gestational age at transfusion $(r=-0.47, p=0.018)$, pre transfusion MPI $z$-score $(r=-0.50, p=0.012)$ and feto-placental volume percentage expansion $(r=-0.41$, $\mathrm{p}=0.044$ ).

Conclusion: Left ventricle myocardial performance index increases significantly after intrauterine blood transfusion and greater changes are associated with procedures at earlier gestational age, lower pre transfusion MPI z-scores and smaller feto-placental volume expansion.

C) 2015 Taylor \& Francis. This provisional PDF corresponds to the article as it appeared upon acceptance. Fully formatted PDF and full text (HTML) versions will be made available soon. OISCLAIMER: The ideas and opinions expressed in the journal's Just Accepted articles do not necessarily reflect those of Taylor \& Francis (the Publisher), the Editors or the journal. The Publisher does not assume any responsibility for any injury and/or damage to persons or property arising from or related to any use of the material contained in these articles. The reader is advised to check the appropriate medical tarerature and the product information currenty provided by the manulacturer of each drug to be professional, relying on his or her independent experience and knowledge of the patient, to determine drug dosages and the best treatment for the patient. Just Accepted articles have undergone full scientific review but none of the additional editorial preparation, such as copyediting, typesetting, and proofreading, as have articles published Int Acasted articles is subject to the therefore, be errors in Just Accepted articles that will be corrected in the final print and inal online version of the 

PAPER 2: CHANGES IN FETAL MYOCARDIAL PERFORMANCE INDEX FOLLOWING INTRAVASCULAR TRANSFUSION: PRELIMINARY REPORT

Assunção RA, Liao AW, Brizot ML, Francisco RP, Zugaib M.

J Matern Fetal Neonatal Med. 2015 Sep 30:1-17

DOI: $10.3109 / 14767058.2015 .1101757$

PMID: 26421506

\section{ABSTRACT}

Objective: To investigate changes in fetal left ventricle myocardial performance index (MPI) following intrauterine intravascular transfusion (IUT).

Methods: Prospective study including 25 IUT performed in 13 singleton pregnancies with maternal Rh D alloimune disease. Left ventricle MPI was evaluated prior to transfusion and repeated $24 \mathrm{~h}$ after each procedure. Delta MPI was calculated as the difference between post and pre transfusion MPI z-scores. Multilevel regression analysis was used to examine the association between delta MPI and gestational age at procedure, fetal middle cerebral artery peak velocity MoM, pre and post MPI and hemoglobin z-score values, volume of blood transfused and feto-placental volume percentage expansion. Adjustments were made for repeat measurements within the same fetus, and across different time points. Significance level was set as 0.05 .

Results: MPI z-score values increased significantly following transfusion (delta MPI $=1.10 \pm 2.47, p=0.036$ ). Delta MPI showed a significant correlation with gestational age at transfusion $(r=-0.47, p=0.018)$, pre transfusion MPI zscore $(r=-0.50, p=0.012)$ and feto-placental volume percentage expansion $(r=-0.41, p=0.044)$.

Conclusion: Left ventricle myocardial performance index increases significantly after intrauterine blood transfusion and greater changes are 
associated with procedures at earlier gestational age, lower pre transfusion MPI z-scores and smaller feto-placental volume expansion.

Keywords: Myocardial performance index; Alloimmunization, Pulsed-wave Doppler; Fetal cardiac function; Intrauterine transfusion; Tei index

\section{INTRODUCTION}

The incidence of maternal alloimmune disease has decreased dramatically over the last decades with the introduction of anti-D immunoglobulin prophylaxis during late pregnancy and after birth 1 . Nevertheless, it remains a prevalent condition in underdeveloped countries where it is still associated with increased perinatal morbidity and mortality ${ }^{2}$.

Placental transfer of maternal anti-erythrocyte antibodies into the fetal circulation induces hemolysis and anemia. As a result, several adaptive mechanisms take place in order to maintain an adequate fetal tissue oxygenation. Circulatory changes, such as increased cardiac output and a hyperdinamic circulation, play a key role under these circumstances. However, if hemolysis is not compensated by increased erythropoiesis, fetal hydrops eventually develops and intrauterine death may occur ${ }^{3}$.

In severe cases, intrauterine transfusion is an effective treatment and perinatal survival rates range from 81 to $94 \%{ }^{4}$. Nevertheless, non-procedure related fetal losses are still observed in $1,6 \%$ of the cases despite adequate treatment, especially at an early gestational age ${ }^{5}$.

A possible explanation for these unexpected fetal losses includes failure of fetal adaptation following transfusion to volume overload. As a matter of fact, Papanna et al. have hypothesized that increase in fetal myocardial performance index (MPI) observed in twin-twin transfusion recipients following laser therapy may be associated with increased risk of intrauterine death ${ }^{6}$. 
Our previous study showed a significant reduction in fetal left ventricle MPI as anemia progresses ${ }^{7}$. This suggests that myocardial performance not only remains preserved but is actually enhanced in fetal anemia. The aim of the present study is to examine changes that occur in fetal myocardial performance index following intrauterine transfusion.

\section{METHODS}

This prospective study was carried out at a tertiary referral center for fetal medicine (Hospital das Clínicas, São Paulo University Medical School, Brazil). Women with singleton pregnancies and Rh D alloimmune disease were invited to take part in the study. Institutional ethics committee approved the study (CAPPesq 80460) and all women who participated gave informed consent. The cases reported in this study have also been included in a previous publication ${ }^{7}$.

Gestational age was calculated according to the first date of the last menstrual period (LMP) whenever it was confirmed by the earliest ultrasound. When LMP was unreliable, or there was discrepancy between LMP and ultrasound dates, dating was based on ultrasound findings. Fetal structural abnormalities were investigated in all cases with a detailed anomaly scan and specialist fetal echocardiography examination.

At each visit, fetal middle cerebral artery (MCA) was examined according to the previously described technique ${ }^{8}$. Peak systolic velocity measurements were recorded and multiples of the median (MoM) values were calculated according to gestational age ${ }^{9}$. Pregnancies with increased fetal MCA peak velocity (>1.5 MoM) underwent intrauterine intravascular transfusion due to suspected fetal anemia. All examinations were performed trans abdominally with a curved $3.5-5.0 \mathrm{MHz}$ probe and Voluson 730 Expert/E8 equipment (General Electric Medical Systems, Austria). Data was prospectively entered into an electronic spreadsheet (Excel, Microsoft Corporation, USA). 
Prior to each transfusion, fetal MCA and left ventricle myocardial performance index (MPI) were evaluated in the absence of fetal corporal and respiratory movements with Doppler sample gate set between 2-4mm, wall motion filter $>190 \mathrm{~Hz}$ and high sweep-speed to allow simultaneous identification of 3-4 cardiac cycles on the screen. Doppler beam was manually adjusted to keep insonation angle below $20^{\circ}$. All MPI Doppler evaluations were performed by a single experienced operator (De Assunção RA) and assessment was repeated 24 hours after each procedure.

Left ventricle MPI evaluation technique has been described in a previous publication ${ }^{7}$. Briefly, in an apical five-chamber view of the heart, Doppler sample volume was placed on the lateral wall of the ascending aorta, below the aortic valve and just above the mitral valve. Pulsed Doppler trace included both the E/A and the aortic blood flow waveforms and care was also taken to clearly identify valve click echoes. Isovolumetric contraction time (ICT) was estimated from the closure of the mitral valve, to the opening of the aortic valve. Ejection time (ET) was determined from the opening to the closure of the aortic valve. Isovolumetric relaxation time (IRT) was defined from the closure of the aortic valve to the opening of the mitral valve. Time calipers were placed just before the echo of the each valve click 10. MPI was calculated as (ICT + IRT)/ET and converted into z-score according to reference values published by Cruz-Martínez et al (MPI zscore= observed MPI - expected mean MPI for gestation / standard deviation) ${ }^{11}$.

At each transfusion, fetal hemoglobin levels were measured in blood samples collected prior to transfusion and at the end of each procedure. Hemoglobin z-score ( $\mathrm{Hb}$ z-score) values were calculated as: measured hemoglobin - mean hemoglobin for gestation / standard deviation ${ }^{12}$. Pancuronium (0.1 $\mathrm{mg}$ per $\mathrm{kg}$ of ultrasound estimated fetal weight) was administered for fetal paralysis whenever transfusion was performed in a free loop of umbilical cord or the placenta was posterior. 
All transfusions were performed with fresh type $\mathrm{O}$ Rh $\mathrm{D}$ negative adult packed red blood cells, previously irradiated with 25 Gy of gamma radiation, washed, and filtered. According to fetal $\mathrm{Hb}$ levels at the beginning of each transfusion, the amount of blood to be administered was calculated in order to reach post transfusion levels equivalent to the $95^{\text {th }}$ centile for the corresponding gestational age, or a total feto-placental volume expansion (FPV) of $50 \%$. Expected FPV was calculated according to the formula: $10^{\wedge}\left(-0,28725+0,11263 * \mathrm{GA}-0,0011 * \mathrm{GA}^{\wedge} 2\right)$, where GA is gestational age in weeks ${ }^{13}$. Feto-placental expansion was calculated as the ratio between the amount of blood transfused and expected FPV.

After each transfusion, follow-up appointments were scheduled every 7 to 14 days and the decision to perform a subsequent transfusion was based on MCA PSV values or an expected decline rate in fetal hemoglobin of $0.3 \mathrm{~g} / \mathrm{dl}$ per day ${ }^{14}$.

Delta MPI was calculated as the difference between post and pre transfusion MPI z-scores. Regression analysis was used to investigate the association between delta MPI and gestational age, fetal MCA MoM and left ventricle MPI, hemoglobin z-score values, volume of blood transfused and feto-placental expansion. Repeat measurements were adjusted with multilevel modelling where the first level was set for gestational age and the second level was related to measurements obtained for the same fetus. Statistical analysis was performed with Minitab 16 (Minitab, USA) and MLwiN version 2.27 (Centre for Multilevel Modelling, University of Bristol, United Kingdom). Significance level was set at 0.05 .

\section{RESULTS}

During the study period, pre and post intrauterine transfusion MPI values were recorded in 13 singleton pregnancies with maternal $R h \quad D$ alloimmune disease. Table 1 summarizes maternal characteristics and perinatal outcome information. 
Overall 25 cordocentesis were performed: 8 (61.5\%) women had a single procedure, $1(7.7 \%)$ had $2,1(7.7 \%)$ had 3 , and another $3(23.1 \%)$ underwent four transfusions during the entire pregnancy. Three (23.1\%) fetuses were hydropic at the first procedure. Ultrasound findings and transfusion details are summarized in table 2.

Table 1 - Maternal characteristics and perinatal outcome in 13 singleton pregnancies with maternal $\mathrm{Rh} \mathrm{D}$ alloimmune disease

\begin{tabular}{lc}
\hline & $\begin{array}{c}\text { mean } \pm \text { standard deviation / } \\
\mathrm{n}(\%)\end{array}$ \\
\hline maternal age, years & $33.2 \pm 4.5$ \\
past history of alloimmune disease & \\
none & $3(23.1)$ \\
phototherapy & $2(15.4)$ \\
intrauterine/exchange transfusion & $2(15.4)$ \\
stillbirth / neonatal death & $6(46.1)$ \\
gestational age at delivery, weeks & $34.2 \pm 2.6$ \\
still birth & $1(7.7)$ \\
live birth & $12(92.3)$ \\
birth weight, grams & $2339 \pm 651$ \\
$<$ 1500g & $1(7.7)$ \\
< 2500g & $6(46.2)$ \\
Need of exchange transfusion & $12(92.3)$ \\
Number of exchange transfusions & $1.4 \pm 0.9$ \\
postnatal complications & \\
cholestasis & $1(7.7)$ \\
kernicterus & $1(7.7)$ \\
pulmonary hypertension & $1(7.7)$ \\
respiratory distress syndrome & $1(7.7)$ \\
pulmonary broncho dysplasia & $1(7.7)$ \\
sepsis & $2(15.4)$ \\
hospital stay, days & $24.9 \pm 23.9$ \\
\hline
\end{tabular}


Table 2 - Ultrasound findings and intrauterine transfusion details in 13 singleton pregnancies treated for fetal anemia. Values expressed as mean \pm standard deviation. MoM: multiples of the median for gestational age, MPI: myocardial performance index, SD: standard deviation

\begin{tabular}{|c|c|c|c|}
\hline & \multicolumn{2}{|c|}{$\begin{array}{l}\text { Intrauterine transfusion } \\
\qquad(\mathrm{n}=25)\end{array}$} & $p$ \\
\hline gestational age at procedure, weeks & \multicolumn{2}{|c|}{$27.8 \pm 4.3$} & \\
\hline volume of blood transfused, $\mathrm{ml}$ & \multicolumn{2}{|c|}{$45 \pm 22$} & \\
\hline $\begin{array}{l}\text { feto-placental blood volume expansion, \% } \\
\qquad \begin{array}{l}> \\
>\end{array}, \mathrm{n}(\%) \\
\quad 50 \%, \mathrm{n}(\%)\end{array}$ & $\begin{array}{r}34.9 \\
9 \\
3\end{array}$ & $\begin{array}{l}\text { 11.7 } \\
\text { 3) } \\
\text { 2) }\end{array}$ & \\
\hline & before & after & \\
\hline left ventricle MPI & $0.54 \pm 0.13$ & $0.66 \pm 0.23$ & 0.038 \\
\hline $\begin{array}{l}\text { middle cerebral artery peak velocity } \\
\qquad \mathrm{cm} / \mathrm{s} \\
\mathrm{MoM}\end{array}$ & $\begin{array}{l}66.3 \pm 15.5 \\
1.78 \pm 0.24\end{array}$ & $\begin{array}{l}45.2 \pm 19.1 \\
1.25 \pm 0.29\end{array}$ & $\begin{array}{l}<0.001 \\
<0.001\end{array}$ \\
\hline $\begin{array}{l}\text { fetal hemoglobin } \\
\qquad \begin{array}{l}\text { g/dl } \\
\text { z-score, SD }\end{array}\end{array}$ & $\begin{array}{r}6.4 \pm 2.5 \\
-6.5 \pm 2.5\end{array}$ & $\begin{array}{l}13.2 \pm 3.2 \\
0.80 \pm 3.5\end{array}$ & $\begin{array}{l}<0.001 \\
<0.001\end{array}$ \\
\hline
\end{tabular}

MPI z-score values increased significantly following transfusion (delta $\mathrm{MPI}=1.10 \pm 2.47, \mathrm{p}=0.036)$. No differences were observed comparing delta MPI values at first transfusion $(n=13)$ and subsequent procedures $(n=12$, median difference $=0.83, p=0.31$ ). Post transfusion MPI $z$-score values did not show a significant correlation with the respective pre transfusion MPI Zscores $(r=0.11, p=0.60)$.

Regression analysis adjusted for repeat measurements within the same fetus showed a significant correlation between delta MPI and gestational age at transfusion $(r=-0.47, p=0.018)$. Multilevel regression, adjusted for both repeat measurements within the same fetus, and across different time points, showed significant association beween delta MPI and pre transfusion MPI z-score $(r=-0.50, p=0.012)$ and FPV $(r=-0.41, p=0.044$; table 3, figure 1). 
Table 3 - Multilevel regression analysis for the prediction of changes in fetal left ventricle myocardial performance index zscore before and after intrauterine transfusion. MPI: myocardial performance index

\begin{tabular}{|c|c|c|c|c|c|c|}
\hline \multirow[b]{2}{*}{ Predictor } & \multicolumn{2}{|c|}{ fixed component } & \multicolumn{2}{|c|}{ random component variance } & \multirow[b]{2}{*}{ r } & \multirow[b]{2}{*}{$\mathrm{p}$} \\
\hline & intercept & constant & fetus-level & $\begin{array}{l}\text { gestational } \\
\text { age-level }\end{array}$ & & \\
\hline Gestational age at transfusion & $8.551(2.833)$ & $-0.268(0.101)$ & 4.578 & - & -0.47 & 0.018 \\
\hline Pre transfusion MPI z-score & $2.249(0.750)$ & $-0.796(0.247)$ & 3.805 & 1.495 & -0.50 & 0.012 \\
\hline $\begin{array}{l}\text { Feto-placental volume percentage } \\
\text { expansion }\end{array}$ & $2.963(1.567)$ & $-0.059(0.041)$ & 3.157 & 2.534 & -0.41 & 0.044 \\
\hline
\end{tabular}


$1 \mathrm{~A}$.

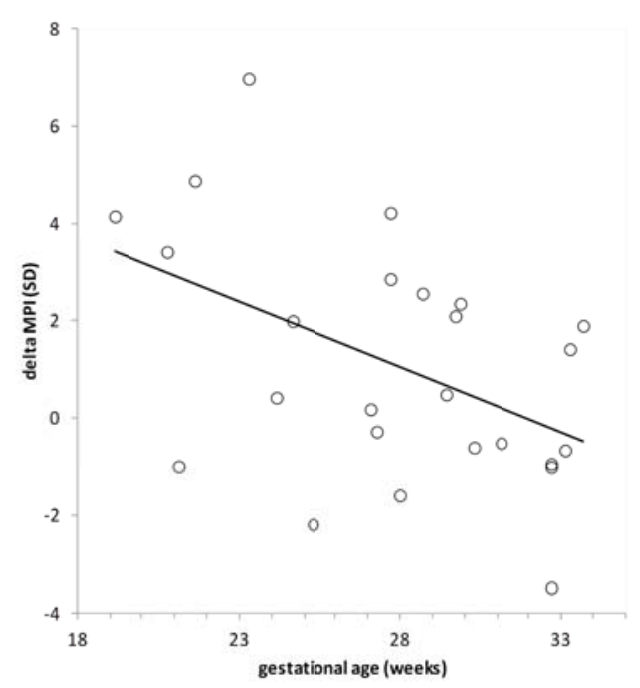

$1 \mathrm{C}$.

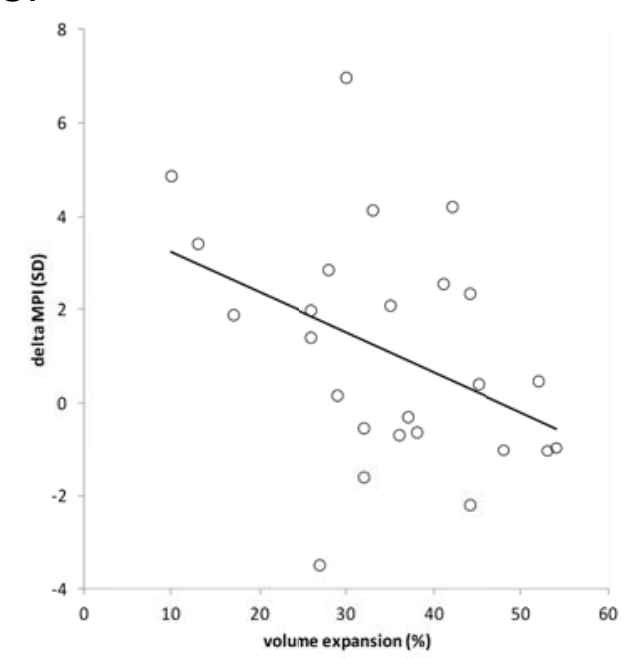

$1 \mathrm{~B}$.

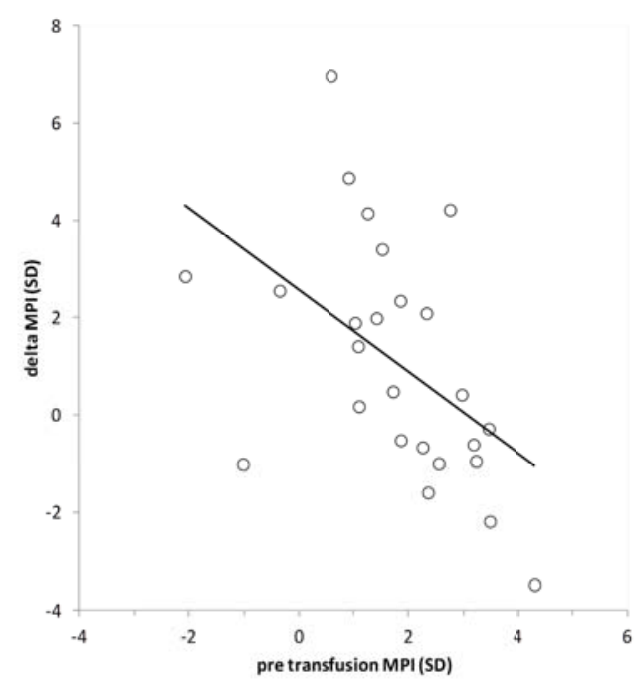

Figure 1 - Correlation between fetal left ventricle myocardial performance index (MPI) z-score difference before and after intrauterine transfusion with: $1 \mathrm{~A}$. gestational age at transfusion $(r=-0.47$, $p=0.018) ; 1 B$. pre transfusion MPI z-score $(r=-0.50, p=0.012) ; 1 \mathrm{C}$. feto-placental volume percentage expansion $(r=-0.41, p=0.044)$. Delta: difference observed before and after transfusion; MPI: left ventricle myocardial performance index z-score; SD: standard deviation.

Delta MPI did not correlate with pre transfusion fetal middle cerebral artery peak systolic velocity MoM values $(r=-0.12, p=0.56)$, pre $(r=-0.36$, 
$\mathrm{p}=0.08)$ and post $(\mathrm{r}=0.02, \mathrm{p}=0.92)$ transfusion hemoglobin $\mathrm{z}$-scores and transfused blood volume $(r=-0.38, p=0.06)$.

\section{DISCUSSION}

Myocardial performance index (MPI) is a novel non invasive tool used to evaluate cardiac function, and high MPI values are associated with ventricle dysfunction. To the best of our knowledge this is the first study that demonstrates increase in left ventricle myocardial performance index after intravascular blood transfusion in anemic fetuses.

Since post transfusion MPI z-score is the sum of pre transfusion MPI and delta MPI, lack of a significant correlation between pre and post procedure MPI z-scores indicates that additional factors may account for the degree of change that occurs in fetal myocardial contractility following transfusion.

As a matter of fact, our study shows that greater MPI changes occur in procedures at earlier gestational age, when pre transfusion MPI z-scores are lower and FPV smaller. Although repeat measures were recorded in 5 cases, variance in measurements obtained from the same fetus at different occasions is accounted for with multilevel modeling statistical analysis.

Lindenburg et al have shown that fetal losses occur more frequently in alloimmune disease before 20 weeks, despite adequate treatment. This increased perinatal mortality is possibly related to the greater severity of the disease and technical challenges for intra uterine transfusion imposed by early gestational age. Nevertheless, non procedure related losses are still observed in about $2 \%$ of the cases and could be related to a natural limitation for small fetuses to adapt to volume overload imposed by the transfusion ${ }^{5}$.

After IUT, there is reversal of the fetal hyperdynamic circulation, as demonstrated by the significant decrease in the middle cerebral artery peak velocity ${ }^{15}$. These findings are likely to be the result of a decrease in cardiac output due to the increase in blood hemoglobin concentration and viscosity, 
and decrease in venous return. Such decrease in venous return (preload) may account for the reduction in ejection time, and increase in relaxation time.

However, despite remarkable capacity of the human fetus to tolerate and adapt to blood volume expansions, if such changes are too rapid and severe, cardiac dysfunction may become apparent, especially in extremely premature fetuses with acidosis. In fact, Bilardo et al have previously proposed that these cases might benefit from combined intravascular and intraperitoneal transfusions in order to avoid intravascular volume overload 16

Although delta MPI did not correlate with fetal hemoglobin levels prior to transfusion, our previous publication showed a significant association between fetal left ventricle MPI z-score and the degree of fetal anemia ${ }^{7}$. It is possible that with greater sample size a direct association between changes in MPI and severity of fetal anemia may also be demonstrated.

In the present study, mean FPV was 35\%, and expansion was greater than $40 \%$ in one third of the cases. Naturally, one would expect greater changes in fetal MPI to be associated with greater feto-placental volume expansions. Nevertheless an inverse correlation was observed and may actually reflect the more severe cases of fetal anemia in which profound changes in the fetal physiology may compromise and eventually hamper fetal cardiac and circulatory adaptation despite smaller volume overload. In fact, a single fetal death was observed (following an uncomplicated first transfusion performed at 23 weeks, non hydropic fetus, initial $\mathrm{Hb}$ level of $3.3 \mathrm{~g} / \mathrm{dl}$ and $30 \%$ FPV) and delta MPI was coincidently the greatest observed in the study $(+6.8 S D)$.

One of the limitations of this study is the inclusion of 3 hydropic fetuses. Although changes in MPI may be particularly different under this circumstance, these cases are associated with worse prognosis and investigations of potential parameters that can help predict perinatal outcome are particularly important. 
Significant changes in fetal MPI have been previously demonstrated in several situations such as the recipient fetus of twin-twin transfusion syndrome ${ }^{6,17,18}$, growth restricted fetuses ${ }^{19,20}$, non immune hydrops ${ }^{21}$ and in maternal diabetes ${ }^{21,22}$. Certainly, the hypothesis that the degree of MPI change following IUT could be a useful predictor of adverse outcome and non procedure related fetal losses in pregnancies with alloimune disease remains to be investigated in further studies involving greater number of cases with severe fetal disease. If this proves to be true, as we have previously shown that fetal cardiac troponin $\mathrm{T}$ also correlates inversely with the degree of anemia in pregnancies complicated by $\mathrm{Rh} D$ alloimmunization, possibly reflecting myocardial injury and poor prognosis ${ }^{23}$, the combination of both biochemical and sonographic parameters may help identify fetuses at greatest risk of decompensation. Fetal right ventricle MPI data has not been presented in the present study because of the lack of correlation with fetal anemia that was demonstrated in our previous study ${ }^{7}$.

Although technically more challenging, MPI evaluation while the transfusion procedure is performed may be a new parameter to assess fetal adaptation towards volume overload and help determine the optimal volume of blood to be transfused within each procedure. Induction of fetal paralysis with pancuronium during IUT can be associated with cardiovascular effects such as tachycardia and hypertension ${ }^{24}$ and possible effects on fetal MPI would also have to be evaluated. As a matter of fact, Papanna et al have demonstrated that it is possible to evaluate fetal MPI during fetoscopy for twin-twin transfusion syndrome and it has been hypothesized that greater changes in recipient fetuses MPI during laser treatment may be associated with subsequent fetal death ${ }^{6}$.

Since delta MPI did not differ between first transfusions and subsequent procedures, longitudinal assessment of fetal MPI changes throughout subsequent procedures, may also be an additional parameter in the management of this disease. 
Although maternal alloimune disease is becoming an increasingly rare condition in developed countries, treatment of fetal anemia is still often necessary in developing countries and due to other causes such as congenital infection. We believe that there are additional aspects of fetal MPI evaluation that still need to be investigated and this non invasive tool may prove to be a promising parameter in the management of fetal anemia.

\section{REFERENCES}

1 Moise KJ, Argoti PS: Management and prevention of red cell alloimmunization in pregnancy: A systematic review. Obstet Gynecol 2012; 120:1132-1139.

2 Zipursky A, Paul VK: The global burden of rh disease. Arch Dis Child Fetal Neonatal Ed 2011;96:F84-85.

3 Nicolaides $\mathrm{KH}$ : Studies on fetal physiology and pathophysiology in rhesus disease. Semin Perinatol 1989;13:328-337.

$4 \quad$ Lindenburg IT, van Kamp IL, Oepkes D: Intrauterine blood transfusion: Current indications and associated risks. Fetal Diagn Ther 2014.

5 Lindenburg IT, van Kamp IL, van Zwet EW, Middeldorp JM, Klumper FJ, Oepkes D: Increased perinatal loss after intrauterine transfusion for alloimmune anaemia before 20 weeks of gestation. BJOG 2013;120:847-852.

6 Papanna R, Mann LK, Molina S, Johnson A, Moise KJ: Changes in the recipient fetal tei index in the peri-operative period after laser photocoagulation of placental anastomoses for twin-twin transfusion syndrome. Prenat Diagn 2011;31:176-180. 
7 de Assunção RA, Liao AW, de Lourdes Brizot M, Francisco RP, Zugaib M: Myocardial performance index in fetal anemia. Prenat Diagn 2015;35:192-196.

8 Nishie EN, Brizot ML, Liao AW, Carvalho MH, Toma O, Zugaib M: A comparison between middle cerebral artery peak systolic velocity and amniotic fluid optical density at $450 \mathrm{~nm}$ in the prediction of fetal anemia. Am J Obstet Gynecol 2003;188:214-219.

9 Mari G, Deter RL, Carpenter RL, Rahman F, Zimmerman R, Moise KJ, Dorman KF, Ludomirsky A, Gonzalez R, Gomez R, Oz U, Detti L, Copel JA, Bahado-Singh R, Berry S, Martinez-Poyer J, Blackwell SC: Noninvasive diagnosis by doppler ultrasonography of fetal anemia due to maternal red-cell alloimmunization. Collaborative group for doppler assessment of the blood velocity in anemic fetuses. N Engl J Med 2000;342:9-14.

10 Hernandez-Andrade E, López-Tenorio J, Figueroa-Diesel H, SaninBlair J, Carreras E, Cabero L, Gratacos E: A modified myocardial performance (tei) index based on the use of valve clicks improves reproducibility of fetal left cardiac function assessment. Ultrasound Obstet Gynecol 2005;26:227-232.

11 Cruz-Martínez R, Figueras F, Bennasar M, García-Posadas R, Crispi F, Hernández-Andrade E, Gratacós E: Normal reference ranges from 11 to 41 weeks' gestation of fetal left modified myocardial performance index by conventional doppler with the use of stringent criteria for delimitation of the time periods. Fetal Diagn Ther 2012;32:79-86.

12 Nicolaides $\mathrm{KH}$, Soothill PW, Clewell WH, Rodeck $\mathrm{CH}$, Mibashan RS, Campbell S: Fetal haemoglobin measurement in the assessment of red cell isoimmunisation. Lancet 1988;1:1073-1075. 
13 Nicolaides $\mathrm{KH}$, Clewell $\mathrm{WH}$, Rodeck $\mathrm{CH}$ : Measurement of human fetoplacental blood volume in erythroblastosis fetalis. Am J Obstet Gynecol 1987;157:50-53.

14 Nishie EN, Liao AW, Brizot MeL, Assunção RA, Zugaib M: Prediction of the rate of decline in fetal hemoglobin levels between first and second transfusions in red cell alloimmune disease. Prenat Diagn 2012;32:11231126.

15 Mari G, Rahman F, Olofsson P, Ozcan T, Copel JA: Increase of fetal hematocrit decreases the middle cerebral artery peak systolic velocity in pregnancies complicated by rhesus alloimmunization. J Matern Fetal Med 1997;6:206-208.

16 Bilardo $\mathrm{CM}$, Nicolaides $\mathrm{KH}$, Campbell S: Doppler studies in red cell isoimmunization. Clin Obstet Gynecol 1989;32:719-727.

17 Stirnemann JJ, Mougeot M, Proulx F, Nasr B, Essaoui M, Fouron JC, Ville Y: Profiling fetal cardiac function in twin-twin transfusion syndrome. Ultrasound Obstet Gynecol 2010;35:19-27.

18 Raboisson MJ, Fouron JC, Lamoureux J, Leduc L, Grignon A, Proulx F, Gamache S: Early intertwin differences in myocardial performance during the twin-to-twin transfusion syndrome. Circulation 2004;110:3043-3048.

19 Comas M, Crispi F, Cruz-Martinez R, Martinez JM, Figueras F, Gratacós E: Usefulness of myocardial tissue doppler vs conventional echocardiography in the evaluation of cardiac dysfunction in early-onset intrauterine growth restriction. Am J Obstet Gynecol 2010;203:45.e41-47. 
20 Crispi F, Hernandez-Andrade E, Pelsers MM, Plasencia W, Benavides-Serralde JA, Eixarch E, Le Noble F, Ahmed A, Glatz JF, Nicolaides $\mathrm{KH}$, Gratacos E: Cardiac dysfunction and cell damage across clinical stages of severity in growth-restricted fetuses. Am J Obstet Gynecol 2008;199:254.e251-258.

21 Ichizuka K, Matsuoka R, Hasegawa J, Shirato N, Jimbo M, Otsuki K, Sekizawa A, Farina A, Okai T: The tei index for evaluation of fetal myocardial performance in sick fetuses. Early Hum Dev 2005;81:273-279.

22 Tsutsumi T, Ishii $M$, Eto $G$, Hota $M$, Kato $H$ : Serial evaluation for myocardial performance in fetuses and neonates using a new doppler index. Pediatr Int 1999;41:722-727.

23 Nomura RM, Brizot MeL, Liao AW, Nishie EN, Zugaib M: The effect of fetal anemia on fetal cardiac troponin $t$ in pregnancies complicated by rhd alloimmunization. J Matern Fetal Neonatal Med 2013;26:246-249.

24 Miller RD: Pharmacokinetics of atracurium and other non-depolarizing neuromuscular blocking agents in normal patients and those with renal or hepatic dysfunction. Br J Anaesth 1986;58 Suppl 1:11S-13S. 

Functional cardiac assessment has proven to be an important morbidity and mortality marker in several pathologies, and can improve neonatal outcomes ${ }^{(54,55,86)}$. Myocardial performance index (MPI) is a new technique used to evaluate cardiac function ${ }^{(62,63)}$. As it is a noninvasive technique, independent of heart rate and ventricular shape that evaluates global cardiac function (systolic and diastolic), it may improve fetal cardiac evaluation $(77,81)$. This present study encompasses fetal cardiac function evaluation due RhD alloimmune disease, using fetal MPI.

MPI is a pulsed-wave derived index that incorporates measurement of cardiac time intervals and is defined as the sum of the isovolumetric contraction time (ICT) and isovolumetric relaxation time (IRT) divided by the ejection time $(\mathrm{ET})^{(62)}$. High $\mathrm{MPI}$ values are associated with ventricle dysfunction ${ }^{(63,57,64,74)}$.

In the first paper, we investigate the relationship between fetal hemoglobin levels and fetal MPI for both ventricles, prior to intrauterine transfusion (IUT) was investigated. We found that left ventricle (LV) MPI reduces as fetal anemia worsens, whereas no significant changes were observed in the right ventricle (RV). These findings indicate that fetal LV cardiac performance not only remains preserved but is actually enhanced in cases of moderate/severe fetal anemia.

Fetal anemia is associated with hematological and hemodynamic adaptative mechanisms in order to maintain adequate tissue oxygenation. Fetus compensates anemia by increase cardiac output and hyperdinamic circulation. The mechanisms attributed are: decrease in blood viscosity leading to increase venous return, hypoxic peripheral vasodilatation and therefore decreased peripheral resistance and increased cardiac contractility (25).

As a matter of fact, if the process of anemia is not interrupted, fetal hydrops may occur ${ }^{(25)}$. One of the hypotheses is cardiac decompensation 
due to cardiac ischemia, reduced contractility and dysfunction ${ }^{(29)}$. However, the present study shows that left ventricular cardiac function is preserved, and no changes were observed in RV.

This finding is corroborated by Hecher et al. ${ }^{(34)}$, which investigated the effect of anemia on fetal venous, arterial and intracardiac blood flows by color Doppler in 38 fetuses with suspected anemia due to alloimmune disease. They reported that fetal anemia is associated with hyperdynamic circulation in both arterial and venous vessels. Also observed that even in severe anemia, there was no evidence of congestive heart failure.

Likewise, Tongsong et al. ${ }^{(92)}$ investigated cardiac function in hydrops fetalis due to anemia in Bart's Syndrome using venous Doppler flow. Bart's Syndrome is a hereditary hemoglobinopathy caused by reduced synthesis of alpha-globin chains which lead to severe and early anemia. It corresponds to $70 \sim 80 \%$ of fetal hydrops cases in Southeast Asia ${ }^{(93)}$. They observed that hydrops due to Bart's hemoglobinopathie is not associated with high central venous pressures and suggest that cardiac decompensation is not the underlying mechanism is this disease. They also mention that the hypervolemia could be responsible for cardiomegaly and also would be a sign of myocardial competence and not heart failure.

Therefore, a long-term follow-up study of children that had undergone intrauterine transfusions due to red cell isoimmunization, showed no differences in resting ventricular function compared to controls ${ }^{(94)}$.

In fetal life, the spatial cardiac anatomy allows the evaluation of inflow and outflow tracts of the LV simultaneously in a single Doppler waveform. Thus, each component of LV MPI (ICT, IRT and ET) could be analyzed, resulting in a better understanding of the physiological mechanisms in the cardiac cycle. This technique was first described by Friedman et al. ${ }^{(83)}$.

This study observes that reduction of LV MPI was simultaneously related to the increase in ET and reduction in IRT. These changes are likely to reflect adaptative mechanisms observed in fetal anemia. Prolongation of ejection time is possibly related to earlier opening of the aortic valve due to 
reduced fetal peripheral vascular resistance and lower pressure gradient, triggered by tissue hypoxia. On the other hand, increased pressure in the left atria due to the hyperdinamic circulation and increased venous return may cause earlier opening of the mitral valve during diastole and reduction in isovolumetric relaxation time. Hecher et al. ${ }^{(34)}$ demonstrated that E/A ratio values in the atrioventricular valves were normal suggesting normal ventricular filling despite severe fetal anemia.

However, no correlation between fetal hemoglobin levels and the RV MPI was found. One would expect a correlation because RV is considered as dominant in intrauterine life ${ }^{(95)}$. One of the hypotheses may be related to the assessment of the inflow and the outflow of RV in two distinct times.

Another hypothesis could be due to the high resistance in pulmonary vascular vasoconstriction induced by hypoxia ${ }^{(96)}$. In LV MPI we speculated that different pressure gradient due to peripheral vasodilation could be responsible for the prolongation of ejection time. However, in RV MPI, this mechanism may not occur. So, in order to clarify if the lack of a significant association between right ventricle MPI and the degree of fetal anemia is due to greater measurement variability or reflects a true absence of association, additional studies investigating simple and reproducible methods such as STIC TAPSE (tricuspid annular plane systolic excursion) are necessary ${ }^{(97)}$.

Briefly, cardiac troponin $T(\mathrm{cTn}-\mathrm{T})$ is one of the three proteins of the complex that regulates calcium-dependent interaction of myosin with actin during cardiac contraction. Increased serum levels of cTn-T have been used as a marker of myocardial injury ${ }^{(98,99)}$. Our research project, considered the cTn-T serum levels evaluation at the cordocentesis, however, there was a lack of material sample in some cases, and in order to avoid sampling bias, the cTn-T values were not presented in this study.

In this same institution, Normura et al. (91) conducted a study to evaluate the effect of fetal anemia on fetal cTn-T in 20 pregnancies complicated by $\mathrm{RhD}$ alloimmunization. They demonstrated a significant negative correlation between the level of fetal hemoglobin and the values of 
cTn-T $(r=-0.43, p=0.002)$. Additionally, in the subgroup of patients with increased cTn-T values at the first IUT, there was a greater association with perinatal mortality. Therefore, they concluded that dosage of the cTn-T serum levels could be useful in the management of pregnancies complicated by RhD alloimmunization.

Nonetheless, we observed that progressive levels of anemia are associated with lower LV MPI values, suggesting cardiac compensatory adaptative mechanism. Then, further studies should be taken to better understand of the interaction between cTn-T, hemoglobin levels and MPI.

Indeed, other authors have reported an increase of serum cTn-T levels in patients undergoing hemodialysis or with chronic renal failure, without myocardial dysfunction ${ }^{(100,101)}$. Increased serum levels of cTn-T were also detected in athletes bloodstream after strenuous physical exercise and marathons ${ }^{(102,103)}$.

Therefore, it is possible that initially, an increase of cTn-T levels occurs in fetal circulation due to the increased myocardial contractility and the consequent hyperdynamic circulation. Whereas in more advanced stages of the fetal anemia, the elevated levels of cTn-T were associated with increased perinatal mortality as a direct consequence of the worsening of the illness.

In the second paper, we investigated the influence of intrauterine transfusion in the cardiovascular system in fetal anemia, using LV MPI. In this study only LV MPI was analyzed due to its significant association with pre-transfusion fetal hemoglobin levels observed at the first phase of the study (104). The pre and post transfusion MPI values measured were converted into a zeta score (z-score).

First we noted that there was no direct relationship between the LV MPI zeta score (z score) values between pre and post IUT. Since post transfusion MPI z-score is the sum of pre transfusion MPI and delta MPI, lack of a significant correlation between pre and post procedure MPI z-scores 
indicates that additional factors may account for the degree of change that occurs in fetal myocardial contractility following transfusion.

Delta MPI was calculated as the difference between post and pre transfusion MPI z-scores. Regression analysis was used to investigate the association between delta MPI and gestational age, fetal middle cerebral artery (MCA) MoM and left ventricle MPI, hemoglobin z-score values, volume of blood transfused and feto-placental expansion (FPV).

As a matter of fact, our study shows that greater MPI changes occur in procedures at earlier gestational age, when pre transfusion MPI z-scores are lower and FPV smaller. Lindenburg et al. ${ }^{(52)}$ have shown that fetal losses occur more frequently in alloimmune disease before 20 weeks, despite adequate treatment. In this study, this increased perinatal mortality is possibly related to a natural limitation for small fetuses to adapt to volume overload imposed by the transfusion.

However, despite remarkable capacity of the human fetus to tolerate and adapt to blood volume expansions, if such changes are too rapid and severe, cardiac dysfunction may become apparent, especially in extremely premature fetuses with acidosis. In fact, Bilardo et al. ${ }^{(35)}$ have previously proposed that these cases might benefit from combined intravascular and intraperitoneal transfusions in order to avoid intravascular volume overload.

In the present study, mean FPV was 35\%, and expansion was greater than $40 \%$ in one third of the cases. Naturally, one would expect greater changes in fetal MPI to be associated with greater feto-placental volume expansions. Nevertheless an inverse correlation was observed and may actually reflect the more severe cases of fetal anemia in which profound changes in the fetal physiology may compromise and eventually hamper fetal cardiac and circulatory adaptation despite smaller volume overload. In fact, a single fetal death was observed (following an uncomplicated first transfusion performed at 23 weeks, non hydropic fetus, initial $\mathrm{Hb}$ level of $3.3 \mathrm{~g} / \mathrm{dl}$ and $30 \%$ FPV) and delta MPI was coincidently the greatest observed in the study (+6.8SD). 
Although technically more challenging, MPI evaluation while the transfusion procedure is performed may be a new parameter to assess fetal adaptation towards volume overload and help determine the optimal volume of blood to be transfused within each procedure. While delta MPI did not differ between first transfusions and subsequent procedures, longitudinal assessment of fetal MPI changes throughout subsequent procedures, may also be an additional parameter in the management of this disease.

Significant changes in fetal MPI have been previously demonstrated in several situations such as the recipient fetus of twin-twin transfusion syndrome ${ }^{(58,59)}$, growth restricted fetuses ${ }^{(34,56,88)}$, no nimmune hydrops ${ }^{(57)}$ and in maternal diabetes ${ }^{(57,81)}$. Certainly, the hypothesis that the degree of MPI change following IUT could be a useful predictor of adverse outcome and non procedure related fetal losses in pregnancies with alloimune disease remains to be investigated in further studies involving greater number of cases with severe fetal disease and the combination of biochemical parameters may help identify fetuses at greatest risk of decompensation.

A weak point in this study was the reduced sample. However, we feel accomplished to experience the significant reduction in the incidence of this disease in clinical practice. Prior to the 1950s, a sensitized Rh negative pregnant woman had a $50 \%$ risk of presenting perinatal death ${ }^{(105)}$.Currently, in experience centers the overall mortality is around $10 \%$ in severe anemic fetuses $(52,106)$

This reduction is associated with the introduction of antenatal immunoprophylaxis. Moreover, even in sensitized pregnancies, skilled professionals proactively monitoring these cases can foresee complications, intervening at the correct moment and thus reducing drastically the morbidity and mortality associated with this disease ${ }^{(16)}$.

However, despite MPI evaluation being a noninvasive technique, independent of heart rate and cardiac structure, standardization is required in order to obtain the sonogram and a correct measurement of the times in cardiac cycle. 
In 2005, Hernandez-Andrade et al. ${ }^{(84)}$ described that by placing the Doppler sample volume on the lateral wall of the ascending aorta, below the atrioventricular and just above mitral valve, it was possible to simultaneously obtain inflow and outflow of LV. Thus it was possible to identify the clicks of the opening and closing of the cardiac valves, which improves reproducibility of fetal left cardiac function assessment. This new approach to obtain the LV MPI is known mod-MPI, and has been the most widespread used in fetal studies.

Cruz-Martinez et al. ${ }^{(85)}$ established a normal reference range in the evaluation of mod-MPI between 11 and 41 weeks. This reference has been used in many studies, including ours. The advantage of using standard reference curve is that it allows a better comparison of results obtained by different groups, enabling its application in clinical practice.

The learning curve to obtain proficiency and practical skill to perform fetal mod-MPI is on average 65 exams. To obtain ET, ICT and IRT, the number of cases required were 42,77 and 83 respectively. Therefore, it has been shown that it takes time in order to train a skilled professional to perform this technique ${ }^{(107)}$.

However, once a qualified professional is trained, MPI can be performed in perinatal centers with currently available ultrasound equipment. The average time to perform and calculate MPI is 110 seconds (range: $35-$ 235) ${ }^{(84)}$.

In addition, there are softwares under development with algorithms which promises allow the clicks of the opening and closing of the atrioventricular and semilunar valves to be automatically detected and instantly calculate the MPI-mod ${ }^{(108,109,110)}$. This will be an important step for turning MPI-mod from a research tool into an everyday basis tool for clinical practice purposes.

Our study emphasizes the observation that no cardiac insufficiency was observed as a result of anemia triggered by RhD alloimmunization. Our goal is to investigate if this adaptive mechanism also occurs in other 
alloimmune anemias, such as those caused by anti-Kell and the ones resulting from infection by the parvovirus and others.

Moreover, with the automation software implementation, the MPI evaluation can be optimized during the intra-uterine transfusion with real-time information that can help detecting higher risk cardiac decompensation cases, as well as gathering additional statistical data for further analysis. 
6 Conclusões 

Não foram observados sinais de insuficiência cardíaca na anemia fetal decorrente da aloimunização RhD. Nos casos de anemia moderada/grave foi observado melhora do desempenho miocárdico.

Após a transfusão intra-uterina para correção da anemia fetal na aloimunização, foram observados sinais de descompensação miocárdica, relacionados à idade gestacional precoce, a menores valores do índice de performance miocárdica pré transfusional e a menor expansão volêmica.

A realização do índice de performance miocárdica durante a transfusão intrauterina pode auxiliar na melhora da sobrevida fetal, principalmente nas gestações com idade gestacional precoce. 

7 Anexos 

ANEXO

TERMO DE CONSENTIMENTO LIVRE E ESCLARECIDO

HOSPITAL DAS CLÍNICAS DA FACULDADE DE MEDICINA DA UNIVERSIDADE DE SÃO PAULO-HCFMUSP

DADOS DE IDENTIFICAÇÃO DO SUJEITO DA PESQUISA OU RESPONSÁVEL LEGAL

1.NOME::

DOCUMENTO DE IDENTIDADE $\mathrm{N}^{\circ}$ : SEXO :.$M \square F \square$ DATA NASCIMENTO: $\mathrm{N}^{\circ}$ APTO:

ENDEREÇO CIDADE

BAIRRO TELEFONE:DDD (.......)

2.RESPONSÁVEL LEGAL:

NATUREZA (grau de parentesco, tutor, curador etc.)

DOCUMENTO DE IDENTIDADE : SEXO: $M \square F \square$ DATA NASCIMENTO.: ..................... ENDEREÇO: $\mathrm{N}^{\circ}$ APTO:

BAIRRO: CIDADE:

CEP. TELEFONE:DDD )

\section{DADOS SOBRE A PESQUISA}

1. TÍTULO DO PROTOCOLO DE PESQUISA: Avaliação das alterações cardiovasculares nas anemias fetais

2. PESQUISADOR: Dr. Adolfo Liao

CARGO/FUNÇÃO: Professor Associado do Departamento de Obstetrícia e Ginecologia, Faculdade de Medicina USP

INSCRIÇÃO CONSELHO REGIONAL No 84.880

UNIDADE DO HCFMUSP: Instituto Central, Hospital das Clínicas FMUSP

3. AVALIAÇÃO DO RISCO DA PESQUISA:

$\begin{array}{lrr}\text { RISCO MÍNIMO [X] } & \text { RISCO MÉDIO [ ] } \\ \text { RISCO BAIXO } & \text { [ ] } & \text { RISCO MAIOR [ ] }\end{array}$

4 .DURAÇÃO DA PESQUISA : 24 meses 


\section{HOSPITAL DAS CLÍNICAS DA FACULDADE DE MEDICINA DA UNIVERSIDADE DE SÃO PAULO-HCFMUSP}

1- Essas informações estão sendo fornecidas para sua participação voluntária neste estudo. O objetivo deste estudo é avaliar as repercussões da anemia fetal na circulação e coração do seu feto. Esta avaliação é feita por meio de exame ultrassonográfico e dosagem de dois hormônios no sangue do feto quando for necessário realizar transfusão de sangue nele intra-útero.

2- Caso você aceite participar, nos seus retornos habituais para checar se o feto está anêmico, serão realizadas avaliações da circulação fetal pela técnica de ultrassonografia com duração média de 20 minutos. Caso seja necessário realizar transfusão de sangue intra útero serão coletados $2 \mathrm{ml} \mathrm{a}$ mais de sangue do cordão umbilical. Essa coleta de sangue adicional não causa nenhum dano à você ou ao feto, uma vez que o procedimento já é necessário para tratar o feto da anemia. O sangue será coletado com agulhas e seringas descartáveis e com o uso de luvas estéreis descartáveis conforme preconizado para a realização da transfusão intra-útero.

3- DESCONFORTO E RISCOS ESPERADOS: O desconforto e o risco esperados com sua participação serão mínimos no momento da ultrassonografia. No caso da coleta do sangue fetal, não haverá desconforto adicional uma vez que a coleta já realizada para avaliar o grau de anemia fetal e transfundir o feto.

4- BENEFICIOS QUE PODERÃO SER OBTIDOS COM A PARTICIPAÇÃO NO ESTUDO: Por meio da avaliação do coração e circulação do seu feto, poderemos obter respostas sobre as alterações da anemia no coração fetal e, com isso, verificar quais são os fetos, que apesar de anêmicos, necessitam de um controle mais rigoroso no acompanhamento pré-natal ou que tem menor chance de se recuperar da anemia e suas repercussões ainda intra-útero.

5- Em qualquer etapa do estudo, você terá acesso aos profissionais responsáveis pela pesquisa para esclarecimento de eventuais dúvidas. $\mathrm{O}$ principal investigador é o Dr. Adolfo Wenjaw Liao que pode ser encontrado de segunda a sexta, 08 às $12 \mathrm{~h}$, na Clínica Obstétrica, $10^{\circ}$ andar Instituto Central, Av. Dr. Eneas de carvalho Aguiar, 255 Cerqueira Cesar Telefone 11 30696209.

Se você tiver alguma consideração ou dúvida sobre a ética da pesquisa, entre em contato com o Comitê de Ética em Pesquisa (CEP) - Rua Ovídio Pires de Campos, 225 - $5^{\circ}$ andar - tel: 3069-6442 ramais 16, 17, 18 ou 20, FAX: 3069-6442 ramal 26 - E-mail: cappesq@hcnet.usp.br 
6- É garantido a você a liberdade de retirar este consentimento a qualquer momento e deixar de participar do estudo, sem qualquer prejuízo à continuidade de seu atendimento nesta Instituição.

7- As informações obtidas com o estudo serão analisadas em conjunto com outras gestantes participantes. Em nenhuma circunstância será divulgada a identificação de qualquer gestante participante do estudo.

8- Não haverá despesas pessoais para o participante em qualquer fase do estudo, incluindo exames e consultas.

9- O pesquisador se compromete a utilizar o material coletado somente para esta pesquisa.

Acredito ter sido suficientemente informado a respeito das informações que li ou que foram lidas para mim, descrevendo o estudo: "Avaliação das alterações cardiovasculares nas anemias fetais".

Eu discuti com a Dra Renata Almeida de Assunção sobre a minha decisão em participar nesse estudo. Ficaram claros para mim quais são os propósitos do estudo, os procedimentos a serem realizados, seus desconfortos e riscos, as garantias de confidencialidade e de esclarecimentos permanentes. Ficou claro também que minha participação é isenta de despesas e que tenho garantia do acesso a tratamento hospitalar quando necessário. Concordo voluntariamente em participar deste estudo e poderei retirar o meu consentimento a qualquer momento, antes ou durante o mesmo, sem penalidades ou prejuízo ou perda de qualquer benefício que eu possa ter adquirido, ou no meu atendimento neste Serviço.

Assinatura do paciente/representante legal Data

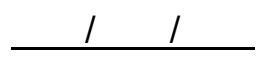

Assinatura da testemunha

Data

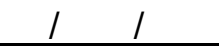

para casos de pacientes menores de 18 anos, analfabetos, semi-analfabetos ou portadores de deficiência auditiva ou visual.

(Somente para o responsável do projeto)

Declaro que obtive de forma apropriada e voluntária o Consentimento Livre e Esclarecido deste paciente ou representante legal para a participação neste estudo. 


\title{
Hospital das Clínicas da FMUSP
}

\section{$306 / 11$}

\author{
Comissão de Ética para Análise de Projetos de Pesquisa - CAPPesq
}

\section{PROJETO DE PESQUISA}

Título: AVALLIAÇÃO DAS ALTERAÇÕES CARDIOVASCULARES NAS ANEMIAS FETAIS

Pesquisador Responsável: Adolfo Wenjaw Liao Versão: 1

Pesquisador Executante: Renata Almeida de Assunção CAAE: 01878312.6.0000.0068

Co-autores: Maria de Lourdes Brizot, Rossana Pulcineli Vieira Francisco, Vera Lúcia Jornada

Krebs, Marcelo Zugaib

Finalidade Acadêmica Doutorado

Instituição: HCFMUSP

Departamento: OBSTETRÍCIA E GINECOLOGIA

\section{PARECER CONSUBSTANCIADO DO CEP}

Registro on-line: 7882

Número do Parecer: 80460

Data da Relatoria: $22 / 08 / 12$

Apresentação do Projeto: Trata-se de projeto de pesquisa para obtenção de Doutorado que cita que apesar do diagnóstico e manejo das anemias fetais estarem bem consolidados na literatura, pouco foi investigado sobre as alterações na circulação venosa fetal e os danos ao miocárdico fetal. Diante dessa lacuna, o presente estudo justifica-se pela necessidade de melhor entendimento sobre a disfunção cardíaca, a circulação venosa e a análise dos marcadores de lesão e função miocárdica em fetos anêmicos.

Objetivo da Pesquisa: Avaliar, em fetos com anemia ou risco de anemia fetal, a função miocárdica global a a circulação venกsa do feto por meio de por meio de ultrassonografia e dopplerfluxometria e marcadores bioquímicos de função (BNP) e lesão miocárdica (cTnT) nos casos submetidos à transfusão intra-uterina ou no sangue do cordão umbilical ao nascimento.

Avaliação dos Riscos e Benefícios: Os procedimentos que serão realizados não expõe as pacientes a riscos adicionais durante o seguimento que terão que fazer e a avaliação dos futuros resultados poderá trazer melhor planejamento na assistência ao procedimento em gestações que cursam com anemia fetal.

Comentários e Considerações sobre a Pesquisa: A introdução e a revisão da literatura estão abrangentes, com texto claro e bem escrito. A justificativa do estudo e os objetivos são claros, assim como o método muito bem descrito e completo.

Considerações sobre os Termos de apresentação obrigatória: Adequados

Recomendações: Aprovação por esse comitê

Conclusões ou Pendências e Lista de Inadequações: Aprovação por esse comitê

Situação do Parecer: Aprovado

Necessita Apreciação da CONEP: Não

Consideraçð̃es Finais a critério do CEP: Aprovado
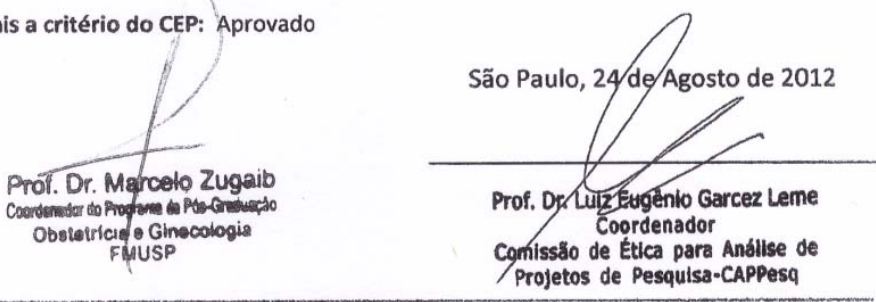

Rua Dr. Ovídio Pires de Campos, 225 - Prédio da Administração - 5 andar CEP 05403-010 - São Paulo - SP. 
8 Referências 

1. Rote NS, McCance KL. Alterations in Immunity and Inflammation. In: McCance KL, Huether SE, editors. Pathophysiology: The Biologic Basis for Disease in Adults And Children. 1. 7 ed ed. St Louis, Missouri: Elsevier Health Sciences; 2014. p. 1840.

2. Westhoff $\mathrm{CM}$. The structure and function of the Rh antigen complex. Semin Hematol. 2007;44(1):42-50.

3. Moise $\mathrm{KJ}$, Jr. Management of rhesus alloimmunization in pregnancy. Obstet Gynecol. 2008;112(1):164-76.

4. Ron ME, Waldron PE, Cashore WJ, Alarcon P. Hemolytic disease of the fetus and newborn. In: Alarcon PA, Werner E, Christense RD, editors. Neonatal Hematology

Pathogenesis, Diagnosis, and Management of Hematologic Problems. Second Edition ed. New Yord: Cambridge University Press; 2013. p. 65-90.

5. Levine $P$, Vogel $P$, Katzin EM, Burnham L. PATHOGENESIS OF ERYTHROBLASTOSIS FETALIS: STATISTICAL EVIDENCE. Science. 1941;94(2442):371-2.

6. Hadley AG, Turner C. Pathophysiology of the alloimune cytopenia. In: Hadley A, Soothill P, editors. Alloimmune Disorders of Pregnancy: Anaemia, Thrombocytopenia and Neutropenia in the Fetus and Newborn. 1. First ed ed. United States: Cambridge University Press; 2002. p. 279.

7. Winters JL, Pineda AA, Gorden LD, Bryant SC, Melton LJ, Vamvakas $E C$, et al. RBC alloantibody specificity and antigen potency in Olmsted County, Minnesota. Transfusion. 2001;41(11):1413-20. 
8. Baiochi E, Nardozza LMM. Aloimunização. Rev Bras Ginecol Obstet 2009;31(6):311-9.

9. Chávez GF, Mulinare J, Edmonds LD. Epidemiology of Rh hemolytic disease of the newborn in the United States. JAMA. 1991;265(24):3270-4.

10. Chilcott J, Lloyd Jones M, Wight J, Forman K, Wray J, Beverley C, et al. A review of the clinical effectiveness and cost-effectiveness of routine antiD prophylaxis for pregnant women who are rhesus-negative. Health Technol Assess. 2003;7(4):iii-62.

11. Tovey LA. Antenatal anti-D immunoglobulin. Lancet. 1983;2(8355):918.

12. Tovey LA. Oliver memorial lecture. Towards the conquest of $\mathrm{Rh}$ haemolytic disease: Britain's contribution and the role of serendipity. Transfus Med. 1992;2(2):99-109.

13. Huchet J, Dallemagne S, Huchet C, Brossard Y, Larsen M, ParnetMathieu F. [Ante-partum administration of preventive treatment of Rh-D immunization in rhesus-negative women. Parallel evaluation of transplacental passage of fetal blood cells. Results of a multicenter study carried out in the Paris region]. J Gynecol Obstet Biol Reprod (Paris). 1987;16(1):101-11.

14. Mayne S, Parker JH, Harden TA, Dodds SD, Beale JA. Rate of RhD sensitisation before and after implementation of a community based antenatal prophylaxis programme. BMJ. 1997;315(7122):1588.

15. Martin JA, Hamilton BE, Sutton PD, Ventura SJ, Menacker F, Munson ML. Births: final data for 2002. Natl Vital Stat Rep. 2003;52(10):1-113. 
16. Moise KJ, Argoti PS. Management and prevention of red cell alloimmunization in pregnancy: a systematic review. Obstet Gynecol. 2012;120(5):1132-9.

17. Zipursky A, Paul VK. The global burden of Rh disease. Arch Dis Child Fetal Neonatal Ed. 2011;96(2):F84-5.

18. Schmidt L, Correa MJ, Loures L. Atualizações na profilaxia da isoimunização Rh. Femina. 2010;38(7):345-52.

19. Pacheco CAMS. Doença Hemolítica Perinatal RhD: um problema de saúde pública no Brasil. Rio de Janeiro: Fundação Osvaldo Cruz, Instituto Fernandes Figueira; 2013.

20. Chinoca K, Liao A, Bianchi J, Francisco R, Jens E, Zugaib M. Caracterização imunohematológica de gestantes aloimunizadas da Clínica Obstétrica do Hospital das Clínicas da FMUSP. Congresso Brasileiro de Hematologia, Hemoterapia e Terapia Celular; Rio de Janeiro2012.

21. Bert P. La Pression Barometrique. Masson, Paris1878 1943.

22. Nicolaides $\mathrm{KH}$, Rodeck $\mathrm{CH}$, Millar DS, Mibashan RS. Fetal haematology in rhesus isoimmunisation. $\mathrm{Br}$ Med $\mathrm{J}$ (Clin Res Ed). 1985;290(6469):661-3.

23. P B. La Pression Barometrique. Masson, Paris1878 1943.

24. Haase VH. Regulation of erythropoiesis by hypoxia-inducible factors. Blood Rev. 2013;27(1):41-53.

25. Nicolaides $\mathrm{KH}$. Studies on fetal physiology and pathophysiology in rhesus disease. Semin Perinatol. 1989;13(4):328-37. 
26. HOGG GR. Cardiac lesions in hemolytic disease of the newborn. J Pediatr. 1962;60:352-60.

27. Kirschbaum TH, Brinkman CR, Assali NS. Effects of maternal-fetal blood exchange transfusion in fetal lambs. Am J Obstet Gynecol. 1971;110(2):190-202.

28. Fumia FD, Edelstone DI, Holzman IR. Blood flow and oxygen delivery to fetal organs as functions of fetal hematocrit. Am J Obstet Gynecol. 1984;150(3):274-82.

29. Nicolaides $\mathrm{KH}$, Soothill PW, Clewell WH, Rodeck $\mathrm{CH}$, Mibashan RS, Campbell S. Fetal haemoglobin measurement in the assessment of red cell isoimmunisation. Lancet. 1988;1(8594):1073-5.

30. Gill RW. Pulsed Doppler with B-mode imaging for quantitative blood flow measurement. Ultrasound Med Biol. 1979;5(3):223-35.

31. Rightmire DA, Nicolaides $\mathrm{KH}$, Rodeck $\mathrm{CH}$, Campbell S. Fetal blood velocities in $\mathrm{Rh}$ isoimmunization: relationship to gestational age and to fetal hematocrit. Obstet Gynecol. 1986;68(2):233-6.

32. Copel JA, Grannum PA, Green JJ, Belanger K, Hanna N, Jaffe CC, et al. Fetal cardiac output in the isoimmunized pregnancy: a pulsed Dopplerechocardiographic study of patients undergoing intravascular intrauterine transfusion. Am J Obstet Gynecol. 1989;161(2):361-5.

33. Rizzo G, Nicolaides KH, Arduini D, Campbell S. Effects of intravascular fetal blood transfusion on fetal intracardiac Doppler velocity waveforms. Am J Obstet Gynecol. 1990;163(4 Pt 1):1231-8. 
34. Hecher K, Snijders R, Campbell S, Nicolaides K. Fetal venous, arterial, and intracardiac blood flows in red blood cell isoimmunization. Obstet Gynecol. 1995;85(1):122-8.

35. Bilardo $\mathrm{CM}$, Nicolaides $\mathrm{KH}$, Campbell S. Doppler studies in red cell isoimmunization. Clin Obstet Gynecol. 1989;32(4):719-27.

36. Vyas S, Nicolaides KH, Bower S, Campbell S. Middle cerebral artery flow velocity waveforms in fetal hypoxaemia. $\mathrm{Br} \mathrm{J}$ Obstet Gynaecol. 1990;97(9):797-803.

37. Mari G, Adrignolo A, Abuhamad AZ, Pirhonen J, Jones DC, Ludomirsky A, et al. Diagnosis of fetal anemia with Doppler ultrasound in the pregnancy complicated by maternal blood group immunization. Ultrasound Obstet Gynecol. 1995;5(6):400-5.

38. Mari G, Deter RL, Carpenter RL, Rahman F, Zimmerman R, Moise KJ, et al. Noninvasive diagnosis by Doppler ultrasonography of fetal anemia due to maternal red-cell alloimmunization. Collaborative Group for Doppler Assessment of the Blood Velocity in Anemic Fetuses. $\mathrm{N}$ Engl $\mathrm{J}$ Med. 2000;342(1):9-14.

39. Bahado-Singh RO, Oz AU, Hsu C, Kovanci E, Deren O, Onderoglu L, et al. Middle cerebral artery Doppler velocimetric deceleration angle as a predictor of fetal anemia in Rh-alloimmunized fetuses without hydrops. Am J Obstet Gynecol. 2000;183(3):746-51.

40. Stefos T, Cosmi E, Detti L, Mari G. Correction of fetal anemia on the middle cerebral artery peak systolic velocity. Obstet Gynecol. 2002;99(2):211-5. 
41. Nishie EN, Brizot ML, Liao AW, Carvalho MH, Toma O, Zugaib M. A comparison between middle cerebral artery peak systolic velocity and amniotic fluid optical density at $450 \mathrm{~nm}$ in the prediction of fetal anemia. Am J Obstet Gynecol. 2003;188(1):214-9.

42. Moise KJ. Non-anti-D antibodies in red-cell alloimmunization. Eur J Obstet Gynecol Reprod Biol. 2000;92(1):75-81.

43. Filbey D, Hanson $U$, Wesström $G$. The prevalence of red cell antibodies in pregnancy correlated to the outcome of the newborn: a 12 year study in central Sweden. Acta Obstet Gynecol Scand. 1995;74(9):687-92.

44. Koelewijn JM, Vrijkotte TG, van der Schoot CE, Bonsel GJ, de Haas M. Effect of screening for red cell antibodies, other than anti-D, to detect hemolytic disease of the fetus and newborn: a population study in the Netherlands. Transfusion. 2008;48(5):941-52.

45. Moise KJ. Fetal anemia due to non-Rhesus-D red-cell alloimmunization. Semin Fetal Neonatal Med. 2008;13(4):207-14.

46. Gynecologists ACoOa. ACOG Practice Bulletin No. 75: Management of alloimmunization during pregnancy. Obstet Gynecol. 2006;108(2):457-64.

47. Gynaecologist RCoOa. Green top guidelines. Anti-D immunoglobulin for Rh prophylaxis. London: RCOG; 2002.

48. Lo YM, Bowell PJ, Selinger M, Mackenzie IZ, Chamberlain P, Gillmer $M D$, et al. Prenatal determination of fetal RhD status by analysis of peripheral blood of rhesus negative mothers. Lancet. 1993;341(8853):1147-8.

49. Lindenburg IT, van Kamp IL, Oepkes D. Intrauterine Blood Transfusion: Current Indications and Associated Risks. Fetal Diagn Ther. 2014 
50. Garabedian C, Philippe M, Vaast P, Wibaut B, Salleron J, Delsalle A, et al. Is intrauterine exchange transfusion a safe procedure for management of fetal anaemia? Eur J Obstet Gynecol Reprod Biol. 2014;179:83-7.

51. Yinon Y, Visser J, Kelly EN, Windrim R, Amsalem H, Seaward PG, et al. Early intrauterine transfusion in severe red blood cell alloimmunization. Ultrasound Obstet Gynecol. 2010;36(5):601-6.

52. Lindenburg IT, van Kamp IL, van Zwet EW, Middeldorp JM, Klumper FJ, Oepkes D. Increased perinatal loss after intrauterine transfusion for alloimmune anaemia before 20 weeks of gestation. BJOG. 2013;120(7):84752.

53. Moon-Grady AJ, Hirose S, Kesby G, Menahem S, Tworetzky W. The Fetus as a Cardiac Patient: Assessment and Therapy of Cardiovascular Pathology before Birth. Int J Pediatr. 2010;2010:974520.

54. Crispi F, Gratacós E. Fetal cardiac function: technical considerations and potential research and clinical applications. Fetal Diagn Ther. 2012;32(12):47-64.

55. Godfrey ME, Messing B, Cohen SM, Valsky DV, Yagel S. Functional assessment of the fetal heart: a review. Ultrasound Obstet Gynecol. 2012;39(2):131-44.

56. Comas M, Crispi F, Cruz-Martinez R, Martinez JM, Figueras F, Gratacós E. Usefulness of myocardial tissue Doppler vs conventional echocardiography in the evaluation of cardiac dysfunction in early-onset intrauterine growth restriction. Am J Obstet Gynecol. 2010;203(1):45.e1-7.

57. Ichizuka K, Matsuoka R, Hasegawa J, Shirato N, Jimbo M, Otsuki K, et al. The Tei index for evaluation of fetal myocardial performance in sick fetuses. Early Hum Dev. 2005;81(3):273-9. 
58. Papanna R, Mann LK, Molina S, Johnson A, Moise KJ. Changes in the recipient fetal Tei index in the peri-operative period after laser photocoagulation of placental anastomoses for twin-twin transfusion syndrome. Prenat Diagn. 2011;31(2):176-80.

59. Raboisson MJ, Fouron JC, Lamoureux J, Leduc L, Grignon A, Proulx $\mathrm{F}$, et al. Early intertwin differences in myocardial performance during the twinto-twin transfusion syndrome. Circulation. 2004;110(19):3043-8.

60. Szwast A, Tian Z, McCann M, Donaghue D, Bebbington M, Johnson $\mathrm{M}$, et al. Impact of altered loading conditions on ventricular performance in fetuses with congenital cystic adenomatoid malformation and twin-twin transfusion syndrome. Ultrasound Obstet Gynecol. 2007;30(1):40-6.

61. Guyton A, Hall J. Textbook of Medical Physiology. 11 Ed ed. Philadelphia, Pennsylvania: Elsevier; 2006.

62. Tei C. New non-invasive index for combined systolic and diastolic ventricular function. J Cardiol. 1995;26(2):135-6.

63. Tei C, Ling LH, Hodge DO, Bailey KR, Oh JK, Rodeheffer RJ, et al. New index of combined systolic and diastolic myocardial performance: a simple and reproducible measure of cardiac function--a study in normals and dilated cardiomyopathy. J Cardiol. 1995;26(6):357-66.

64. Tei C, Dujardin KS, Hodge DO, Kyle RA, Tajik AJ, Seward JB. Doppler index combining systolic and diastolic myocardial performance: clinical value in cardiac amyloidosis. J Am Coll Cardiol. 1996;28(3):658-64.

65. Dujardin KS, Tei C, Yeo TC, Hodge DO, Rossi A, Seward JB. Prognostic value of a Doppler index combining systolic and diastolic performance in idiopathic-dilated cardiomyopathy. Am $\mathrm{J}$ Cardiol. 1998;82(9):1071-6. 
66. Poulsen SH, Jensen SE, Nielsen JC, Møller JE, Egstrup K. Serial changes and prognostic implications of a Doppler-derived index of combined left ventricular systolic and diastolic myocardial performance in acute myocardial infarction. Am J Cardiol. 2000;85(1):19-25.

67. Tei C, Nishimura RA, Seward JB, Tajik AJ. Noninvasive Dopplerderived myocardial performance index: correlation with simultaneous measurements of cardiac catheterization measurements. J Am Soc Echocardiogr. 1997;10(2):169-78.

68. Ishii M, Tsutsumi T, Himeno W, Eto G, Furui J, Hashino K, et al. Sequential evaluation of left ventricular myocardial performance in children after anthracycline therapy. Am J Cardiol. 2000;86(11):1279-81, A9.

69. Eidem BW, Tei C, O'Leary PW, Cetta F, Seward JB. Nongeometric quantitative assessment of right and left ventricular function: myocardial performance index in normal children and patients with Ebstein anomaly. $\mathrm{J}$ Am Soc Echocardiogr. 1998;11(9):849-56.

70. Mooradian SJ, Goldberg CS, Crowley DC, Ludomirsky A. Evaluation of a noninvasive index of global ventricular function to predict rejection after pediatric cardiac transplantation. Am J Cardiol. 2000;86(3):358-60.

71. Ichihashi K, Yada Y, Takahashi N, Honma Y, Momoi M. Utility of a Doppler-derived index combining systolic and diastolic performance (Tei index) for detecting hypoxic cardiac damage in newborns. J Perinat Med. 2005;33(6):549-52.

72. Poulsen SH, Jensen SE, Tei C, Seward JB, Egstrup K. Value of the Doppler index of myocardial performance in the early phase of acute myocardial infarction. J Am Soc Echocardiogr. 2000;13(8):723-30. 
73. LaCorte JC, Cabreriza SE, Rabkin DG, Printz BF, Coku L, Weinberg A, et al. Correlation of the Tei index with invasive measurements of ventricular function in a porcine model. J Am Soc Echocardiogr. 2003;16(5):442-7.

74. Eto G, Ishii M, Tei C, Tsutsumi T, Akagi T, Kato H. Assessment of global left ventricular function in normal children and in children with dilated cardiomyopathy. J Am Soc Echocardiogr. 1999;12(12):1058-64.

75. Williams RV, Ritter S, Tani LY, Pagoto LT, Minich LL. Quantitative assessment of ventricular function in children with single ventricles using the Doppler myocardial performance index. Am J Cardiol. 2000;86(10):1106-10.

76. Ishii M, Eto G, Tei C, Tsutsumi T, Hashino $K$, Sugahara $Y$, et al Quantitation of the global right ventricular function in children with normal heart and congenital heart disease: a right ventricular myocardial performance index. Pediatr Cardiol. 2000;21(5):416-21.

77. Eidem BW, Edwards JM, Cetta F. Quantitative assessment of fetal ventricular function: establishing normal values of the myocardial performance index in the fetus. Echocardiography. 2001;18(1):9-13.

78. Eidem BW, Sapp BG, Suarez CR, Cetta F. Usefulness of the myocardial performance index for early detection of anthracycline-induced cardiotoxicity in children. Am J Cardiol. 2001;87(9):1120-2, A9.

79. Harada K, Tamura M, Toyono M, Yasuoka K. Effect of dobutamine on a Doppler echocardiographic index of combined systolic and diastolic performance. Pediatr Cardiol. 2002;23(6):613-7.

80. Cheung EW, Lam WW, Cheung SC, Cheung YF. Functional implications of the right ventricular myocardial performance index in patients after surgical repair of tetralogy of Fallot. Heart Vessels. 2008;23(2):112-7. 
81. Tsutsumi T, Ishii M, Eto $G$, Hota $M$, Kato $H$. Serial evaluation for myocardial performance in fetuses and neonates using a new Doppler index. Pediatr Int. 1999;41(6):722-7.

82. Mori Y, Rice MJ, McDonald RW, Reller MD, Wanitkun S, Harada K, et al. Evaluation of systolic and diastolic ventricular performance of the right ventricle in fetuses with ductal constriction using the Doppler Tei index. Am J Cardiol. 2001;88(10):1173-8.

83. Friedman D, Buyon J, Kim M, Glickstein JS. Fetal cardiac function assessed by Doppler myocardial performance index (Tei Index). Ultrasound Obstet Gynecol. 2003;21(1):33-6.

84. Hernandez-Andrade E, López-Tenorio J, Figueroa-Diesel H, SaninBlair J, Carreras E, Cabero L, et al. A modified myocardial performance (Tei) index based on the use of valve clicks improves reproducibility of fetal left cardiac function assessment. Ultrasound Obstet Gynecol. 2005;26(3):227-32.

85. Cruz-Martínez R, Figueras F, Bennasar M, García-Posadas R, Crispi F, Hernández-Andrade $E$, et al. Normal reference ranges from 11 to 41 weeks' gestation of fetal left modified myocardial performance index by conventional Doppler with the use of stringent criteria for delimitation of the time periods. Fetal Diagn Ther. 2012;32(1-2):79-86.

86. Van Mieghem T, Gucciardo L, Lewi P, Lewi L, Van Schoubroeck D, Devlieger $\mathrm{R}$, et al. Validation of the fetal myocardial performance index in the second and third trimesters of gestation. Ultrasound Obstet Gynecol. 2009;33(1):58-63.

87. Crispi F, Hernandez-Andrade E, Pelsers MM, Plasencia W, Benavides-Serralde JA, Eixarch E, et al. Cardiac dysfunction and cell damage across clinical stages of severity in growth-restricted fetuses. Am $\mathrm{J}$ Obstet Gynecol. 2008;199(3):254.e1-8. 
88. Cruz-Martinez R, Figueras F, Benavides-Serralde A, Crispi F, Hernandez-Andrade E, Gratacos E. Sequence of changes in myocardial performance index in relation to aortic isthmus and ductus venosus Doppler in fetuses with early-onset intrauterine growth restriction. Ultrasound Obstet Gynecol. 2011;38(2):179-84.

89. Cruz-Martinez R, Figueras F, Hernandez-Andrade E, Oros D, Gratacos E. Changes in myocardial performance index and aortic isthmus and ductus venosus Doppler in term, small-for-gestational age fetuses with normal umbilical artery pulsatility index. Ultrasound Obstet Gynecol. 2011;38(4):400-5.

90. Letti Müller AL, Barrios PeM, Kliemann LM, Valério EG, Gasnier R, Magalhães JA. Tei index to assess fetal cardiac performance in fetuses at risk for fetal inflammatory response syndrome. Ultrasound Obstet Gynecol. 2010;36(1):26-31.

91. Nomura RM, Brizot MeL, Liao AW, Nishie EN, Zugaib M. The effect of fetal anemia on fetal cardiac troponin $T$ in pregnancies complicated by RhD alloimmunization. J Matern Fetal Neonatal Med. 2013;26(3):246-9.

92. Tongsong T, Tongprasert F, Srisupundit K, Luewan S. Venous Doppler studies in low-output and high-output hydrops fetalis. Am J Obstet Gynecol. 2010;203(5):488.e1-6.

93. Tongsong T, Wanapirak C, Srisomboon J, Piyamongkol W, Sirichotiyakul S. Antenatal sonographic features of 100 alpha-thalassemia hydrops fetalis fetuses. J Clin Ultrasound. 1996;24(2):73-7.

94. Dickinson JE, Sharpe J, Warner TM, Nathan EA, D'Orsogna L. Childhood cardiac function after severe maternal red cell isoimmunization. Obstet Gynecol. 2010;116(4):851-7. 
95. Rudolph AM, Heymann MA. The circulation of the fetus in utero. Methods for studying distribution of blood flow, cardiac output and organ blood flow. Circ Res. 1967;21(2):163-84.

96. Anderson DF, Faber JJ, Morton MJ, Parks CM, Pinson CW, Thornburg $\mathrm{KL}$. Flow through the foramen ovale of the fetal and new-born lamb. $\mathrm{J}$ Physiol. 1985;365:29-40.

97. Messing B, Gilboa Y, Lipschuetz M, Valsky DV, Cohen SM, Yagel S. Fetal tricuspid annular plane systolic excursion (f-TAPSE): evaluation of fetal right heart systolic function with conventional M-mode ultrasound and spatiotemporal image correlation (STIC) M-mode. Ultrasound Obstet Gynecol. 2013;42(2):182-8.

98. Ohman EM, Armstrong PW, Christenson RH, Granger CB, Katus HA, Hamm CW, et al. Cardiac troponin $\mathrm{T}$ levels for risk stratification in acute myocardial ischemia. GUSTO IIA Investigators. N Engl J Med. 1996; 335(18):1333-41.

99. Collinson PO, Stubbs PJ, Kessler AC, Study MEORIOTT. Multicentre evaluation of the diagnostic value of cardiac troponin T, CK-MB mass, and myoglobin for assessing patients with suspected acute coronary syndromes in routine clinical practice. Heart. 2003;89(3):280-6.

100. Abbas NA, John RI, Webb MC, Kempson ME, Potter AN, Price CP, et al. Cardiac troponins and renal function in nondialysis patients with chronic kidney disease. Clin Chem. 2005;51(11):2059-66.

101. Ooi DS, House AA. Cardiac troponin T in hemodialyzed patients. Clin Chem. 1998;44(7):1410-6. 
102. Legaz-Arrese A, López-Laval I, George K, Puente-Lanzarote JJ, Mayolas-Pi C, Serrano-Ostáriz E, et al. Impact of an endurance training program on exercise-induced cardiac biomarker release. Am J Physiol Heart Circ Physiol. 2015;308(8):H913-20.

103. Sedaghat-Hamedani F, Kayvanpour E, Frankenstein L, Mereles D, Amr A, Buss S, et al. Biomarker changes after strenuous exercise can mimic pulmonary embolism and cardiac injury-a metaanalysis of 45 studies. Clin Chem. 2015;61(10):1246-55.

104. de Assunção RA, Liao AW, de Lourdes Brizot M, Francisco RP, Zugaib M. Myocardial performance index in fetal anemia. Prenat Diagn. 2015;35(2):192-196.

105. Bowman JM. The management of Rh-Isoimmunization. Obstet Gynecol. 1978;52(1):1-16.

106. Van Kamp IL, Klumper FJ, Oepkes D, Meerman RH, Scherjon SA, Vandenbussche FP, et al. Complications of intrauterine intravascular transfusion for fetal anemia due to maternal red-cell alloimmunization. Am J Obstet Gynecol. 2005;192(1):171-7.

107. Cruz-Martinez R, Figueras F, Jaramillo JJ, Meler E, Méndez A, Hernandez-Andrade E, et al. Learning curve for Doppler measurement of fetal modified myocardial performance index. Ultrasound Obstet Gynecol. 2011;37(2):158-62.

108. Wang J, Henry A, Redmond S, Welsh AW. OC08.02:automation of the fetal myocardial performance index. Ultrasound Obstet Gynecol. 2014; 44(S1):18. 
109. Maheshwari P, Henry A, Welsh AW. The Fetal Modified Myocardial Performance Index: is automation the future? Biomed Res Int. 2015;2015: 215910.

110. Welsh AW, Maheshwari P, Wang J, Henry A, Chang D, Crispi F, et al. Evaluation of an automated fetal myocardial performance index. Ultrasound Obstet Gynecol. 2015 Oct 1. 